10.4274/tjps.98624

Research Article

\title{
Development of novel freeze-dried mulberry leaves extract-based transfersomal gel
}

\author{
Sopan Nangare ${ }^{*}$, Bhatane Dhananjay ${ }^{2}$, Rushikesh Mali $^{3}$, Mayuri Shitole ${ }^{4}$ \\ 1* Junior Research Fellow, \\ H. R. Patel Institute of Pharmaceutical Education and \\ Research, Shirpur-425405, Dhule, \\ Maharashtra (India).
}

2.3\&4 Department of Pharmaceutics,

Bharati Vidyapeeth College of Pharmacy, Kolhapur-416013,

Maharashtra state, India

\begin{abstract}
:
Nowadays, an antioxidant is important for health associated concern in concert with acne vulgaris. Acne vulgaris is interrelated to the development of free radicals that unite with cells. Mulberry leaves have phenolic compounds that include antioxidants like quercetin. An antioxidant is a scavenger of free radicals. The current study deals with the development of mulberry leaves extract-based transfersomes gel containing quercetin by a thin layer hydration method for topical antioxidant delivery. It was scrutinized by encapsulating the drug in a choice of transfersomes formulations. The batch optimization was carried out by particle size and zeta analysis, entrapment efficiency (\%), polydispersity index, in vitro drug release, drug content. An optimized batch MF5 provides entrapment efficiency (\%) of quercetin in the vesicles $86.23 \%$ and $95.79 \%$ drug release. It furnishes vesicle spherical shape with an average diameter of $118.7 \mathrm{~nm}$, and $-45.11 \mathrm{mV}$ zeta potential. The MG1 formulation furnishes the superior antioxidant activity, drug content, and entrapment efficiency, ex vivo drug release, spreadability homogeneity and stability than the MG2. The presence of quercetin in the extract and gel formulation was confirmed by using HPTLC. It is evident from this study that, mulberry leaves extract transfersomes gel are a promising prolonged delivery system for quercetin and have reasonably good stability characteristics. This research recommends that mulberry leaves extract transfersomes gel can be potentially used in the treatment of acne vulgaris through the transdermal drug delivery system.

Keywords: transfersomes, mulberry leaves, quercetin, antioxidant activity, transfersomes gel Mr. Sopan Nangare, Junior Research Fellow, H. R. Patel Institute of Pharmaceutical Education and Research, Shirpur-425405, Dhule, Maharashtra (India).

Tel.: +919561141110

0000-0002-6513-3336

E-mail address: snangareopan@gmail.com

06.08 .2019

05.12 .2019

\section{Introduction}

In the modern era, acne is the most common skin disease worldwide (1). The research scenario is around $85 \%$ world population affecting between 11 to 30 years at some point.

About 4.8 million peoples per year are affected by acne $(2,3)$. Principally, it is a multifactorial disease of the pilosebaceous unit, which effects in comedones or severe
\end{abstract}


inflammatory lesions $(4,5)$ in the skin mainly in the face. This is related to the elevated rate of sebum excretion, abnormal proliferation of keratinocytes, overload production of male hormone androgens, oil-producing glands on the face and inflammatory response initiated by bacterial antigens and cytokines (6). Besides this, oxidative stress is majorly responsible for skin diseases like acne. Principally, the oxidative stress is initiated by free radicals/reactive oxygen species (ROS) $(7,8)$. In acne vulgaris, the sebum contains hydroxyl, nitrous oxide and superoxide like ROSs are present, which creates irritation during acne, inflammation, etc. Interestingly, the active presence in the plant contains the exceptional antioxidant capacity and the scientific report revealed that the herbal formulation showed the ability to repair damage caused due to the ROS. Additionally, the various scientific reports revealed that the natural antioxidants showed a less adverse effect as compared to the synthetic antioxidant compounds (8). The encapsulation of anti-acne drugs in vesicular and particulate delivery systems is a pioneering and the substitution approach for minimizing the side effects and preserving their efficacy. Presently development of a novel drug delivery system with the intention of high therapeutic activity along with patient compliance with conquering the penetration difficulties asscocited with transdermal drug delivery system (9). Morus alba L. (mulberry) generally known as a medicinal plant that has been traditionally used. The main content of mulberry leaves extract which is normally referred to phenolics; such as quercetin (quercetin 3-(6-malonylglucoside), isoquercetin, rutin, and some other flavonoids hold have been identified in mulberry leaves(10). It has been used to treat inflammation, cough, hypertension, cancer, and fever due to its medicinal value. The polyphenolic compound of mulberry leaves serves the antioxidant properties by scavenging free radicals and guard many organs against oxidative stress (11). The utilization of muiberry leaves in formulation development can offer several advantages like easy availability, low cost, non-toxic formulation and enhances sericulture farming. Plenty of literature revealed that quercetin reduces the production of interleukin- 6 and the expression of metalloproteinase- 1 and consequently, reduces inflammation and fibroblast proliferation (12). Also, as an antioxidant, quercetin scavenges the ROS and ultimately repaired the damaged cell. From the past few decades, sustained and efficient drug delivery is taking noteworthy attention of researchers, transdermal drug delivery is one of them and along with that, it offered productive significance and advantages (13). The novel era of drug delivery by using transfersomes exists as a hydrated core surrounded by an uitra-deformable lipid layer complex, which was developed by Gregor Cevc in the year 1991 (14). Generally, transfersomes made up intercellular sealing of lipids. It increases flexibility, reduces the risk of absolute vesicle rupture in the skin and permits transfersomes to penetrate the natural water gradient across the epidermis, after application to the skin. It can be utilized for the delivery of synthetic and herbal drugs $(15,16)$. Recently, considerable attention has been focused on developing a new lipidic nanovesicle based transdermal drug delivery system. Transfersomes have a deformable, flexible and higher affinity for penetration through the skin to the systemic circulation. Transdermal administration of transfersomes vesicles has a great advantage over other vesicles and owing to all these advantages; we attempt to develop the transfersomal gel formulation of mulberry leaves extract. After that, prepared transfersomes gels were evaluated for entrapment efficiency, particle morphology, particle size, zeta potential, polydispersity index, swelling index, viscosity and $\mathrm{pH}$ behavior, FTIR, antioxidant activity, deformability index, and penetration study using Franz diffusion cells. HPTLC was used to analyze the level of active substances contained in the extract. At the conclusion, novel transfersomal prepared gel could be exploring the application of natural mulberry leaves extract containing antioxidant (quercetin) for the treatment of acne like skin diseases. Also, it could overcome the drug resistivity and adverse effects of currently engaged acne therapy.

\section{Material and methods}




\subsection{Material}

Mulberry leaves (local market, Indapur, Maharastra), Ethanol AR (70 \%) and TWEEN80 (Loba Chemie Pvt. Mumbai), PHOSPHOLIPON 90G, Carbapol 940, PROPYLENE

GLYCOL, Formic acid (Merk life sciences), Diethyl ether, Ethyl acetate, Toulene, Petroleum ether, 2,2-diphenyl-1-picrylhydrazyl (DPPH), Ascorbic acid, Quercetin (Yucca enterprises, Mumbai).

\subsection{Processing and extraction of mulberry leaves}

The mulberry leaves were collected from the local market Indapur, (MS) India, in July. Briefly, the collected leaves were washed systematically under the running water to eradicate soil and other stuff stuck to leaves. Clean leaves were dried, grind and passed through ASTM \#30. Powder $(50 \mathrm{~g})$ of mulberry leaves subjected to Soxhlet extraction using a $70 \%$ Ethanol AR as solvent(17). Finally, the extract was subjected to physical and phytochemical examination.

\subsection{Freeze drying (FD)}

The mulberry leaves extract solution was frozen at $-20^{\circ} \mathrm{C}$ for $24 \mathrm{hr}$ and then dried using lyophilizer (Labconco, United Kingdom.) at pressure $0.013 \mathrm{mbar}$ and temperature $-49^{\circ} \mathrm{C}$. The obtained extract powder was milled by mortar and pestle to achieve a fine powder.

\subsubsection{Isolation of phytoconstituents}

FD extract $(3 \mathrm{~g})$ was successively extracted with $50 \mathrm{~mL}$ of petroleum ether (fraction I), $50 \mathrm{~mL}$ of diethyl ether (fraction II) and 50mL of ethyl acetate (fraction III) respectively, with the assist of a separating funnel. Complete extraction was ensured by repeated three times of replication for every batch. Owing to the presence of fatty acids and free flavonoids respectively in fraction I and II was rejected. In addition, fraction III was used for further processing as it contained quercetin, also, it was concentrated and hydrolyzed using $7 \%$ sulphuric acid $(10 \mathrm{~mL} / \mathrm{g}$ extract) up to $5 \mathrm{hr}$. The hydrolyzed fraction was filtered and extracted with ethyl acetate (1:1/ thrice) via a separating funnel (18).

\subsection{Thin-layer chromatography}

The isolated portion was chromatographed in comparison with the quercetin as a reference standard (std.) along with Silica gel G TLC plates (Indian herbal pharmacopeia, 2002) by using toluene: ethyl acetate: formic acid (5:4:0.2) as a mobile phase (19).

\subsection{UV-Spectrometric analysis}

The UV spectrum of the isolated quercetin of mulberry leaves, std quercetin, and the extract was recorded using a UV-Visible Spectrophotometer (Jasco V-630)(20).

\subsection{Calibration curve}

\subsubsection{Calibration curve of std and isolated quercetin}

Five working solutions of quercetin with concentrations of $10,20,30,40$ and $50 \mu \mathrm{g} / \mathrm{mL}$ in methanol were prepared and absorbance was recorded at $246 \mathrm{~nm} \lambda \max$ for each sample.

\subsection{FTIR Spectioscopy}

FTIR absorption spectrum of FD mulberry leaves extract was determined by ATR-FTIR (Jasco-V-530 model) using the $\mathrm{KBr}$ dispersion method.

\subsection{Antioxidant assay}

\subsection{In Vitro antioxidant activity by DPPH method}

DPPH is a rapid as well as a sensitive method to estimate the antioxidant capacity of different plant extracts. Also, the visual observation of antioxidant activity is possible. In brief, antioxidants react with DPPH which is a steady free radical and it reduces to the DPPH-H. Reduction in the absorbance of the solution was measured using a UV-Vis spectrophotometer at $517 \mathrm{~nm}(8,21)$. The potential to scavenge the DPPH radical was measured by the following formula(1).

DPPH Scavenged $(\%)=\frac{\text { Absorbance of control-Absorbance of Test }}{\text { Absorbance of control }}$. 


\subsection{Optimization of transfersomes of FD mulberry leaves extract 2.9.1. Preparation of transfersomes}

The transfersomes of FD mulberry leaves extract were formulated by the thin layer hydration method(22). The composition of transfersomes for MF1, MF2, MF2, MF3, MF4, MF5, MF6 batches reported in Table 1. In these techniques, phopholipon90G (phospholipids), tween 80 (Age activator) and mulberry leaves extract was added to the round bottom flask and dissolved in dichloromethane (solvent). Then, the organic solvent evaporated by using a rotary evaporator above the lipid transition temperature at $50^{\circ} \mathrm{C}$, under reduced pressure to velocity used was $60 \mathrm{rpm}$. After complete evaporation of the solvent, a thin layer on the inner wall of the flask was observed. Then, the deposited lipid film hydrated by dehydration process these were performed using phosphate buffer $(\mathrm{pH} 7.4)$ until all the thin layer was peeled off. The rehydration process was carried out in the temperature of $37 \pm 2^{\circ} \mathrm{C}, 100 \mathrm{rpm}$ for $30 \mathrm{~min}$. in absence of vacuum condition. Finally, fully hydrated transfersomes suspensions were collected in a vial, then the particle size of the vesicle was reduced by ultrasonication for $5 \mathrm{~min}$ with the amplitude of 25.

Table 1: Preparation of Mulberry leaves extract transfersomes

\subsubsection{Morphological characterization}

Prepared transfersomes was subjected to the morphology evaluation. Herein, the Vesicle's morphology of transfersomes was observed by Motic microscope

\subsubsection{Percentage entrapment efficiency $(\% \mathrm{EE})$}

The $\% \mathrm{EE}$ test was performed by using an ultracentrifugation method (indirect method) with $10,000 \mathrm{rpm}$ for $10 \mathrm{~min}$ at $4^{\circ} \mathrm{C}$, which produces supernatant as a released drug. The total concentration of active compound measurement was performed by dissolving $1 \mathrm{ml}$ suspension of transfersomes with PBS pH 6.8 in a $10 \mathrm{ml}$ flask. The concentration measurement was performed by using UV-Visible spectroscopy at 254nm (23). The \% EE was calculated by using equation (2).

$\% E E=\frac{C \text { total }- \text { C released }}{C \text { total }} \times 100 \ldots \ldots \ldots \ldots(2)$

Where,

$\mathrm{C}_{\text {total }}=$ Total concentration of quercetin $(\mu \mathrm{g} / \mathrm{ml})$ in transfersomes.

$\mathrm{C}_{\text {released }}=$ Untrapped concentration of active $\operatorname{substances}(\mu \mathrm{g} / \mathrm{ml})$ in transfersomes.

\subsubsection{Optimization of transfersomes}

The numbers of proces variables are accounted for characterization and optimization of the transfersomes formulation. Herein, the batch optimization was carried out by particle size analysis, zeta potential, polydispersity index (PDI), \% EE (24).

\subsubsection{In vitro drug reiease of transfersomes}

An in vitro drug release study was performed by using modified Franz diffusion cells.

Dialysis membrane (Hi-Media, Molecular weight 5000D) was arranged between the receptor and donor compartment. After that, the transfersomes of mulberry leaves extract was kept in the donor compartment and the receptor compartment was filled sufficiently with phosphate buffer, pH $7.4(25 \mathrm{~mL})$. The diffusion cells were maintained at $37 \pm 0.5^{\circ} \mathrm{C}$ temperature with constant stirring at 40rpm throughout the experiment. At the different time (min.) 30, 60, 90, $120,150,180,210,240,270,300$ and 360 intervals; $5 \mathrm{~mL}$ of aliquots were withdrawn from receiver compartment through side tube and again fill with $5 \mathrm{~mL}$ and analyzed for drug content by UV Visible spectroscopy (25).

\subsection{Preparation of transfersomes gel}

Herein we used the optimized batch of transfersomes (MF5) for preparation of gel. The 10\% $(\mathrm{w} / \mathrm{v})$ transfersomes suspension was weighed for gel formation. A carbapol 940 was added in purified water, under stirring and allows hydrating for $24 \mathrm{hr}$. Transfersomes suspension was dispersed in the hydrated Carbapol 940 slurry and stirred continued for $30 \mathrm{~min}$. Then, the propylene glycol was added slowly in the slurry. The $\mathrm{pH}$ of the formulation is adjusted by 
triethanolamine and the same procedure was carried out for control extract based gel (MG2) (Table 2) (26).

Table 2: Transfersomes gel of mulberry leaves extract (MG1) and control extract gel(MG2)

\subsection{Evaluation of MG and MG2 gel formulation}

MG1 and MG2 gel formulation were subjected to organoleptic evaluation, FTIR, homogeneity rate, $\mathrm{pH}$ and viscosity measurements, flow property measurements, drug content analysis (27) and \%EE (28).

\subsubsection{Homogeneity rate}

The determination of homogeneity of the formulated gel was done by pressing the little amount of both gels (MG1 and MG2) among the thumb and the index finger. The uniformity was a resolute as a harmonized or not (29).

\subsubsection{Spreadability}

The spreadability test of MG1 and MG2 gel was carried out by pressing $0.5 \mathrm{~g}$ of the final formulation. Briefly, the gel of each batch was subjected between two translucent spherical glass slides and the highest spreading was permitted by leaving them for $5 \mathrm{~min}$. The diameter of the formed circle was calculated to articulate the spreadability of the formulated gel(30).

\subsubsection{HPTLC analysis}

HPTLC analysis was performed by application of the std and isolated quercetin, and MG1 formulation. The samples were prepared by using methanol. After that, the analysis of quertecin was performed on the HPTLC plate of silica gel $60 \mathrm{~F} 254(5 \mathrm{~cm} \times 10 \mathrm{~cm})$ using a mixture of toluene: ethyl acetate: formic acid as a mobile phase in the proportion of 5:4:0.2. Finally, the quercetin colored bands were identified and confirmed via $R_{f}(31)$.

\subsubsection{LOD and LOQ}

Limit of detection (LOD) and limit of quantification (LOQ) are two important terms used to describe the smallest concentration of an analyte that can be reliably measured by an analytical procedure. The LOD and LOQ compounds were detected based on $R f$ value as well as UV/Visible spectral overlaying of respective standard compounds. The LOD was determined based on the lowest concentration detected by the instrument from each of two standards, while the LOQ was determined based on the lowest concentration quantified in the samples.

The determination of LOD and LOQ was calculated using the formula,

$\mathrm{LOD}=1 / 43.3(\mathrm{SD} / \mathrm{S}) \ldots \ldots .(3)$

$\mathrm{LOQ}=1 / 410(\mathrm{SD} / \mathrm{S}) \ldots \ldots . . .(4)$

Where,

$\mathrm{SD}=$ Standard deviation of the response

$\mathrm{S}=$ Slope

\subsubsection{Percent of drug content}

Accurate quantity of MG1 and MG2 gel was taken in a separate beaker and lysed with $50 \mathrm{~mL}$ methanol for $15 \mathrm{~min}$ using ultrasonication and centrifuged at $10,000 \mathrm{rpm}$ for $30 \mathrm{~min}\left(25^{\circ} \mathrm{C}\right)$.

The clear supernatant was collected and added into the $10 \mathrm{~mL}$ methanol and diluted with $\mathrm{pH}$

7.4. The drug content was calculated for quercetin an absorbance using a UV spectrophotometer at $246 \mathrm{~nm}$.

\subsubsection{Ex vivo release studies}

The fresh hairless abdominal skin of the goat was collected from the slaughterhouse and used for release studies after peeling the skin from the underlying cartilage placed inside the receptor compartment (32) (33). In brief, using Franz diffusion cell apparatus the drug release studies were performed. In that, the goat skin was placed in between donor and receptor compartment. The receptor compartment was filled with the phosphate buffer and ethanol mixture in the ratio of $8: 2(15 \mathrm{~mL})$ at $37 \pm 0.5^{\circ} \mathrm{C}$ and gel samples were subjected to the donor compartment. Using magnetic stirrer receptor compartment media stirrer at $25 \mathrm{rpm}$, which 
avoids the saturation of media during the penetration of the active(34). For calculation of percent ex vivo drug release, the sampling was performed for different time intervals.

\subsubsection{Statistical analysis}

All outcomes in this work are expressed as a mean \pm standard deviation (SD). Paired

Student's t-test was used for the comparison of percent ex vivo drug release of two related gel samples (MG1 and MG2) and assumptions for the statistical significance of $p$-value. The difference at $\mathrm{p}<0.05$ was considered to be significant.

\subsubsection{Ex vivo penetration test}

The ex vivo penetration of transfersomes gel was carried out by the fresh hairless abdomin skin of goat through Franz diffusion cell apparatus assembly. The goat skin was assemble between the donor and receptor compartment with an effective diffusion area of $2.26 \mathrm{~cm}^{2}$ and a cell volume of $25 \mathrm{~mL}$. Briefly, the receptor compartment contains the phosphate buffer and ethanol $(8: 2)$ media $(15 \mathrm{~mL})$ at body temperature $37 \pm 0.5^{\circ} \mathrm{C}$ and stirred the receptor compartment media, the gel was placed in the donor compartment and samplings were carried out periodically for $24 \mathrm{hr}$ from the receptor compartment. Along with that, the sink condition was maintained and the collected samples were subjected to UV spectrophotometer analysis. Based on the experimental finding, the permeation coefficient was calculated by using the cumulative amounts of drug permeated per unit area $\left(\mu \mathrm{g} / \mathrm{cm}^{2}\right)$ vs time graph. The transdermal flux was calculated from the slope of the linear portion of the graph.

\subsection{Stability study}

MG1 and MG2 formulations were kept at stability testing for 3 months at a $4^{\circ} \mathrm{C} \pm 2^{\circ} \mathrm{C}$ and $40^{\circ} \mathrm{C} \pm 2{ }^{\circ} \mathrm{C} / 75 \% \pm 5 \% \mathrm{RH}$ stations for determination of the physical and chemical stability of the formulations (as per ICH guidelines).

\section{Results of experimental}

\subsection{Characterization of mulberry leaves extract}

The extraction was performed by the successive hot continuous soxhlet extraction method. The ethanolic extract of mulberry leaves showed greenish color. The phytoconstituents analysis was revealed the presence of sterols, tannins, and phenols, alkaloids. The $\mathrm{pH}$ of the extract was found in 6.5 .

\subsubsection{TLC analysis}

TLC fingerprinting of mulberry leaves extracts done along with std quercetin under UV 254. It showed that spots with the std quercetin and isolated quercetin having an $\mathrm{R}_{\mathrm{f}}$ value 0.38 and 0.31 , respectively (Figure 1). At the conclusion, quercetin analysis using TLC pate confirmed that the presence of quercetin in an extract.

\section{Figure 1: TLC plate developed under UV light at $254 \mathrm{~nm}$}

After that, the UV spectra of std quercetin was observed at $254 \mathrm{~nm}$, which confirmed the purity and presence of quercetin in the sample prepared sample(Figure 2a). Also, the UV spectra of isolated quercetin from mulberry leaves extract were obtained at $246 \mathrm{~nm}$ and confirm the existence of quercetin in extract(Figure 2b).

\section{Figure 2: UV spectra of standard quercetin(a) and isolated quercetin from(b)}

\subsubsection{Calibration curve of standard quercetin and isolated quercetin}

The calibration curve of the std (Figure 3a) and isolated quercetin (Figure 3b) showed the linearity along with 0.999 and $0.996 R^{2}$, respectively. It provides the confirmation of the purity of quercetin.

\section{Eigure 3: Calibration curve of std quercetin(a) and isolated quercetin (b)}

\subsubsection{FTIR spectra of std and quercetin isolated mulberry extract}

FTIR investigations were revealed the presence of quercetin. In brief, std quercetin showed the peak of $\mathrm{O}-\mathrm{H}$ stretching at $3387.47 \mathrm{~cm}^{-1}, \mathrm{C}=\mathrm{C}$ stretching at $1605.47 \mathrm{~cm}^{-1}, \mathrm{C}-\mathrm{H}$ blending at $1446.70 \mathrm{~cm}^{-1}, \mathrm{C}=\mathrm{O}$ stretching at $1659.83 \mathrm{~cm}^{-1}, \mathrm{O}-\mathrm{H}$ Bending at $1316 \mathrm{~cm}^{-1}, \mathrm{C}-\mathrm{O}$ Aliphatic stretching at $1165.63 \mathrm{~cm}^{-1}$ (Figure $4 \mathrm{a}$ ). The observed frequencies for isolated quercetin from 
the extract of mulberry leaves have been shown in Figure 4b. It showed the O-H (strong) stretching at $3288.26 \mathrm{~cm}^{-1}, \mathrm{C}-\mathrm{H}$ stretching at $2916.94 \mathrm{~cm}^{-1}, \mathrm{C}=\mathrm{O}$ stretching at $1731.51 \mathrm{~cm}^{-1}$, $\mathrm{C}-\mathrm{H}$ Bending at $1415.10 \mathrm{~cm}^{-1}, \mathrm{C}-\mathrm{O}$ stretching at $1026.95 \mathrm{~cm}^{-1}$ which provides the confirmation of quercetin in the extract (Figure $4 \mathrm{~b}$ ). These pragmatic frequencies confirmed that the isolated fraction was quercetin concerning std quercetin.

Figure 4: FTIR spectra of std quercetin(a) and FTIR spectra of isolated quercetin (b)

\subsubsection{Antioxidant activity}

The antioxidant activity of the FD extract showed an excellent result in contrast to standard ascorbic acid. The isolated quercetin of mulberry leaves, ascorbic acid (std), and std quercetin furnished the antioxidant activity $67.2 \%, 83.20 \%$, and $69.54 \%$ consistently. Among these, isolated quercetin exhibited good free radical scavenging capacity and it's comparable to the standard quercetin antioxidant activity.

\subsection{Characterization and optimization of transfersomes}

\subsubsection{Shape of vesicle}

The shape of the vesicle by Motic microscopy was revealed that no aggregation and irregularities in transfersomes, along with that the spherical structures of vesicles were observed in the range of 110 to $460 \mathrm{~nm}$ diameter. Hence, it provides confirmation that the successful construction of Transfersomes vesicles (Figure 5)

\section{Figure 5: Unsonicated transfersomes vesicles by motic microscopy}

\subsubsection{Optimization of transfersomes}

\section{Particles size analysis and Polydispersity index (PDI)}

The size distribution of transfersomes suspension was determined by particle size analyzer (Nanoplus) which works on the by photon correlation spectroscopy (Table 3). Owing to the surfactant, the vesicle size observed within the range of 114.5 to $416.6 \mathrm{~mm}$. The PDI values of the formulation were observed in the range of 0.270 to 0.628 . Based on the particle size and PDI value, it concludes that the consistent particle size distribution within the formulation.

Table 3: Characterization and optimization of prepared transfersomes

\section{Zeta potential}

The Zeta potential provides the knowledge of particle aggregation or flocculation in suspension. Herein, the transfersomes batch (MF1 to MF6) showed zeta potential in the range of -21.19 to $-45.11 \mathrm{mV}$. These results specify the stability of the transfersomes in a suspension.

\section{Percent entrapment efficiency}

$\%$ EE was calculated by using the ultra-centrifugation method. In brief, the un-entrapped drug was separated and calculated the amount of it. After that, the entrapment efficiency was calculated for transfersomes. From the estimation of the \%EE, the MF1 to MF6 showed 57.65 to 86.23 percent $\%$ EE.

\subsubsection{In vitro release of transfersomes}

The determination of percent drug release in phosphate ( $\mathrm{pH} 7.4)$ was carried out by using the slope of quertecin in phosphate buffer ( $\mathrm{pH}$ 7.4) calibration curve (Figure 6). The comparison of MF1 to MF6 batch in vitro cumulative release of the diffusion study was shown in Figure 7 , it was $90.34 \%, 92.07 \%, 91.69 \% 92.03 \%, 95.79 \%, 91.42 \%$ respectively. Among all the batches, the MF5 showed the extended-release 95.79\% after 6 hrs (Figure 7). Herein, based on the $\%$ EE, particle size analysis, zeta potential, and PDI we selected the MF5 batch was an optimized batch and used for further process of gel formulation.

Figure 6: Calibration curve of extract ( $\mathrm{pH} 7.4$ )

Figure 7: In Vitro release profile of transfersomes

\subsubsection{FTIR spectra of Transfersomes}


The FTIR spectra of transfersomes gel showed the peaks for O-H stretching, C-H stretching, $\mathrm{C}-\mathrm{O}$ stretching and $\mathrm{C}=\mathrm{O}$ stretching, $\mathrm{C}-\mathrm{H}$ bending, $\mathrm{C}-\mathrm{O}$ starching around $3334 \mathrm{~cm}^{-1}, 2923 \mathrm{~cm}^{-1}$, $2853 \mathrm{~cm}^{-1}, 1620 \mathrm{~cm}^{-1}, 1453 \mathrm{~cm}^{-1}, 1035 \mathrm{~cm}^{-1}$ respectively, which is an about same as an std quercetin FTIR. The appearance of the above peaks in Figure 8, confirmed the presence of quercetin and other compounds. It was found that there is no interaction between quercetin and excipients used in formulation development.

\section{Figure 8: FTIR spectra of transfersomes}

\subsection{Evaluation of MG1 and MG2}

The MG2 gel showed a greenish color, glossy appearance. It's because of the direct contact of an extract of the gel-forming agent and MG1 gel furnished slightly greenish color, transparent as well as the glossy appearance. It's because of the extract was entrapped into the lipid vesicles. Both gels showed a somewhat sweet odor and demonstrated exceptional homogeneity.

\subsubsection{Measurement of viscosity MG1 and MG2}

The viscosity of MG1 and MG2 gel formulations were determined by using by Brookfield Viscometer at different time intervals (Figure 9). MG1 and MG2 showed a remarkable result of viscosity. It is because of carbapol and it could advantageously to resist drug leakage. Concurrently, the $\mathrm{pH}$ of the gel was précised by a digital $\mathrm{pH}$ meter (Figure 10) and it showed that the MF1 gives the constant $\mathrm{pH}$ after $6 \mathrm{hrs}$ and in the case of MF2, variation in the $\mathrm{pH}$ was observed.

Figure 9: Viscosity of MG1 and MG2 gel

\section{Figure 10: $p H$ of MG1 and MG2 gel}

\subsubsection{Swelling index}

The MG1 gel showed good water-holding capability. Here in the hydrogen bond facilitates the structure to swell the excipients. A comparis on of MG1 and MG2 showed the swelling index up to $99.61 \%$ and $96.27 \%$, respectively ( $\mathrm{n}=3$, Figure 11 ).

Figure 11: Swelling index of transferos mal ge!

\subsubsection{Flow properties}

The flow properties of MG1 and $\mathrm{MG} 2 \mathrm{gel}$ were computed at different day intervals. It was observed that the MG1 gel showed bette flow properties as compared to the MG2 as shown in Table 4. Outcomes of the flow properties conclude that the MG1 provides exceptional tensile strength, elongation rate, and spreadability. Along with exhibited a good homogeneity rate as compared to the MG2 batch.

\section{Table 4: The flow properties of MG1 and MG2 gel}

\subsubsection{Entrapment efficiency, drug content and antioxidant activity}

The \% drug content of the MG1 and MG2 formulation was found $98.23 \%$ and $89.52 \%$ respectively (Figure 12a). Besides, the MG1 gel formulation showed superior antioxidant activity $(66.72 \%)$ as compared to an MG2 gel formulation (59.23\%) as shown in Figure 12a. The MG2 gel antioxidant activity, drug content was found to quite less and it can be because of extract getting degraded during the manufacturing process of the gel. The MG1 and MG2 gel formulation showed $85.6 \%, 81.20 \% \mathrm{EE}$. The formation of multi-laminar vesicles complex in transfersomes enhances the $\% \mathrm{EE}$ (Figure $12 \mathrm{~b}$ ).

\section{Fiqure 12: Antioxidant properties (a) and \%EE(b) of MG1 and MG2 gel}

\subsubsection{HPTLC analysis}

Optimized parameter for std quercetin, isolated quercetin and gel formulation (MG1) containing quercetin by HPTLC at $246 \mathrm{~nm}$ reported in Table 5. The spectrum scan of std quercetin is comparable with an isolated compound and formulation containing quercetin (Figure 13). For extract, retention time was found to be $8.4 \mathrm{~min}$ which coincided with standard quercetin. The results of tests carried on standard and isolated Quercetin and 
formulation are summarized in Figure 14. It assured that the presence of quercetin in the gel formulation, along with that there is no interaction between excipients and quercetin. Table 5: Optimized Parameter of HPTLC for quercetin isolation

Figure 13: a. std. quercetin (Track 1), b. Isolated quercetin (Track 2) and c. gel formulation (Track 3)

Figure 14: Overlay at 246nm of pure quercetin, isolated quercetin, and formulation in HPTLC

\subsubsection{LOD and LOQ}

The limits of detection (LOD) were determined to be 0.25 and $0.23 \mathrm{ng} / \mathrm{spot}$ and the limit o quantification (LOQ) was found to be 0.6 and $0.5 \mathrm{ng} / \mathrm{spot}$ for std quercetin and isolated quercetin respectively. The values remain quite similar for both compounds, which revealed the sensitivity of the method.

\subsubsection{Ex vivo percent drug release}

The ex vivo percent drug release of MG1 and MG2 was carried out in phosphate buffer pH 7.4 through goat skin using Franz diffusion cells (Figure 15). The dissolution profile of MG1 $(96.86 \%)$ shown an excellent drug release as compared to the MG2 $(88.23 \%)$ up to $24 \mathrm{hrs}$. A statistically significant test for comparison of the ex vivo release of MG1 and MG2 was done by pairing the T-test. By conventional criteria, the considered difference between MG 1 (Transerosomes gel ) and MG 2 (Control gel) was statisticaliy significant at the level of $\mathrm{p}<0.05$.

Figure 15: Dissolution profile of MG2 and MG2 gel.

\subsubsection{Ex vivo permeation test}

The MG1 gel showed better transdermal flux as compared to the MG2 (35.52 \pm 3.02 and $26.01 \pm 2.02$ respectively). Moreover, it has been shown superior permeation coefficient of MG1 $(0.016 \pm 0.0009)$ than the MG2 $(0.012 \pm 0.0003)$ gel formulation.

\subsection{Stability Studies}

After 3 months of stability at $4 \pm 2^{\circ} \mathrm{C}$ and $40 \pm 2^{\circ} \mathrm{C}$ in sealed glass ampules confirmed the negligible drug leakage. Based on observation, it concludes MG1 gel formulation was more stables at $4 \pm 2^{\circ} \mathrm{C}$ as compared to the $40=2^{\circ} \mathrm{C}$. Furthermore, the leakage of the drug at MG1 batch was found with a minimum as compared to an MG2 gel formulation at both stability stations. The carbapol gel containing viscosity has avoided the movement and fusion of transfersomes; which results in the low drug leakage in gel formulation (MG1). As compared to the drug release of the MGi gel formulation at zero days after stability, it demonstrated excellent product stability. As a result, there is no major variation seen in MG1, before and after stability (Table 6). Hence, it indicates that the MG1 transfersomes based gel formulation is more stable without causing any incompatibility and it would be a promising potential for topical application.

\section{Table 6: Stabilit evaluation of transferosomal gel after 3 month}

\section{Discussion:}

Geis are the semi-solid dosage form system of drug delivery and constitute a good repute among novel pharmaceutical dosage forms. Now a day, herbal nano lipid vesicles based gel formulation is becoming admired due to their safe and effective use. In this study, the transfersomes of mulberry leaves extract were prepared by a thin layer hydration method. Numerous investigations have been revealed that quercetin having exceptional antioxidant potential and it decreases the production rate of interleukin $\square 6$ and the expression of metalloproteinase $\square 1$. Consequently, it reduces inflammation and fibroblast proliferation during the healing process. Besides, plenty of literature claimed that ROS is a major factor for skin diseases (example: acne vulgaris) and antioxidant having scavenging potential to the ROS. The synthetic antioxidant agent having some adverse/side effects. Thus, the nontoxic nature of herbal antioxidants such as quertecin can be effective in the treatment of acne 
vulgaris (12). Herein, the mulberry leaves containing antioxidant active, quercetin was isolated by using TLC, HPTLC, confirmed by using UV spectroscopy, FTIR and compared by using std quercetin. The fruitful outcomes of TLC and UV spectroscopy provide the successful isolation and confirmation of purity of quercetin. The FTIR spectra of std. quercetin, isolated quercetin and gel formulation (MG1) showed the confirmation and excipients compatibility. The development of transfersomes formulation various factors is important. Mainly the size and shape of the vesicle depend on the concentration of phopholipon $90 \mathrm{G}$ and the concentration of surfactants. An increase in the concentration of surfactant increases the entrapment efficiency of vesicles and ultimately it prevents drug leakage $(35,36)$. Outcomes of experimental tabulated in Table 3 , which reveals that the transfersomes prepared by using a specific concentration of tween 80 and phospholipid wer shown the superior result as compared to other formulations. Also, the proper proportion of excipients in batch MF5 showed the highest value of \%EE (86\%). Principally, the particle size of vesicles is an important parameter in the formulation of transfersomes. Generally, particle size distribution based on volume. Moreover, the DLS technique determined PDI value, which is generally in ranges from 0 to 0.6 . If the value of PDI $>0.6$ indicates that the sample has a very broad size distribution. Result showed that the PDI value of each batch changed with particle size (Table 3). The highest polydispersity index value of MF6 was caused by the large particles which were prone to aggregation $(26,37,38)$. Zeta potential is an important parameter to describe the stability of the dispersion system. It is used to measure a magnitude of the electrostatic potential or repulsive force among the same electrical charge of particles in suspension. Also, it gives an idea that particles in suspension undergo aggregation or flocculation. Various scientific reports revealed that the zeta potential is stable when more positive than of $+30 \mathrm{mV}$ or more negative than $-30 \mathrm{mV}(24,26,39)$. Herein, the results revealed that the MF5 transfersomes were more stable than other formulation because their zeta potential is comparatively high. A negative value of zeta potential might be getting from the lipid composition in the formula. Phosphatidylcholine is a zwitterionic compound when isoelectric point 6-7. Also, phosphate buffer, saline at $\mathrm{pH} 7.4$ was used as the hydrating medium in the process of vesicle formulation. In that, the $\mathrm{pH}$ was slightly higher than the isoelectric point of phosphatidylcholine and due to this, the phosphatidylcholine carried a negative charge (24). The de formability index is an important parameter in transfersomes preparation and generally, it is used to examine the flexibility of transfersomes. The deformability index value is influenced by the concentration of phospholipid and surfactant used. The use of excessive surfactant can be lower deformability index value as it can lead to the formation of micelles. The larger the index value of deformability, then the transfersomes will be more flexible and allows transfersomes to penetrate through the skin pores smaller than the size transforms itself (40). The result shows that MF5 transfersomes has the lowest deformability index. Based on the transfersomes characterization results batch optimization was carried out and further formulated into a gel formulation. Formula selected was a batch with the highest percentage of drug entrapped, had size distribution, the value of the polydispersity index within range and had the value of zeta potential which more negative than $-30 \mathrm{mV}$. Based on the summary results MF5 transfersomes was chosen because it had a spherical shape, the highest percentage of drug entrapped $(86.23 \pm 2.1 \%)$, polydispersity index of 0.389 , zeta potential value of -45 , Dv90 particle size of $118.7 \mathrm{~nm}$ and deformability index of $1.03 \pm 0.8$. Simultaneously, mulberry leaves extract based gel (MG2) were prepared for evaluation and comparison with MG1. FTIR of MG1 gel confirmed that there is no interaction between quercetin and excipients. Besides, MG1 gel formulation showed satisfactory flow properties, viscosity, and stable pH. Also, MG1 gel showed the superior swelling index and the homogeneity rate. The antioxidant assay of MG1 gel showed that the good antioxidant activity as compared to the MG2. In MG2 formulation, may be chances of 
the degradation or interaction between quertecin and excipients and due to that the antioxidant activity get slightly diminished.The HPTLC analysis were used for the further phytochemical and pharmacological investigation in gel formulation. In the present study, the phytochemical constituent (quercetin) was identified and confirmed based on the color zone obtained during the HPTLC analysis. The color of the zone with isolated quercetin and transferosomes gel formulation the color of the reference compound (std quercetin) under daylight and UV light after derivatization in the chromatogram confirmed the presence of stable and pure quertecin. This detailed chemical profile may be useful in the identification as well as quality evaluation of drugs concerning plants. Ex vivo percent drug release results conducted on transfersomes gel and control gel showed a significant difference $(p<0.05)$. Furthermore, the penetration rate of MG1 was higher than the MG2. The fruitful findings could be elucidated according to the negative charge of transfersomes (41). These negative charges generated the weak electrostatic repulsion between transfersomes and intercellular components of the skin. After that, this repulsion accelerates the penetration of negatively charged transfersomes through follicles of different skin layers. Additionally, the rapid penetration of transfersomes in the intact part of the basal area of follicles is occurred (42). Herein, the hydration and rehydration temperature, as well as rpm used for the development of transfersomes are key parameters to the penetration mechanism of transfersomes. Also, the phase transition temperature of the surfactant, HLB value of the surfactant, saturation, and unsaturation of alkyl chain length is taking a major account in the penetration mechanism. The prepared M1 gel showed less drug release as compared to control formulation. the possible reason involved in the less leakge from vesicles of transfersomes is greter hydration tempretue than the gel to liquid phase transition temperature and along with that, it provides the superior \%EE $(43,44)$. Stability study revealed that the MG1 gel formulation has admirable stability in different stability station. The outcomes of the present investigation confirmed that the transfersomes of mulberry leaves extract in the gel system offers a new substitute to transdermal drug delivery. Thus, based on the prolific finding the MG1 gel formulation could be utilized in the treatment of anti-acne.

\section{Conclusion}

The present study revealed that the developed novel transferosomal gel of mulberry leaves extract, which enhanced the antioxidant activity as compared to MG2 gel. The optimized batch of transfersomes confirms the excellent zeta potential, particle size, EE (\%), PI, deformability index and in vitro percent drug release. Moreover, the MG1 gel ex vivo drug release and penetration studies indicated that developed transfersomes gel formulation may serve as a promising carrier for better penetration through the skin as compared to the MG2. Although, MG 1 gel demonstrated good homogeneity, spreadability, excipient compatibility, and drug content. As compared to the MG2, the percent EE and antioxidant properties of MG1 was admirable. Consequently, MG1 batch transfersomes gel of mulberry leaves extract offers tremendous antioxidants potential, which creates new opportunities in the topical application for the treatment of acne vulgaris.

\section{Acknowledgment}

The authors wish to thank Ms. Neha Desai, Assistant Professor (Ashokrao Mane College of Pharmacy, Peth-Vadgaon) for her technical support.

\section{Declarations of interest}

The authors report no declarations of interest.

\section{References}

1. Prabu SL, Umamaheswari A, Rajakumar S, Bhuvaneswari P, Muthupetchi S.

Development and Evaluation of Gel Incorporated with Synthesized Silver Nanoparticle from Ocimum gratissimum for the Treatment of Acne Vulgaris. American Journal of Advanced Drug Delivery. 2017;5:107-17. 
2. Vats A, Sharma P. Formulation and evaluation of topical anti acne formulation of coriander oil. International Journal of Pharmacy and Pharmaceutical Science Research. 2012;2(3):61-6.

3. Surekha Baghel CDK, Gidwani B, Gupta A. Novel drug delivery systems of herbal constituents used in acne. International Journal of Contemporary Research and Review. 2017;8(02).

4. Latter G, Grice JE, Mohammed Y, Roberts MS, Benson HA. Targeted Topical Delivery of Retinoids in the Management of Acne Vulgaris: Current Formulations and Novel Delivery Systems. Pharmaceutics. 2019;11(10):490.

5. Ghovvati M, Afshari GK, Nasrollahi SA, Firooz A, Samadi A, Karimi M, et al. Efficacy of topical cinnamon gel for the treatment of facial acne vulgaris: A preliminary study. Biomedical Research and Therapy. 2019;6(1):2958-65.

6. Tahir CM. Pathogenesis of acne vulgaris: simplified. Journal of Pakistan Association of Dermatology. 2016;20(2):93-7.

7. Baek J, Lee M-G. Oxidative stress and antioxidant strategies in dermatology. Redox Report. 2016.

8. Vora J, Srivastava A, Modi H. Antibacterial and antioxidant strategies for acne treatment through plant extracts. Informatics in Medicine Unlocked. 2018;13:128-32.

9. Thakur N, Jain P, Jain V. Formulation development and evaluation of transferosomal gel. Journal of Drug Delivery and Therapeutics. 2018;8(5):168-77.

10. Bown D. The Royal Horticultural Society encyclopedia of herbs \& their uses: Dorling Kindersley Limited; 1995.

11. Pujari A, Jadhav N. design and development of anti-diabetic tablet formulation containing spray dried extract of mulberry leaves. Int J Pharm Sci \& Res. 2019; 10(3): 150109.

12. Lubtikulthum P, Kamanamool N Udompataikul M. A comparative study on the effectiveness of herbal extracts vs $2.5 \%$ benzoyl peroxide in the treatment of mild to moderate acne vulgaris. Journal of cosmetic dermatology. 2019.

13. Bhasin B, Londhe VY. An overyiew of transfersomal drug delivery. International journal of pharmaceutical sciences and research. 2018;9(6):2175-84.

14. Vinod KR, Kumar MS, Anbazhagan S, Sandhya S, Saikumar P, Rohit RT, et al. Critical issues related to transfersomes-novel vesicular system. ACTA Scientiarum Polonorum Technologia Alimentaria. 2012;11(1):67-82.

15. Rajan R, Jose S, Mukund VB, Vasudevan DT. Transferosomes-A vesicular transdermal delivery system for enhanced drug permeation. Journal of advanced pharmaceutical technology \& research. 2011;2(3):138.

16. Malakar J, Sen SO, Nayak AK, Sen KK. Formulation, optimization and evaluation of transferosomal gel for transdermal insulin delivery. Saudi pharmaceutical journal. 2012;20(4):355-63.

17. Zou Y, Liao S, Shen W, Liu F, Tang C, Chen C-Y, et al. Phenolics and antioxidant activity of mulberry leaves depend on cultivar and harvest month in Southern China.

International journal of molecular sciences. 2012;13(12):16544-53.

18. Sanghavi N, Srivastava R, Malode Y. Isolation and identification of the flavonoid "quercetin" from tridax procumbens linn. International Journal of Pharmaceutical Sciences and Research. 2014;5(4):1454-9.

19. Sajeeth C. Quantitative estimation of gallic acid, rutin and quercetin in certain herbal plants by HPTLC method. Der Chemica Sinica. 2010;1(2):80-5.

20. Patil V, Angadi S, Devdhe S. Determination of quercetin by uv spectroscopy as quality control parameter in herbal plant: Cocculus hirsutus. J Chem Pharm Res.

2015;7(1):99-104. 
21. Iqbal S, Younas U, Chan KW, Sarfraz RA, Uddin M. Proximate composition and antioxidant potential of leaves from three varieties of Mulberry (Morus sp.): a comparative study. International journal of molecular sciences. 2012;13(6):6651-64.

22. Chauhan P, Tyagi BK. Herbal novel drug delivery systems and transfersomes. Journal of Drug Delivery and Therapeutics. 2018;8(3):162-8.

23. Rahmi AD, Pangesti DM. Comparison of the Characteristics of Transfersomes and Protransfersomes Containing Azelaic Acid. Journal of Young Pharmacists. 2018;10(2):S11. 24. Duangjit S, Opanasopit P, Rojanarata T, Ngawhirunpat T. Characterization and in vitro skin permeation of meloxicam-loaded liposomes versus transfersomes. Journal of drug delivery. 2011;2011.

25. Laxmi M, Zafaruddin M. Design and characterization of transferosomal gel of repaglinide. Int Res J Pharm. 2015;6(1):37-41.

26. Surini S, Djajadisastra J. Formulation and in vitro Penetration Study of Transfersomes Gel Containing Gotu Kola Leaves Extract (Centella asiatica L. Urban). Journal of Young Pharmacists. 2018;10(1):27.

27. Ali MFM, Salem HF, Abdelmohsen HF, Attia SK. Preparation and clinical evaluation of nano-transferosomes for treatment of erectile dysfunction. Drug design, development and therapy. 2015;9:2431.

28. Laxmi M, Zafaruddin M, Kuchana V. Design and characterization of transferosomal gel of repaglinide. Int Res J Pharm. 2015;6(1):37-41.

29. Preeti MSK. Development of celecoxib transfersomal gel for the treatment of rheumatoid arthritis. Indian J Pharm Biol Res. 2014;2:7-13.

30. Mulani H, Bhise K. QbD Approach in the formulation and evaluation of Miconazole Nitrate loaded ethosomal cream-o-gel. Int Res J Pharm Sci. 2017;8:1-37.

31. Movaliya V, Zaveri M. HPTLC method development and estimation of quercetin in the alcoholic extract of Aerva javanica root. Advance Research in Pharmaceuticals and Biologicals. 2012;2:222-8.

32. Patel R, Singh S, Singh S, Sheth N, Gendle R. Development and characterization of curcumin loaded transfersome for transdermal delivery. Journal of pharmaceutical sciences and research. 2009;1(4):71.

33. Kaza R, Pitchaimani R. Formulation of transdermal drug delivery system: matrix type, and selection of polymer-their evaluation. Current drug discovery technologies. 2006;3(4):279-85.

34. Marwah H, Garg T, Rath G, Goyal AK. Development of transferosomal gel for transdermal delivery of insulin using iodine complex. Drug delivery. 2016;23(5):1636-44.

35. Jain S, Jain P, Umamaheshwari R, Jain N. Transfersomes - a novel vesicular carrier for enhanced transdermal delivery: development, characterization, and performance evaluation. Drug development and industrial pharmacy. 2003;29(9):1013-26.

36. Lichtenberg D, Robson RJ, Dennis EA. Solubilization of phospholipids by detergents structural and kinetic aspects. Biochimica et Biophysica Acta (BBA)-Reviews on Biomembranes. 1983;737(2):285-304.

37. Ascenso A, Raposo S, Batista C, Cardoso P, Mendes T, Praça FG, et al. Development, characterization, and skin delivery studies of related ultradeformable vesicles: transfersomes, ethosomes, and transethosomes. International journal of nanomedicine. 2015;10:5837.

38. Malvern A. Basic Guide to Particle Characterisation. Malvern Instruments, Ltd.: Malvern, UK; 2012.

39. Liu J, Hu G. Advances in studies of phospholipids as carriers in skin topical application. Journal of Nanjing Medical University. 2007;21(6):349-53.

40. Chaudhary H, Kohli K, Kumar V. Nano-transfersomes as a novel carrier for transdermal delivery. International journal of pharmaceutics. 2013;454(1):367-80. 
41. Mitkari B, Korde S, Mahadik K, Kokare C. Formulation and evaluation of topical liposomal gel for fluconazole. Indian J Pharm Educ Res. 2010;44(4):324-33.

42. Shaji J, Lal M. Novel double loaded transferosomes: evidence of superior antiinflammatory efficacy-a comparative study. Int J Curr Pharm Res. 2014;6(2):16-25.

43. Sultana SS, Krishna Sailaja A. Formulation and evaluation of diclofenac sodium transferosomes using different surfactants by thin film hydration method. Der Pharmacia Lettre. 2015;7(11):43-53.

44. Gupta A, Aggarwal G, Singla S, Arora R. Transfersomes: a novel vesicular carrier for enhanced transdermal delivery of sertraline: development, characterization, and performance evaluation. Scientia pharmaceutica. 2012;80(4):1061-80.

\section{Table}

Table 1: Preparation of Mulberry leaves extract transfersomes

Table 2: Transfersomes gel of mulberry leaf extract (MG1) and control extract gel (MG2)

Table 3: Characterization and optimization of prepared transfersomes

Table 4: The flow properties of MG1 and MG2

Table 5: Optimized Parameter of HPTLC for quercetin isolation

Table 6: Stability evaluation of transferosomal gel after 3 month

Table 1: Preparation of Mulberry leaves extract transfersomes

\begin{tabular}{|l|l|l|l|l|l|l|}
\hline \multirow{2}{*}{ Material name } & \multicolumn{6}{l}{ Concentration (\% w/w) } \\
\cline { 2 - 7 } & MF1 & MF2 & MF3 & MF4 & MF5 & MF6 \\
\hline Mulberry leaves extract & 10 & 10 & 10 & 10 & 10 & 10 \\
\hline Tween 80 & 0.3 & 0.3 & 0.3 & 0.4 & 0.4 & 0.4 \\
\hline phopholipon 90G & 2 & 2.5 & 3 & 2 & 2.5 & 3 \\
\hline $\begin{array}{l}\text { Phosphate buffer } \\
\text { (saline pH 7.4) }\end{array}$ & Add 100 & Add 100 & Add 100 & Add 100 & Add 100 & Add 100 \\
\hline
\end{tabular}

Table 2: Transfersomes gel of mulberry leaves extract (MG1) and control extract gel (MG2)

\begin{tabular}{|c|c|c|c|c|c|c|}
\hline Composition & \multirow[b]{2}{*}{ Transfersome } & \multirow[b]{2}{*}{$\begin{array}{l}\text { Extrac } \\
\mathbf{t}\end{array}$} & \multirow[b]{2}{*}{$\begin{array}{l}\text { Carbapo } \\
1 \\
940\end{array}$} & \multirow[b]{2}{*}{$\begin{array}{l}\text { Triethanolamin } \\
\text { e }\end{array}$} & \multirow[b]{2}{*}{$\begin{array}{l}\text { Propylen } \\
\text { e glycol }\end{array}$} & \multirow[b]{2}{*}{$\begin{array}{l}\text { Wate } \\
\mathbf{r}\end{array}$} \\
\hline $\begin{array}{l}\text { Concentratio } \\
\mathbf{n} \\
(\% \mathrm{w} / \mathrm{w})\end{array}$ & & & & & & \\
\hline MIG1 & $\begin{array}{l}\text { Equal to } 10 \% \\
\text { extract }\end{array}$ & - & 1 & 0.1 & 12.5 & $\begin{array}{l}\text { Add } \\
100\end{array}$ \\
\hline MG2 & - & 10 & 1 & 0.1 & 12.5 & $\begin{array}{l}\text { Add } \\
100\end{array}$ \\
\hline
\end{tabular}


Table 3: Characterization and optimization of prepared transfersomes

\begin{tabular}{|l|l|l|l|l|l|}
\hline Batch no. & Particle size & $\begin{array}{l}\text { Zeta } \\
\text { potential }\end{array}$ & PDI & \% EE & $\begin{array}{l}\text { Deformability } \\
\text { Index }\end{array}$ \\
\hline MF1 & $381.9 \mathrm{~nm}$ & $21.19 \mathrm{mV}$ & 0.511 & $68.23 \pm 1.2$ & $3.52 \pm 0.9$ \\
\hline MF2 & $214.5 \mathrm{~nm}$ & $-44.56 \mathrm{mV}$ & 0.421 & $65.23 \pm 1.1$ & $3.63 \pm 0.5$ \\
\hline MF3 & $268.3 \mathrm{~nm}$ & $-21.91 \mathrm{mV}$ & 0.448 & $76.23 \pm 0.9$ & $2.25 \pm 1.3$ \\
\hline MF4 & $401.9 \mathrm{~nm}$ & $-22.39 \mathrm{mV}$ & 0.270 & $77.65 \pm 1.6$ & $3.5 \pm 2.1$ \\
\hline MF5 & $\mathbf{1 1 8 . 7} \mathrm{nm}$ & $\mathbf{- 4 5 . 1 1} \mathrm{mV}$ & $\mathbf{0 . 3 8 9}$ & $\mathbf{8 6 . 2 3} \pm \mathbf{2 . 1}$ & $\mathbf{1 . 0 3} \pm \mathbf{0 . 8}$ \\
\hline MF6 & $416.6 \mathrm{~nm}$ & $-27.73 \mathrm{mV}$ & 0.628 & $80.23 \pm 1.8$ & $2.05 \pm 1.5$ \\
\hline
\end{tabular}

$\mathrm{n}=3,( \pm): \mathrm{sd}$

Table 4: The flow properties of MG1 and MG2

\begin{tabular}{|c|c|c|c|c|}
\hline \multirow{2}{*}{ Properties } & \multicolumn{2}{|l|}{ MG1 } & MG2 & \\
\hline & 0 days & 10 days & 0 dàys & 10 days \\
\hline Homogeneity rate $(1 / 10 \mathrm{~mm})$ & $60.54 \pm 1.6$ & $99.58 \pm 2.9$ & $59.23=1.2$ & $99.03 \pm 3.6$ \\
\hline Tensile strength $(\mathrm{Kg} / \mathrm{cm})$ & $30.25 \pm 0.9$ & $35.62 \pm 1.7$ & $30.01 \pm 1.9$ & $33.87 \pm 2.8$ \\
\hline Elongation rate (\%) & $200.21 \pm 1.4$ & $282.3 \pm 2.5$ & $199.56 \pm 1.6$ & $276.2 \pm 3.1$ \\
\hline Spreadability $(\mathrm{cm})$ & $9.80 \pm 0.9$ & $9.98 \pm 0.9$ & $8.01 \pm 0.9$ & $8.26 \pm 0.9$ \\
\hline
\end{tabular}

$\mathrm{n}=3,( \pm): \mathrm{sd}$

Table 5: Optimized Parameter of HPTLC for quercetin isolation

\begin{tabular}{|c|c|c|c|}
\hline Parameters & Description & Parameters & Description \\
\hline $\begin{array}{l}\text { Stationary } \\
\text { Phase }\end{array}$ & $\begin{array}{l}\text { Merck Silica gel } 60 \text { F254 HPTLC } \\
\text { pre-coated plates }\end{array}$ & Plate size & $4.0 \mathrm{~cm} \times 10.0 \mathrm{~cm}$ \\
\hline $\begin{array}{l}\text { Mode of } \\
\text { seraration }\end{array}$ & Normal phase & $\begin{array}{l}\text { Development } \\
\text { chamber }\end{array}$ & $\begin{array}{l}\text { Camag twin trough } \\
\text { chamber }\end{array}$ \\
\hline Mobile phase & $\begin{array}{l}\text { Ethyl acetate: Toluene: Formic } \\
\text { acid }(4: 3.5: 0.5 \mathrm{v} / \mathrm{v} / \mathrm{v})\end{array}$ & Bandwidth & $7.0 \mathrm{~mm}$ \\
\hline $\begin{array}{l}\text { Chamber } \\
\text { saturation }\end{array}$ & $30 \mathrm{~min}$ & $\begin{array}{l}\text { Space between } \\
\text { the bands }\end{array}$ & $7.0 \mathrm{~mm}$ \\
\hline $\begin{array}{l}\text { Sample } \\
\text { applicator }\end{array}$ & Camag Linomat V & Syringe & Hamilton, $100.0 \mu \mathrm{L}$ \\
\hline $\begin{array}{l}\text { Distance from } \\
\text { the edges of the } \\
\text { plat }\end{array}$ & $13.0 \mathrm{~mm}$ & $\begin{array}{l}\text { Rate of a } \\
\text { sample } \\
\text { application }\end{array}$ & $150 \mathrm{~nL} / \mathrm{sec}$ \\
\hline Lamp and & Deuterium, 246nm & Development & $85.0 \mathrm{~mm}$ \\
\hline
\end{tabular}




\begin{tabular}{|l|l|l|l|}
\hline wavelength & \multicolumn{1}{|c|}{ distance } & \\
\hline $\begin{array}{l}\text { Densitometric } \\
\text { scanner }\end{array}$ & $\begin{array}{l}\text { Camag Scanner IV equipped with win-CATS Planar Chromatography } \\
\text { manager software version 1.4.7 }\end{array}$ \\
\hline
\end{tabular}

Table 6: Stability evaluation of transferosomal gel after 3 months

\begin{tabular}{|c|c|c|c|c|}
\hline \multirow{2}{*}{\multicolumn{3}{|c|}{ Properties }} & \multicolumn{2}{|l|}{ Gel formulation } \\
\hline & & & MG1 & MG2 \\
\hline \multirow{5}{*}{$\left(4^{\circ} \mathrm{C} \pm 2^{\circ} \mathrm{C}\right)$} & & Color & Slightly yellowish & Greenish \\
\hline & & pH & $5.62 \pm 0.23$ & $5.89 \pm 0.95$ \\
\hline & & Viscosity(CPS) & $14005 \pm 230$ & $13202 \pm 456$ \\
\hline & & $\operatorname{EE}(\%)$ & $84.96 \pm 2.35$ & $78.35 \pm 3.69$ \\
\hline & & Drug content $(\%)$ & $98.01 \pm 2.61$ & $89.40 \pm 3.10$ \\
\hline \multirow{5}{*}{$\left(40^{\circ} \mathrm{C} \pm 2^{\circ} \mathrm{C}\right)$} & a) & & Slightly yellowish & Greenish \\
\hline & & $\mathbf{H}$ & $5.95 \pm 1.02$ & $6.23 \pm 1.63$ \\
\hline & & Viscosity(cps) & $13750 \pm 412$ & $12889 \pm 362$ \\
\hline & & $\operatorname{EE}(\%)$ & $83.69 \pm 4.02$ & $73.23 \pm 5.06$ \\
\hline & & Drug content (\%) & $97.96 \pm 00.97$ & $84.25 \pm 2.96$ \\
\hline
\end{tabular}

$\mathrm{n}=3,( \pm): \mathrm{sd}$

\section{Legend}

Figure

Figure 1: TLC plate developed under UV light at $254 \mathrm{~nm}$

Figure 2: UV spectra of Standard quercetin (a) Isolated quercetin (b)

Figure 3: Calibration curve of Standard quercetin(a) and Isolated quercetin (b)

Figure 4: FTIR spectra of Standard quercetin (a) and Isolated quercetin(b)

Figure 5: Unsonicated transfersomes vesicles by Motic microscopy

Figure 6: Calibration curve of extract ( $\mathrm{pH} 7.4)$ 
Figure 7: In Vitro release profile of transfersomes

Figure 8: FTIR spectra of transfersomes

Figure 9: Viscosity of MG1 and MG2 gel

Figure 10: $\mathrm{pH}$ of MG1 and MG2 gel

Figure 11: Swelling index of transferosomal gel

Figure 12: Antioxidant properties and \%EE of MG1 and MG2 gel

Figure 13: a. Standard quercetin (Track 1), b. Isolated quercetin (Track 2) and c. Gel formulation (Track 3)

Figure 14: Overlay at 246nm of Standard quercetin, Isolated quercetin, and Formulation (MG1) in HPTLC

Figure 15: Dissolution profile of MG2 and MG2 gel.

Figure 1: TLC plate developed under UV light at $254 \mathrm{~nm}$

Figure 2: UV spectra of Standard quercetin (a) Isolated quercetin (b) 

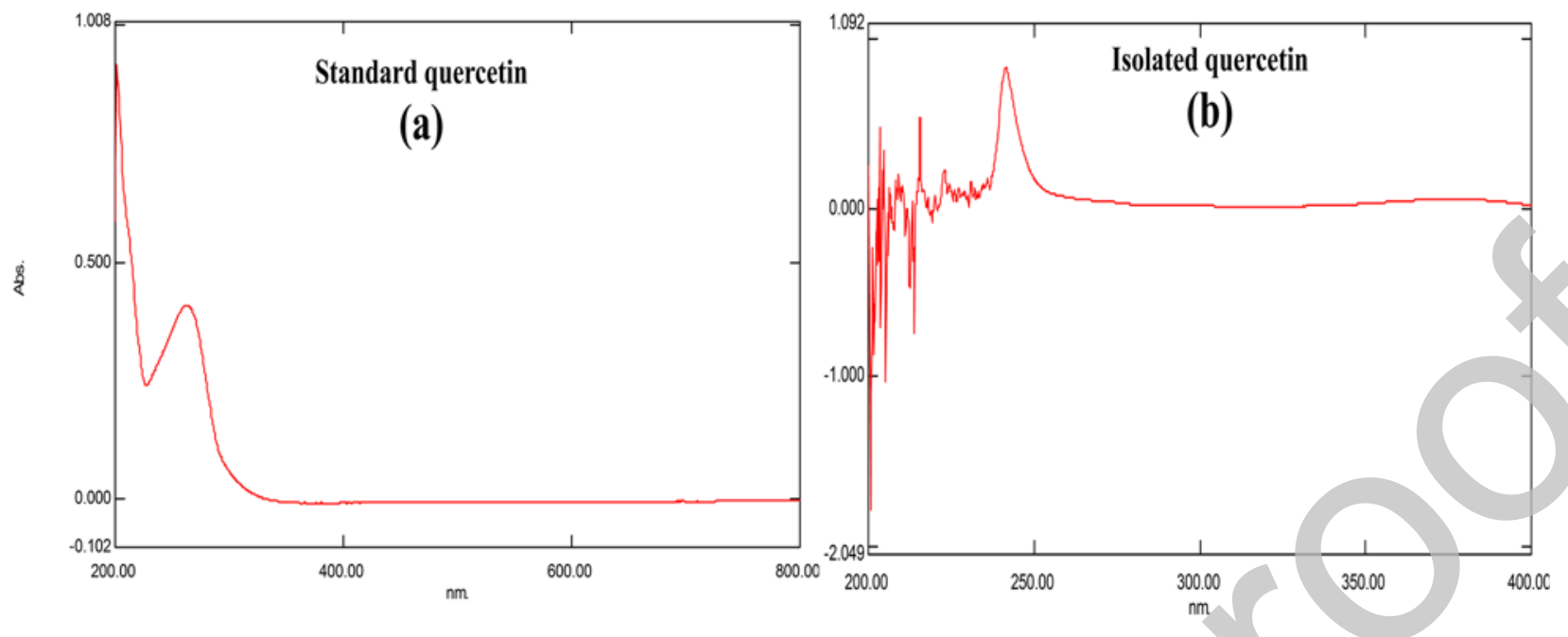

Figure 3: Calibration curve of Standard quercetin(a) and Isolated quercetin (b)
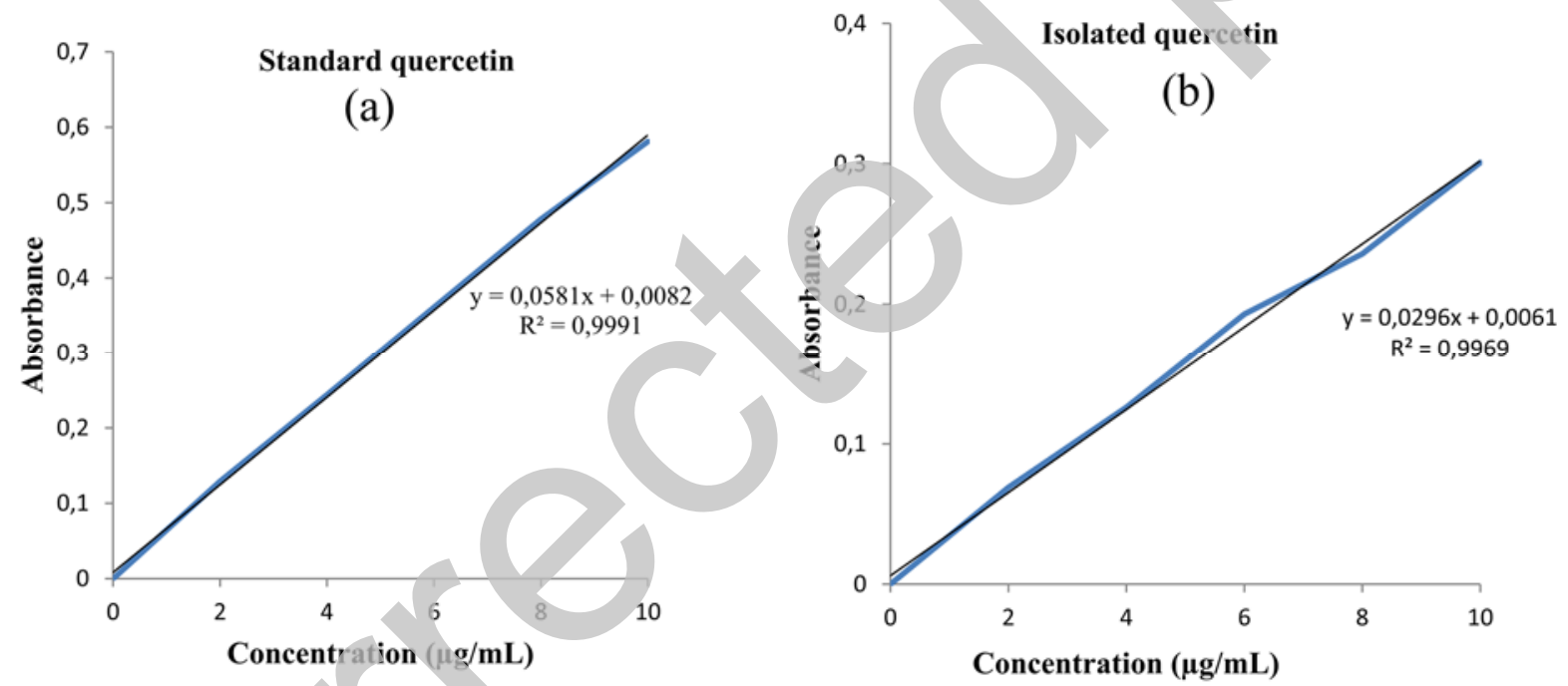

Figure 4: FTIR spectra of Standard quercetin (a) and Isolated quercetin(b)

1. Prabu SL, Umamaheswari A, Rajakumar S, Bhuvaneswari P, Muthupetchi S.

Development and Evaluation of Gel Incorporated with Synthesized Silver Nanoparticle from Ocimum gratissimum for the Treatment of Acne Vulgaris. American Journal of Advanced Drug Delivery. 2017;5:107-17.

2. Vats A, Sharma P. Formulation and evaluation of topical anti acne formulation of coriander oil. International Journal of Pharmacy and Pharmaceutical Science Research. 2012;2(3):61-6.

3. Surekha Baghel CDK, Gidwani B, Gupta A. Novel drug delivery systems of herbal constituents used in acne. International Journal of Contemporary Research and Review. 2017;8(02).

4. Latter G, Grice JE, Mohammed Y, Roberts MS, Benson HA. Targeted Topical Delivery of Retinoids in the Management of Acne Vulgaris: Current Formulations and Novel Delivery Systems. Pharmaceutics. 2019;11(10):490. 
5. Ghovvati M, Afshari GK, Nasrollahi SA, Firooz A, Samadi A, Karimi M, et al. Efficacy of topical cinnamon gel for the treatment of facial acne vulgaris: A preliminary study. Biomedical Research and Therapy. 2019;6(1):2958-65.

6. Tahir CM. Pathogenesis of acne vulgaris: simplified. Journal of Pakistan Association of Dermatology. 2016;20(2):93-7.

7. Baek J, Lee M-G. Oxidative stress and antioxidant strategies in dermatology. Redox Report. 2016.

8. Vora J, Srivastava A, Modi H. Antibacterial and antioxidant strategies for acne treatment through plant extracts. Informatics in Medicine Unlocked. 2018;13:128-32.

9. Thakur N, Jain P, Jain V. Formulation development and evaluation of transferosomal gel. Journal of Drug Delivery and Therapeutics. 2018;8(5):168-77.

10. Bown D. The Royal Horticultural Society encyclopedia of herbs \& their uses: Dorling Kindersley Limited; 1995.

11. Pujari A, Jadhav N. design and development of anti-diabetic tablet formulation containing spray dried extract of mulberry leaves. Int J Pharm Sci \& Res . 2019; 10(3): 150109.

12. Lubtikulthum P, Kamanamool N, Udompataikul M. A comparative study on the effectiveness of herbal extracts vs $2.5 \%$ benzoyl peroxide in the treatment of mild to moderate acne vulgaris. Journal of cosmetic dermatology. 2019.

13. Bhasin B, Londhe VY. An overview of transfersomal drug delivery. International journal of pharmaceutical sciences and research. 2018;9(6):2175-8

14. Vinod KR, Kumar MS, Anbazhagan S, Sandhya S, Saikumar P, Rohit RT, et al. Critical issues related to transfersomes-novel vesicular system. ACTA Scientiarum Polonorum Technologia Alimentaria. 2012;11(1):67-82.

15. Rajan R, Jose S, Mukund VB, Vasudevan DT. Transferosomes-A vesicular transdermal delivery system for enhanced drug permeation. Journal of advanced pharmaceutical technology \& research. 2011;2(3):138.

16. Malakar J, Sen SO, Nayak AK, Sen KK Formulation, optimization and evaluation of transferosomal gel for transdermal insulin delivery. Saudi pharmaceutical journal. 2012;20(4):355-63.

17. Zou Y, Liao S, Shen W, Liu F, Tang C, Chen C-Y, et al. Phenolics and antioxidant activity of mulberry leaves depend on cultivar and harvest month in Southern China.

International journal of molecular sciences. 2012;13(12):16544-53.

18. Sanghavi N, Srivastava R, Malode Y. Isolation and identification of the flavonoid "quercetin" from trida procumbens linn. International Journal of Pharmaceutical Sciences and Research. 2014;5(4):1454-9.

19. Sajeeth C. Quantitative estimation of gallic acid, rutin and quercetin in certain herbal plants by HPTLC method. Der Chemica Sinica. 2010;1(2):80-5.

20. Patil V, Angadi S, Devdhe S. Determination of quercetin by uv spectroscopy as quality control parameter in herbal plant: Cocculus hirsutus. J Chem Pharm Res. 2015;7(1):99-104.

21. Iqbal S, Younas U, Chan KW, Sarfraz RA, Uddin M. Proximate composition and antioxidant potential of leaves from three varieties of Mulberry (Morus sp.): a comparative study. International journal of molecular sciences. 2012;13(6):6651-64.

22. Chauhan P, Tyagi BK. Herbal novel drug delivery systems and transfersomes. Journal of Drug Delivery and Therapeutics. 2018;8(3):162-8.

23. Rahmi AD, Pangesti DM. Comparison of the Characteristics of Transfersomes and Protransfersomes Containing Azelaic Acid. Journal of Young Pharmacists. 2018;10(2):S11. 
24. Duangjit S, Opanasopit P, Rojanarata T, Ngawhirunpat T. Characterization and in vitro skin permeation of meloxicam-loaded liposomes versus transfersomes. Journal of drug delivery. 2011;2011.

25. Laxmi M, Zafaruddin M. Design and characterization of transferosomal gel of repaglinide. Int Res J Pharm. 2015;6(1):37-41.

26. Surini S, Djajadisastra J. Formulation and in vitro Penetration Study of Transfersomes Gel Containing Gotu Kola Leaves Extract (Centella asiatica L. Urban). Journal of Young Pharmacists. 2018;10(1):27.

27. Ali MFM, Salem HF, Abdelmohsen HF, Attia SK. Preparation and clinical evaluation of nano-transferosomes for treatment of erectile dysfunction. Drug design, development and therapy. 2015;9:2431.

28. Laxmi M, Zafaruddin M, Kuchana V. Design and characterization of transferosomal gel of repaglinide. Int Res J Pharm. 2015;6(1):37-41.

29. Preeti MSK. Development of celecoxib transfersomal gel for the treatment of rheumatoid arthritis. Indian J Pharm Biol Res. 2014;2:7-13.

30. Mulani H, Bhise K. QbD Approach in the formulation and evaluation of Miconazole Nitrate loaded ethosomal cream-o-gel. Int Res J Pharm Sci. 2017;8:1-37.

31. Movaliya V, Zaveri M. HPTLC method development and estimation of quercetin in the alcoholic extract of Aerva javanica root. Advance Research in Pharmaceuticals and Biologicals. 2012;2:222-8.

32. Patel R, Singh S, Singh S, Sheth N, Gendle R. Development and characterization of curcumin loaded transfersome for transdermal delivery. Journal of pharmaceutical sciences and research. 2009;1(4):71.

33. Kaza R, Pitchaimani R. Formulation of transdermal drug delivery system: matrix type, and selection of polymer-their evaluation. Current drug discovery technologies.

2006;3(4):279-85.

34. Marwah H, Garg T, Rath G, Goyal AK. Development of transferosomal gel for transdermal delivery of insulin using iodine complex. Drug delivery. 2016;23(5):1636-44.

35. Jain S, Jain P, Umamaheshwari R, Jain N. Transfersomes - a novel vesicular carrier for enhanced transdermal delivery: development, characterization, and performance evaluation. Drug development and industrial pharmacy. 2003;29(9):1013-26.

36. Lichtenberg D, Robson RJ, Dennis EA. Solubilization of phospholipids by detergents structural and kinetic as pects. Biochimica et Biophysica Acta (BBA)-Reviews on Biomembranes. 1983;737(2):285-304.

37. Ascenso A, Raposo S, Batista C, Cardoso P, Mendes T, Praça FG, et al. Development, characterization, and skin delivery studies of related ultradeformable vesicles: transfersomes, ethosomes, and transethosomes. International journal of nanomedicine. 2015;10:5837.

38. Malvern A. Basic Guide to Particle Characterisation. Malvern Instruments, Ltd.:

Malvern, UK; 2012.

39. Liu J, Hu G. Advances in studies of phospholipids as carriers in skin topical application, Journal of Nanjing Medical University. 2007;21(6):349-53.

40. Chaudhary H, Kohli K, Kumar V. Nano-transfersomes as a novel carrier for transcermal delivery. International journal of pharmaceutics. 2013;454(1):367-80.

41. Mitkari B, Korde S, Mahadik K, Kokare C. Formulation and evaluation of topical liposomal gel for fluconazole. Indian J Pharm Educ Res. 2010;44(4):324-33.

42. Shaji J, Lal M. Novel double loaded transferosomes: evidence of superior antiinflammatory efficacy-a comparative study. Int J Curr Pharm Res. 2014;6(2):16-25.

43. Sultana SS, Krishna Sailaja A. Formulation and evaluation of diclofenac sodium transferosomes using different surfactants by thin film hydration method. Der Pharmacia Lettre. 2015;7(11):43-53. 
44. Gupta A, Aggarwal G, Singla S, Arora R. Transfersomes: a novel vesicular carrier for enhanced transdermal delivery of sertraline: development, characterization, and performance evaluation. Scientia pharmaceutica. 2012;80(4):1061-80.

\section{Table}

Table 1: Preparation of Mulberry leaves extract transfersomes

Table 2: Transfersomes gel of mulberry leaf extract (MG1) and control extract gel (MG2)

Table 3: Characterization and optimization of prepared transfersomes

Table 4: The flow properties of MG1 and MG2

Table 5: Optimized Parameter of HPTLC for quercetin isolation

Table 6: Stability evaluation of transferosomal gel after 3 month

Table 1: Preparation of Mulberry leaves extract transfersomes

\begin{tabular}{|l|l|l|l|l|l|l|}
\hline \multirow{2}{*}{ Material name } & \multicolumn{3}{l}{ Concentration (\% w/w) } \\
\cline { 2 - 8 } & MF1 & MF2 & MF3 & MF4 & MF5 & MF6 \\
\hline Mulberry leaves extract & 10 & 10 & 10 & 10 & 10 & 10 \\
\hline Tween 80 & 0.3 & 0.3 & 0.3 & 0.4 & 0.4 & 0.4 \\
\hline phopholipon 90G & 2 & 2.5 & 3 & 2 & 2.5 & 3 \\
\hline $\begin{array}{l}\text { Phosphate buffer } \\
\text { (saline pH 7.4) }\end{array}$ & Add 100 & Add 100 & Add 100 & Add 100 & Add 100 & Add 100 \\
\hline
\end{tabular}

Table 2: Transfersomes gel of mulberry leaves extract (MG1) and control extract gel (MG2)

\begin{tabular}{|c|c|c|c|c|c|c|}
\hline Composition & \multirow[b]{2}{*}{$\begin{array}{l}\text { Transfersome } \\
\text { s }\end{array}$} & \multirow[b]{2}{*}{$\begin{array}{l}\text { Extrac } \\
t\end{array}$} & \multirow[b]{2}{*}{$\begin{array}{l}\text { Carbapo } \\
1 \\
940\end{array}$} & \multirow[b]{2}{*}{$\begin{array}{l}\text { Triethanolamin } \\
\text { e }\end{array}$} & \multirow[b]{2}{*}{$\begin{array}{l}\text { Propylen } \\
\text { e glycol }\end{array}$} & \multirow[b]{2}{*}{$\begin{array}{l}\text { Wate } \\
\mathbf{r}\end{array}$} \\
\hline $\begin{array}{l}\text { Concentratio } \\
n \\
(\% \mathrm{w} / \mathrm{w}) \\
\end{array}$ & & & & & & \\
\hline MG1 & $\begin{array}{l}\text { Equal to } 10 \% \\
\text { extract }\end{array}$ & - & 1 & 0.1 & 12.5 & $\begin{array}{l}\text { Add } \\
100\end{array}$ \\
\hline MG2 & & 10 & 1 & 0.1 & 12.5 & $\begin{array}{l}\text { Add } \\
100\end{array}$ \\
\hline
\end{tabular}

Table 3: Characterization and optimization of prepared transfersomes

\begin{tabular}{|l|l|l|l|l|l|}
\hline Batch no. & Particle size & $\begin{array}{l}\text { Zeta } \\
\text { potential }\end{array}$ & PDI & \% EE & $\begin{array}{l}\text { Deformability } \\
\text { Index }\end{array}$ \\
\hline MF1 & $381.9 \mathrm{~nm}$ & $21.19 \mathrm{mV}$ & 0.511 & $68.23 \pm 1.2$ & $3.52 \pm 0.9$ \\
\hline MF2 & $214.5 \mathrm{~nm}$ & $-44.56 \mathrm{mV}$ & 0.421 & $65.23 \pm 1.1$ & $3.63 \pm 0.5$ \\
\hline MF3 & $268.3 \mathrm{~nm}$ & $-21.91 \mathrm{mV}$ & 0.448 & $76.23 \pm 0.9$ & $2.25 \pm 1.3$ \\
\hline
\end{tabular}




\begin{tabular}{|l|l|l|l|l|l|}
\hline MF4 & $401.9 \mathrm{~nm}$ & $-22.39 \mathrm{mV}$ & 0.270 & $77.65 \pm 1.6$ & $3.5 \pm 2.1$ \\
\hline MF5 & $\mathbf{1 1 8 . 7} \mathrm{nm}$ & $\mathbf{- 4 5 . 1 1} \mathrm{mV}$ & $\mathbf{0 . 3 8 9}$ & $\mathbf{8 6 . 2 3} \pm \mathbf{2 . 1}$ & $\mathbf{1 . 0 3} \pm \mathbf{0 . 8}$ \\
\hline MF6 & $416.6 \mathrm{~nm}$ & $-27.73 \mathrm{mV}$ & 0.628 & $80.23 \pm 1.8$ & $2.05 \pm 1.5$ \\
\hline
\end{tabular}

$\mathrm{n}=3,( \pm): \mathrm{sd}$

Table 4: The flow properties of MG1 and MG2

\begin{tabular}{|l|l|l|l|l|}
\hline \multirow{2}{*}{ Properties } & \multirow{2}{*}{ MG1 } & \multicolumn{2}{l|}{ MG2 } \\
\cline { 2 - 5 } & 0 days & $\mathbf{1 0}$ days & 0 days & $\mathbf{1 0}$ days \\
\hline Homogeneity rate (1/10mm) & $60.54 \pm 1.6$ & $99.58 \pm 2.9$ & $59.23 \pm 1.2$ & $99.03 \pm 3.6$ \\
\hline Tensile strength (Kg/cm) & $30.25 \pm 0.9$ & $35.62 \pm 1.7$ & $30.01 \pm 1.9$ & $33.87 \pm 2.8$ \\
\hline Elongation rate (\%) & $200.21 \pm 1.4$ & $282.3 \pm 2.5$ & $199.56 \pm 1.6$ & $276.2 \pm 3.1$ \\
\hline Spreadability(cm) & $9.80 \pm 0.9$ & $9.98 \pm 0.9$ & $8.01 \pm 0.9$ & $8.26 \pm 0.9$ \\
\hline
\end{tabular}

$\mathrm{n}=3,( \pm): \mathrm{sd}$

Table 5: Optimized Parameter of HP LC for quercetin isolation

\begin{tabular}{|c|c|c|c|}
\hline Parameters & Description & Parameters & Description \\
\hline $\begin{array}{l}\text { Stationary } \\
\text { Phase }\end{array}$ & $\begin{array}{l}\text { Merck Silica gel } 60 \text { F } 254 \text { HPTLC } \\
\text { pre-coated plates }\end{array}$ & Plate size & $4.0 \mathrm{~cm} \times 10.0 \mathrm{~cm}$ \\
\hline $\begin{array}{l}\text { Mode of } \\
\text { separation }\end{array}$ & Normal phase & $\begin{array}{l}\text { Development } \\
\text { chamber }\end{array}$ & $\begin{array}{l}\text { Camag twin trough } \\
\text { chamber }\end{array}$ \\
\hline Mobile phase & $\begin{array}{l}\text { Ethyl acetate: Toluene: Formic } \\
\text { acid }(4: 3.5: 0.5 \mathrm{v} / \mathrm{v} / \mathrm{v})\end{array}$ & Bandwidth & $7.0 \mathrm{~mm}$ \\
\hline $\begin{array}{l}\text { Chamber } \\
\text { saturation }\end{array}$ & $30 \mathrm{~min}$ & $\begin{array}{l}\text { Space between } \\
\text { the bands }\end{array}$ & $7.0 \mathrm{~mm}$ \\
\hline $\begin{array}{l}\text { Sample } \\
\text { applicator }\end{array}$ & Camag Linomat V & Syringe & Hamilton, $100.0 \mu \mathrm{L}$ \\
\hline $\begin{array}{l}\text { Distance from } \\
\text { the edges of the } \\
\text { plat }\end{array}$ & $13.0 \mathrm{~mm}$ & $\begin{array}{l}\text { Rate of a } \\
\text { sample } \\
\text { application }\end{array}$ & $150 \mathrm{~nL} / \mathrm{sec}$ \\
\hline $\begin{array}{l}\text { Lamp and } \\
\text { wavelength }\end{array}$ & Deuterium, 246nm & $\begin{array}{l}\text { Development } \\
\text { distance }\end{array}$ & $85.0 \mathrm{~mm}$ \\
\hline $\begin{array}{l}\text { Densitometric } \\
\text { scanner }\end{array}$ & \multicolumn{3}{|c|}{$\begin{array}{l}\text { Camag Scanner IV equipped with win-CATS Planar Chromatography } \\
\text { manager software version 1.4.7 }\end{array}$} \\
\hline
\end{tabular}


Table 6: Stability evaluation of transferosomal gel after 3 months

\begin{tabular}{|c|c|c|c|c|}
\hline \multirow{2}{*}{\multicolumn{3}{|c|}{ Properties }} & \multicolumn{2}{|l|}{ Gel formulation } \\
\hline & & & \multirow{2}{*}{$\begin{array}{l}\text { MG1 } \\
\text { Slightly yellowish }\end{array}$} & \multirow{2}{*}{$\begin{array}{l}\text { MG2 } \\
\text { Greenish }\end{array}$} \\
\hline \multirow{5}{*}{$\left(4^{\circ} \mathrm{C} \pm 2^{\circ} \mathrm{C}\right)$} & f) & Color & & \\
\hline & & pH & $5.62 \pm 0.23$ & $5.89 \pm 0.95$ \\
\hline & h) & Viscosity(CPS) & $14005 \pm 230$ & $13202+456$ \\
\hline & & EE $(\%)$ & $84.96 \pm 2.35$ & $78.35 \pm 3.69$ \\
\hline & & Drug content $(\%)$ & $98.01 \pm 2.61$ & $89.40 \pm 3.10$ \\
\hline \multirow{5}{*}{$\left(40^{\circ} \mathrm{C} \pm 2^{\circ} \mathrm{C}\right)$} & f) & Color & Slightly yellowish & Greenish \\
\hline & & pH & $5.95 \pm 1.02$ & $6.23 \pm 1.63$ \\
\hline & h) & Viscosity(cps) & $13750 \pm 412$ & $12889 \pm 362$ \\
\hline & & EE (\%) & $83.69 \pm 4.02$ & $73.23 \pm 5.06$ \\
\hline & & Drug content (\%) & $97.96 \pm 00.97$ & $84.25 \pm 2.96$ \\
\hline
\end{tabular}

$\mathrm{n}=3,( \pm): \mathrm{sd}$

\section{Legend}

\section{Figure}

Figure 1: TLC plate developed under UV light at $254 \mathrm{~nm}$

Figure 2: UV spectra of Standard quercetin (a) Isolated quercetin (b)

Figure 3: Calibration curve of Standard quercetin(a) and Isolated quercetin (b)

Figure 4: FTIR spectra of Standard quercetin (a) and Isolated quercetin(b)

Figure 5: Unsonicated transfersomes vesicles by Motic microscopy

Figure 6: Calibration curve of extract ( $\mathrm{pH} 7.4$ )

Figure 7: In Vitro release profile of transfersomes

Figure 8: FTIR spectra of transfersomes

Figure 9: Viscosity of MG1 and MG2 gel

Figure 10: $\mathrm{pH}$ of MG1 and MG2 gel

Figure 11: Swelling index of transferosomal gel

Figure 12: Antioxidant properties and \%EE of MG1 and MG2 gel

Figure 13: a. Standard quercetin (Track 1), b. Isolated quercetin (Track 2) and c. Gel formulation (Track 3) 
Figure 14: Overlay at 246nm of Standard quercetin, Isolated quercetin, and Formulation (MG1) in HPTLC

Figure 15: Dissolution profile of MG2 and MG2 gel.

Figure 1: TLC plate developed under UV light at $254 \mathrm{~nm}$

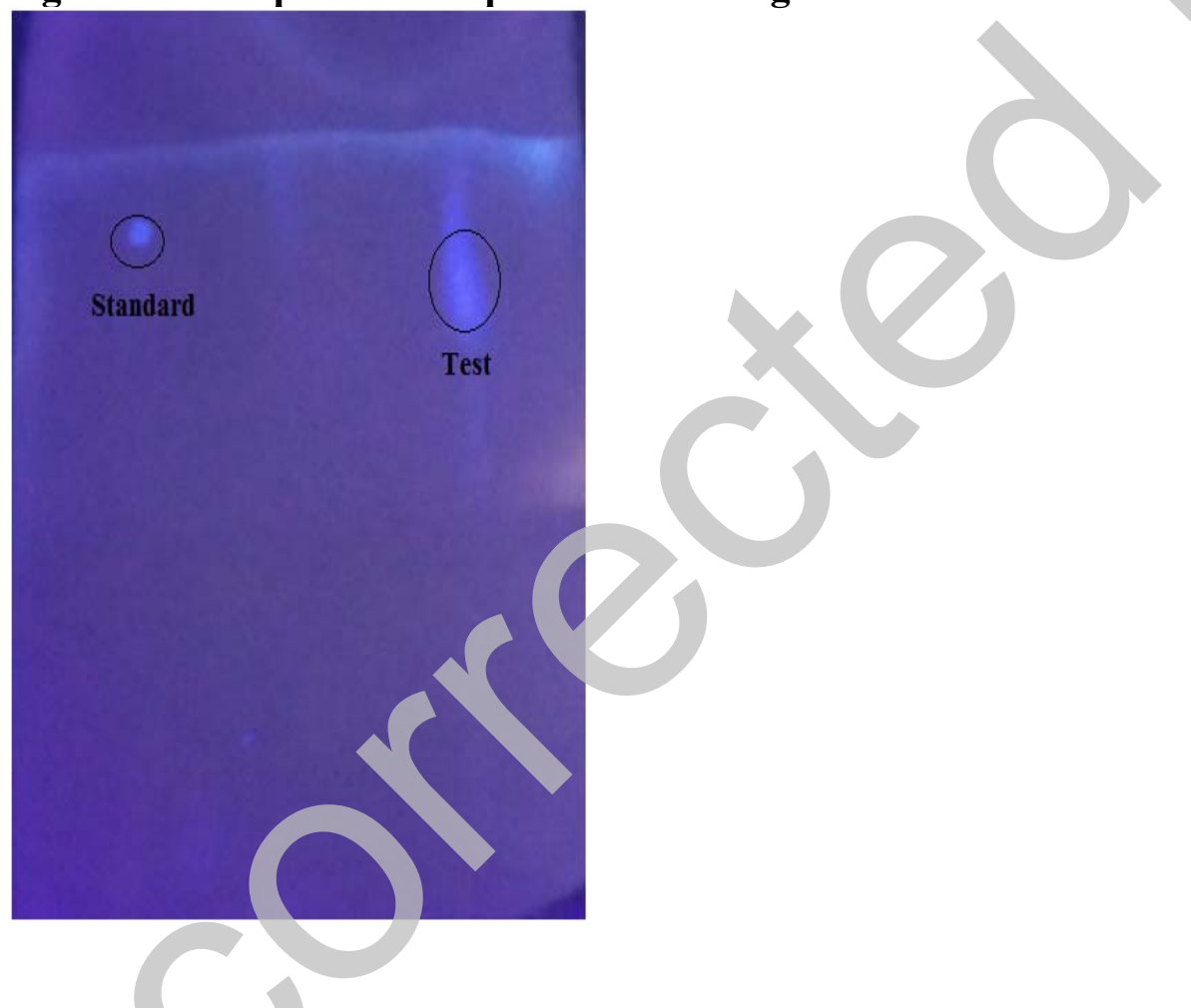

Figure 2: UV spectra of Standard quercetin (a) Isolated quercetin (b) 

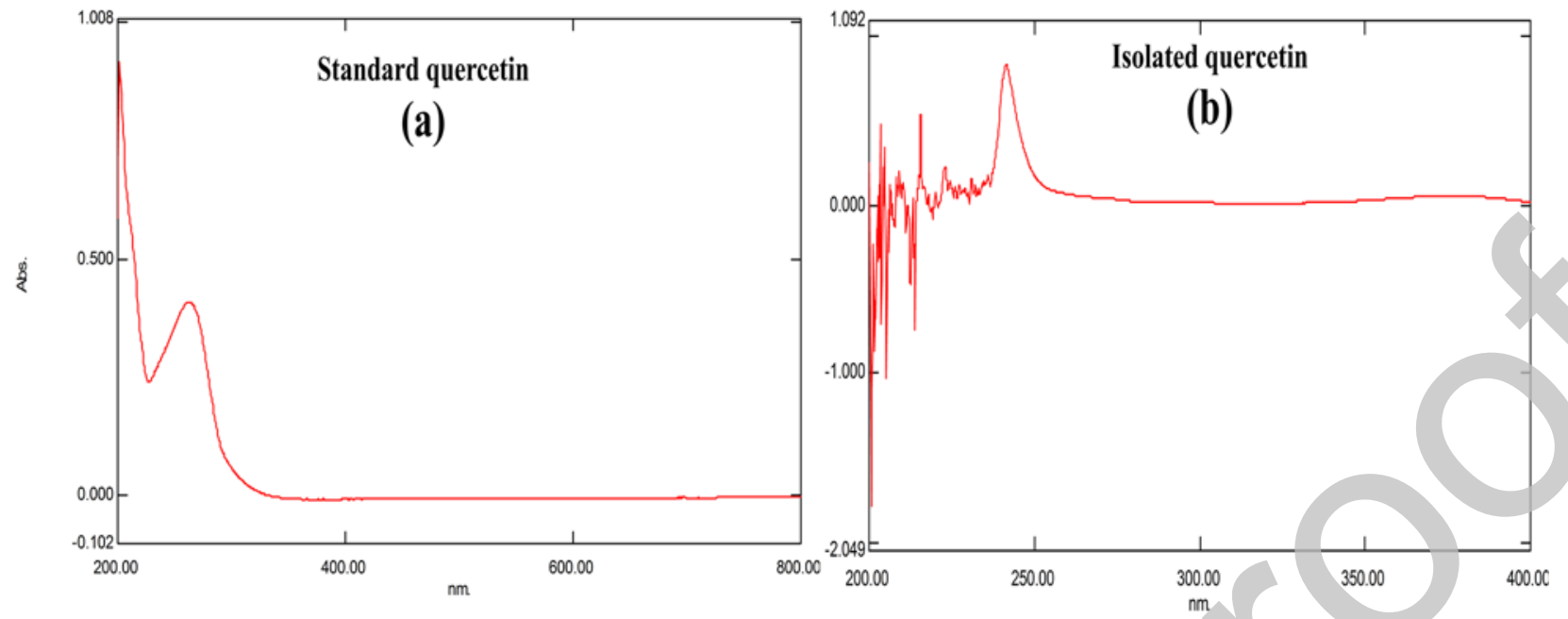

Figure 3: Calibration curve of Standard quercetin(a) and Isolated quercetin (b)
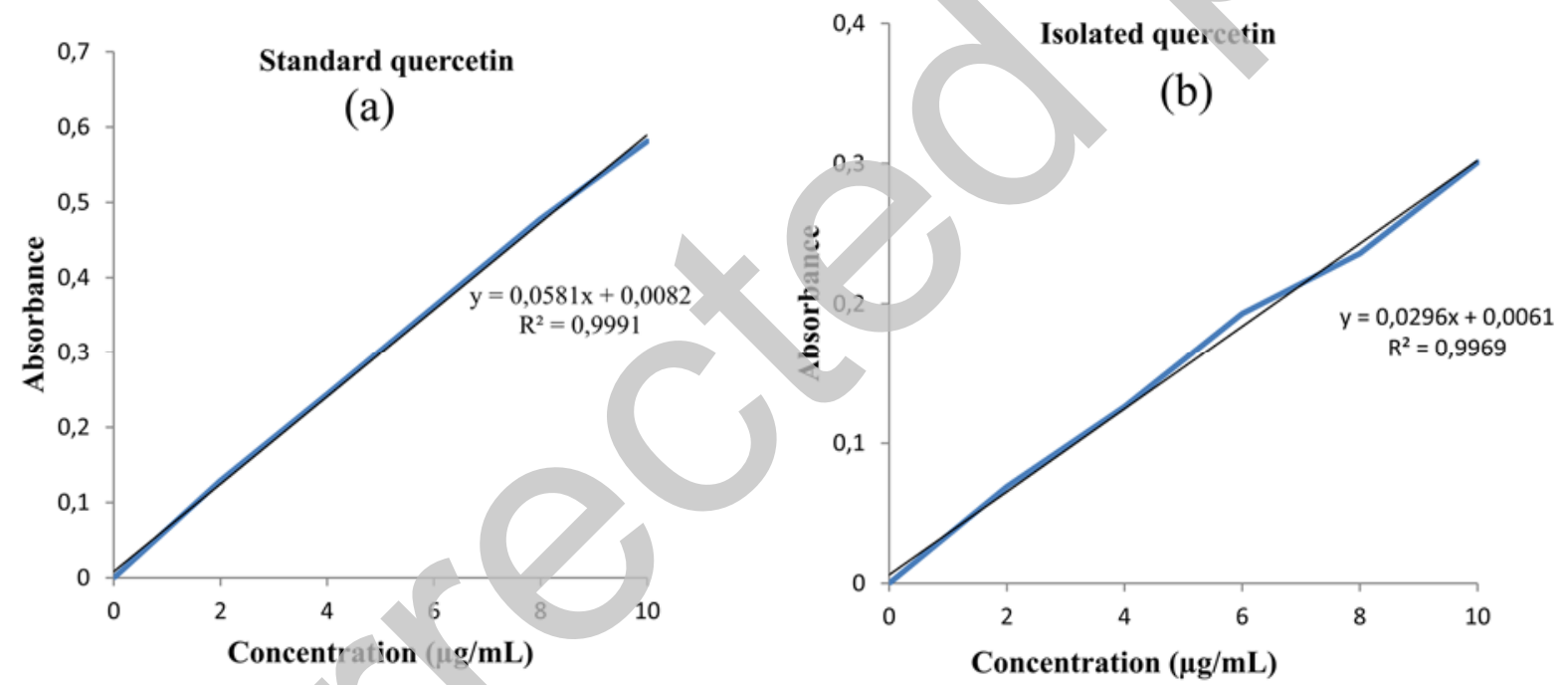

Figure 4: FTIR spectra of Standard quercetin (a) and Isolated quercetin(b) 

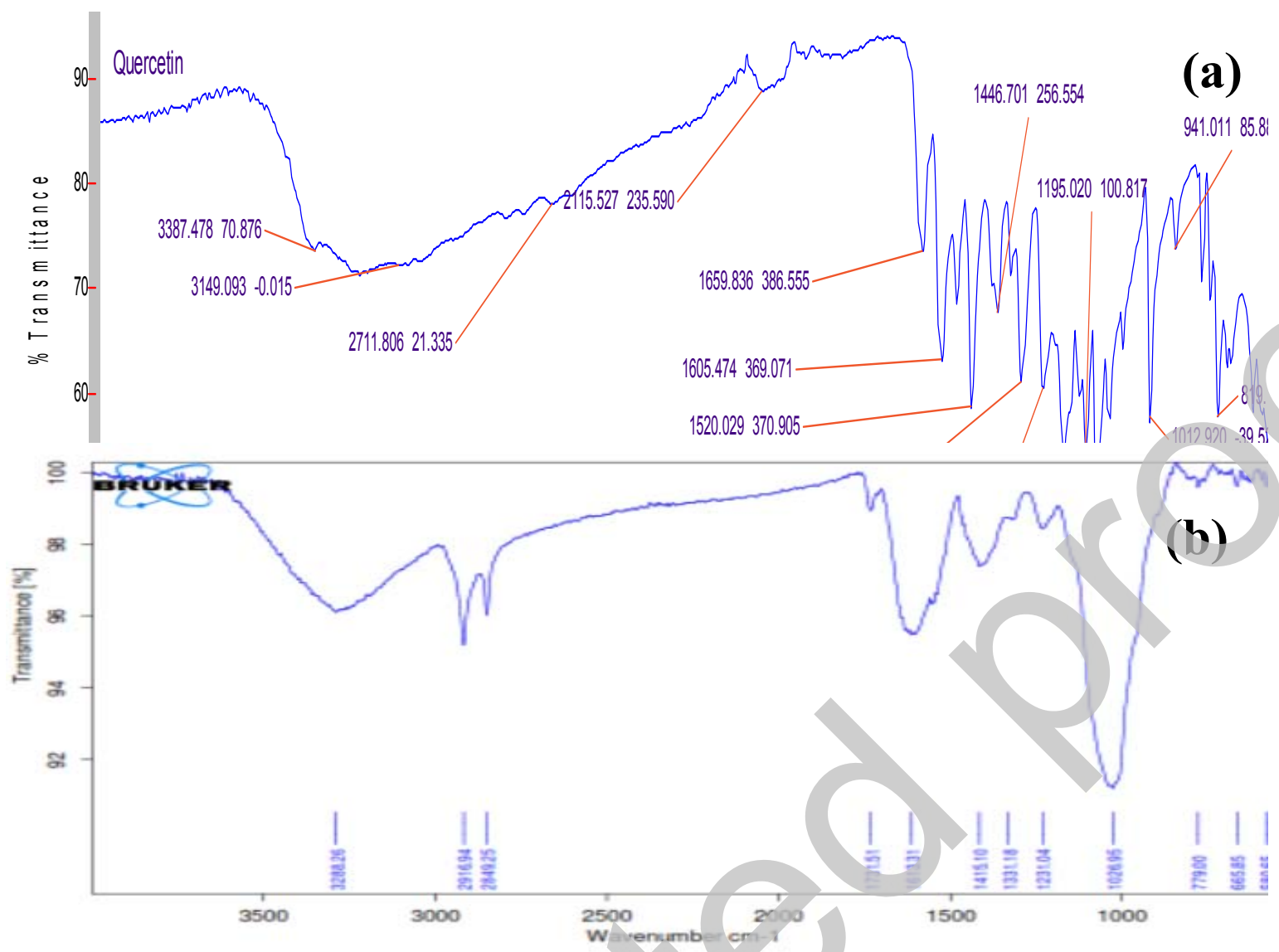

Figure 5: Unsonicated transfersomes vesicles by Motic microscopy

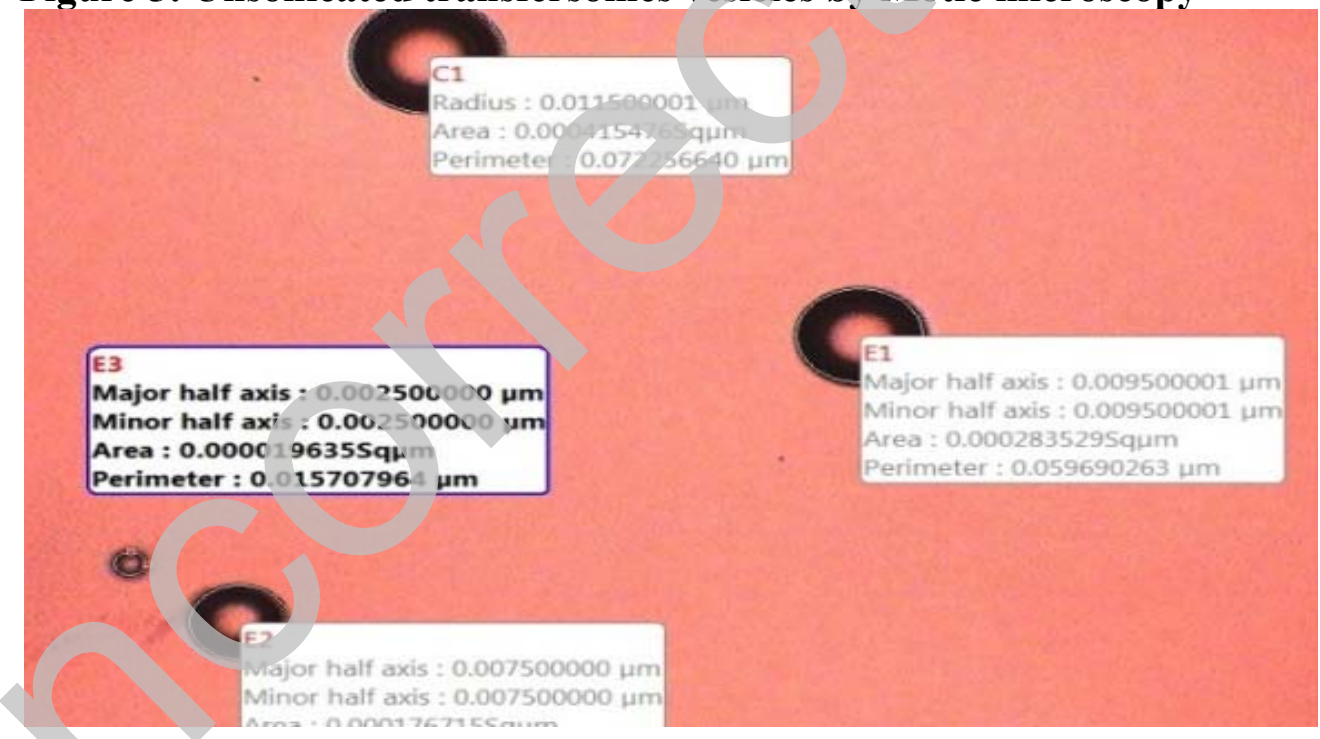

igure 6: Calibration curve of extract (pH 7.4) 


\section{Phospahte buffer (pH 7.4)}

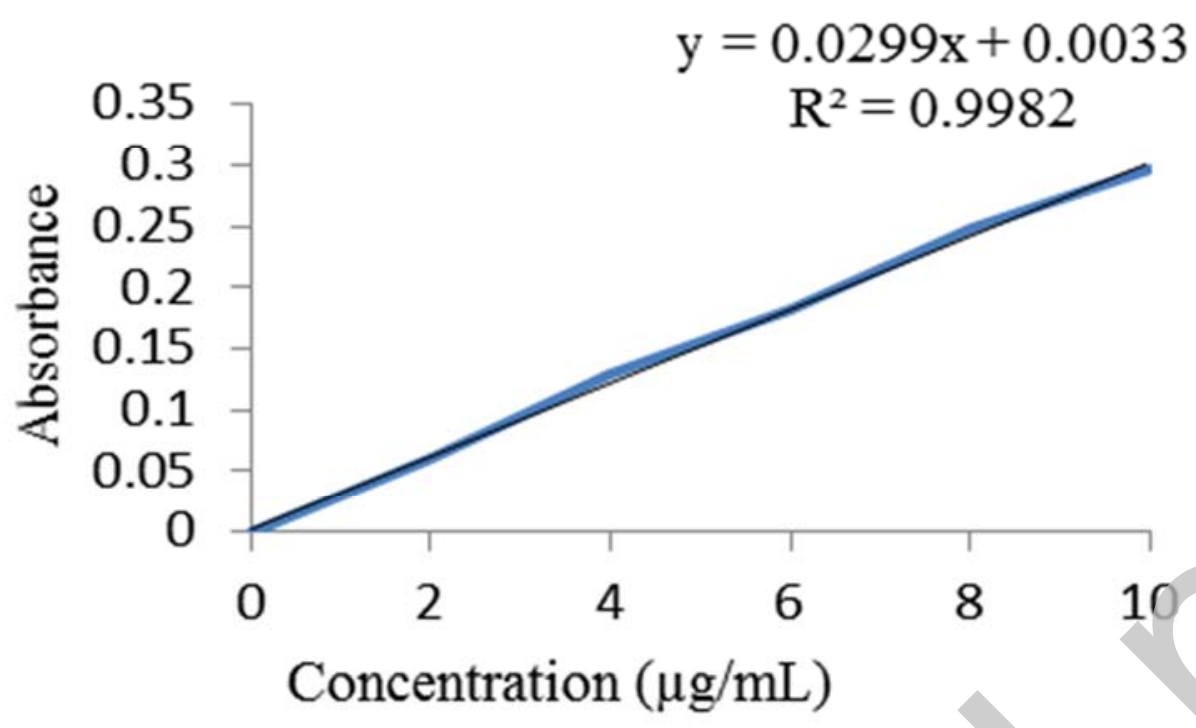

Figure 7: In Vitro release profile of transfersomes

In vitro release profile of Transfersomes

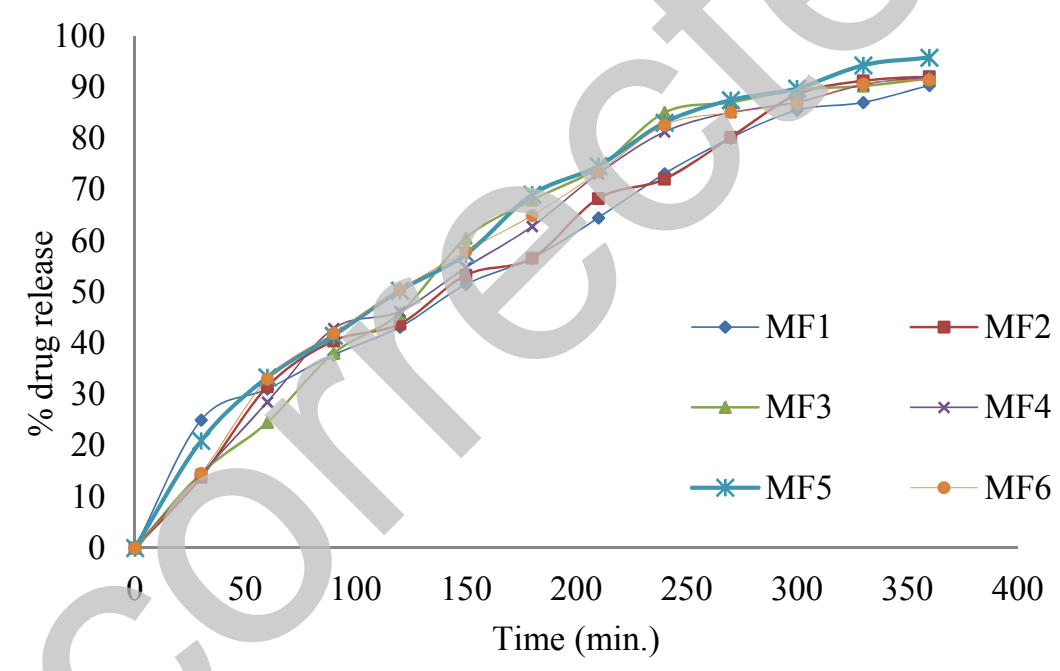

Figure 8: FTIR spectra of transfersomes 


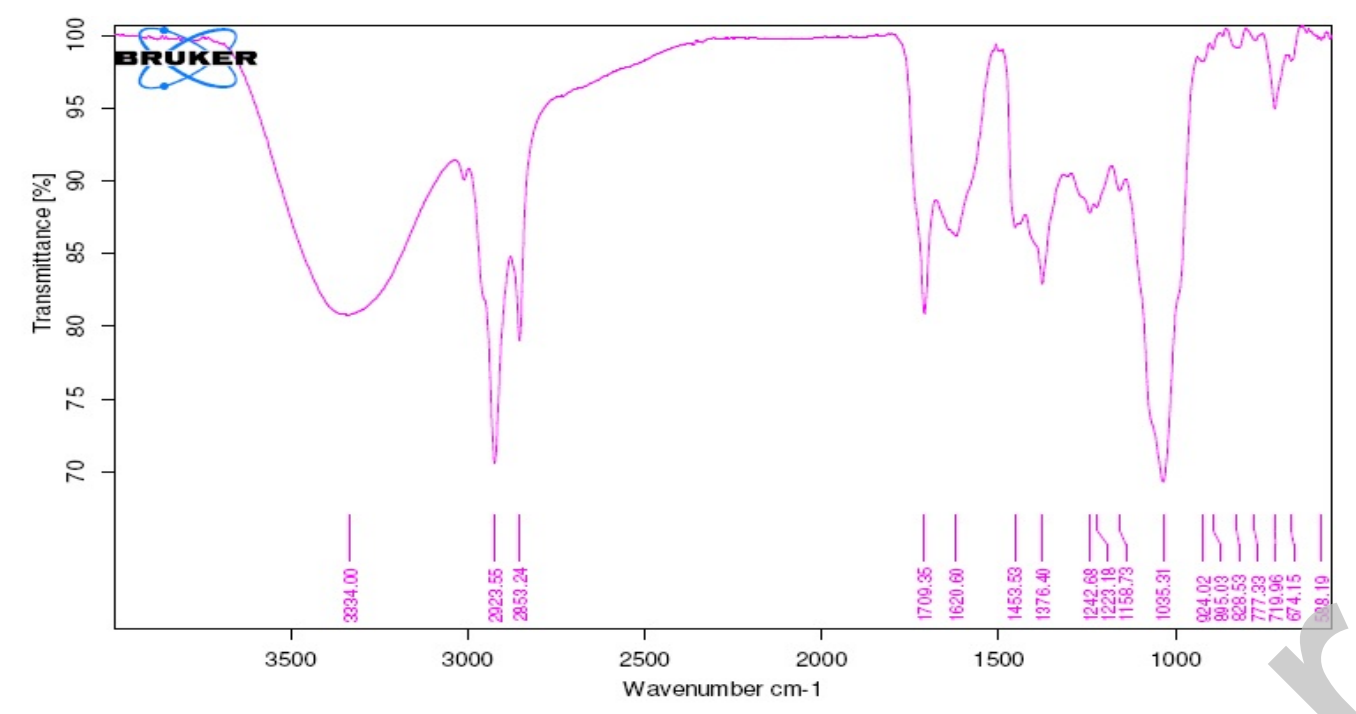

Figure 9: Viscosity of MG1 and MG2 gel

Viscosity of gel

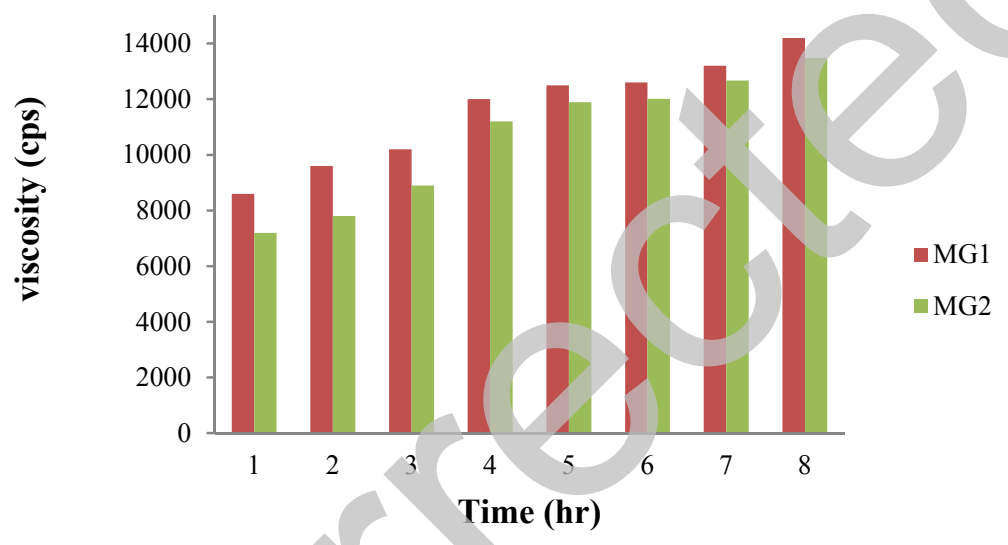

Figure 10: pH of MG1 and MG2 gel 
pH of gel

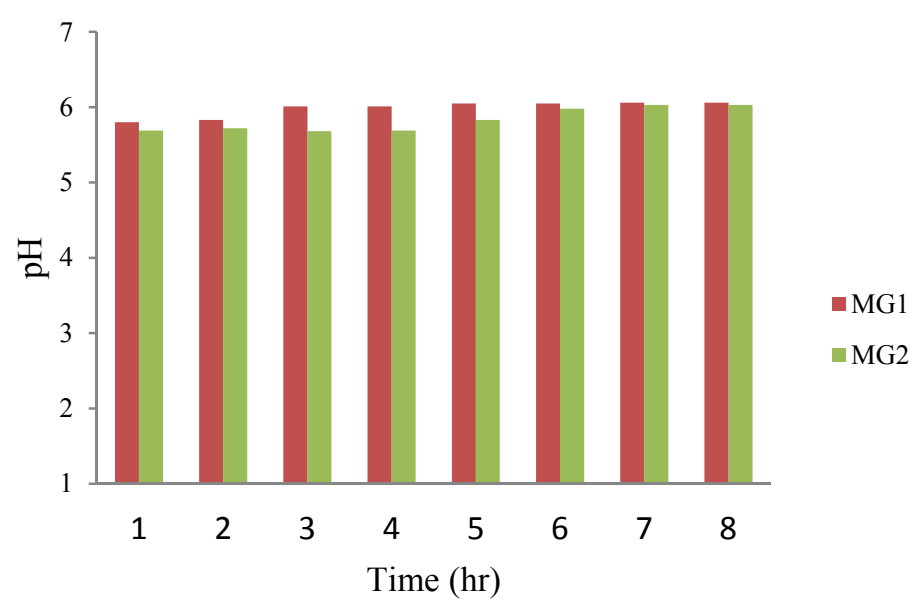

Figure 11: Swelling index of transferosomal gel

Swelling index $(\%)$

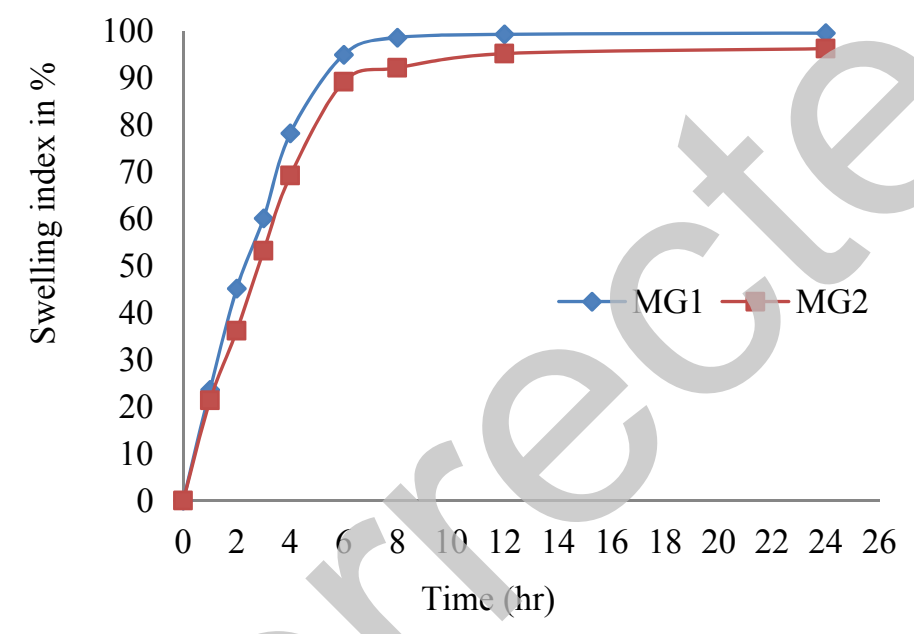

Figure 12: Antioxidant properties and \%EE of MG1 and MG2 gel 

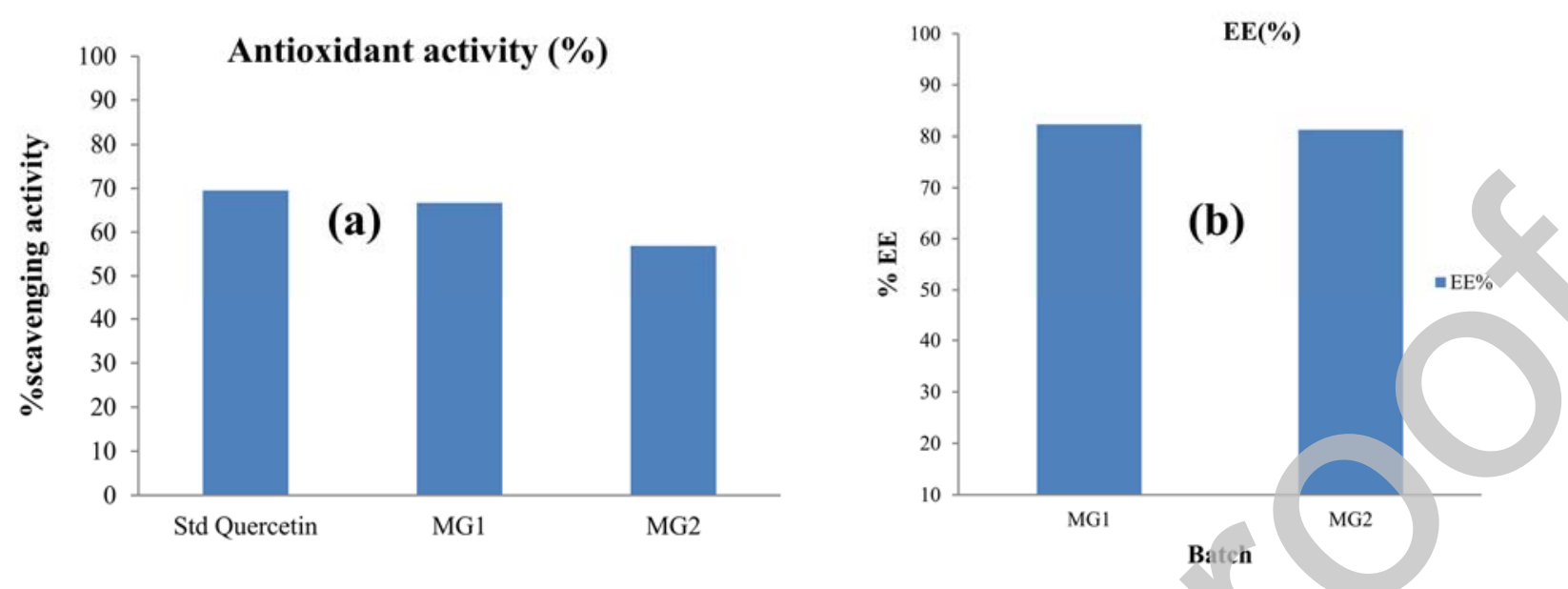

Fiqure 13: a. Std quercetin (Track 1), b. Isolated quercetin (Track 2) and c. Gel formulation (Track 3) 

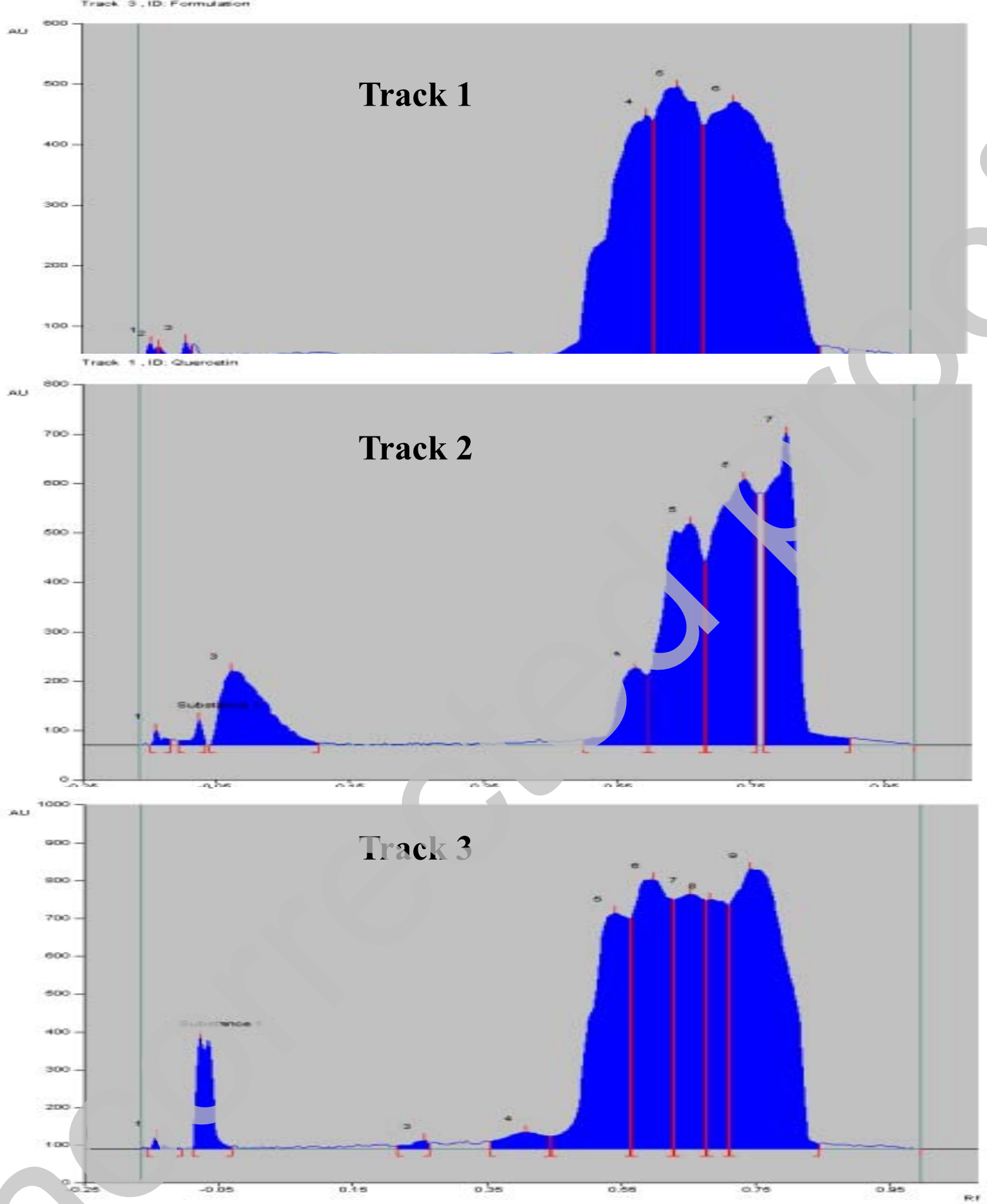

Figure 14: Overlay at 246nm of Standard quercetin, Isolated quercetin, and Formulation (MG1) in HPTLC 


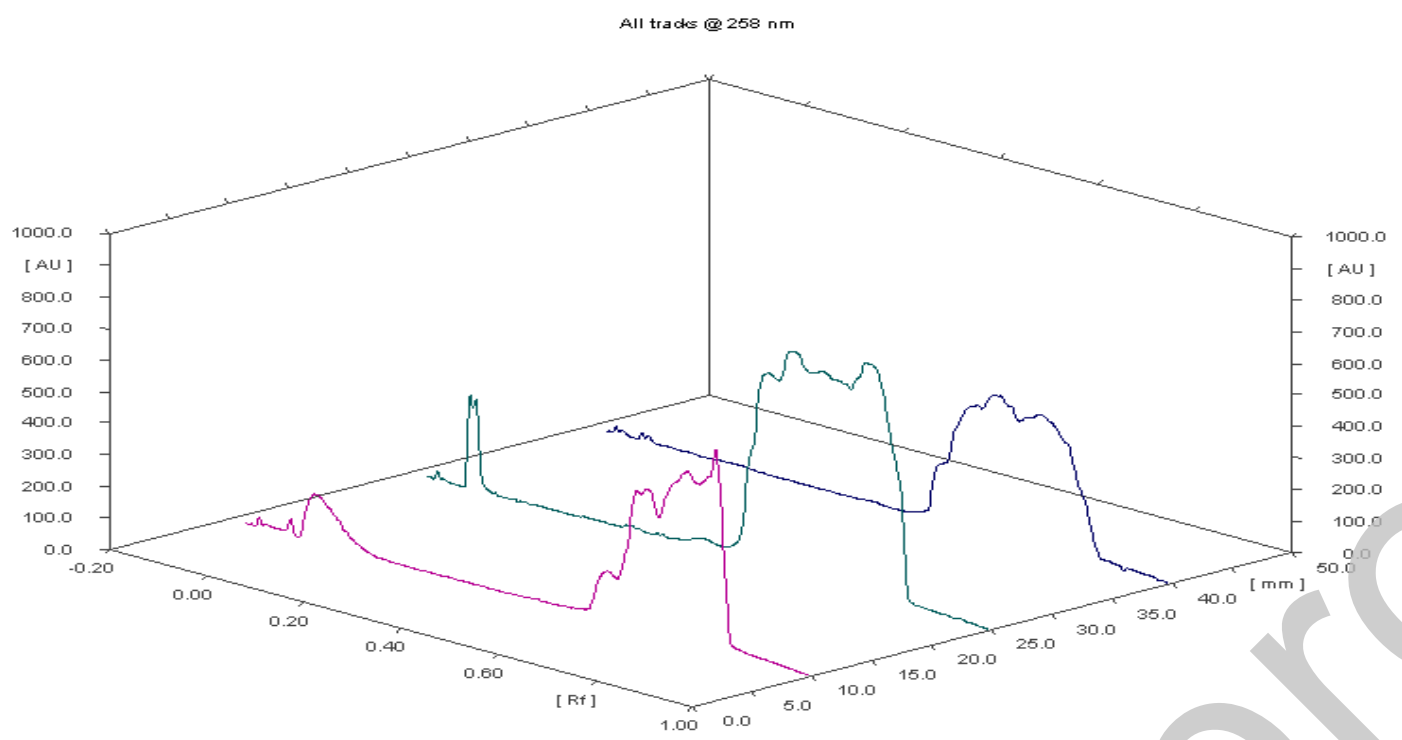

Figure 15: Dissolution profile of MG2 and MG2 gel

Ex vivo percent drug release

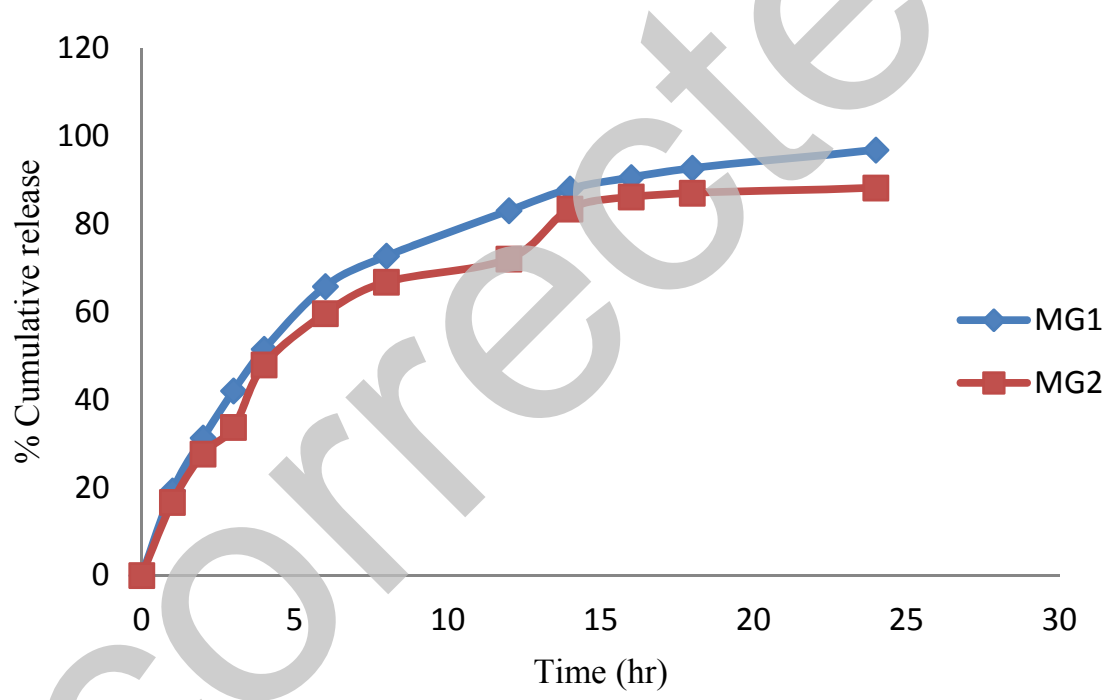

Figure 5: Unsonicated transfersomes vesicles by Motic microscopy 


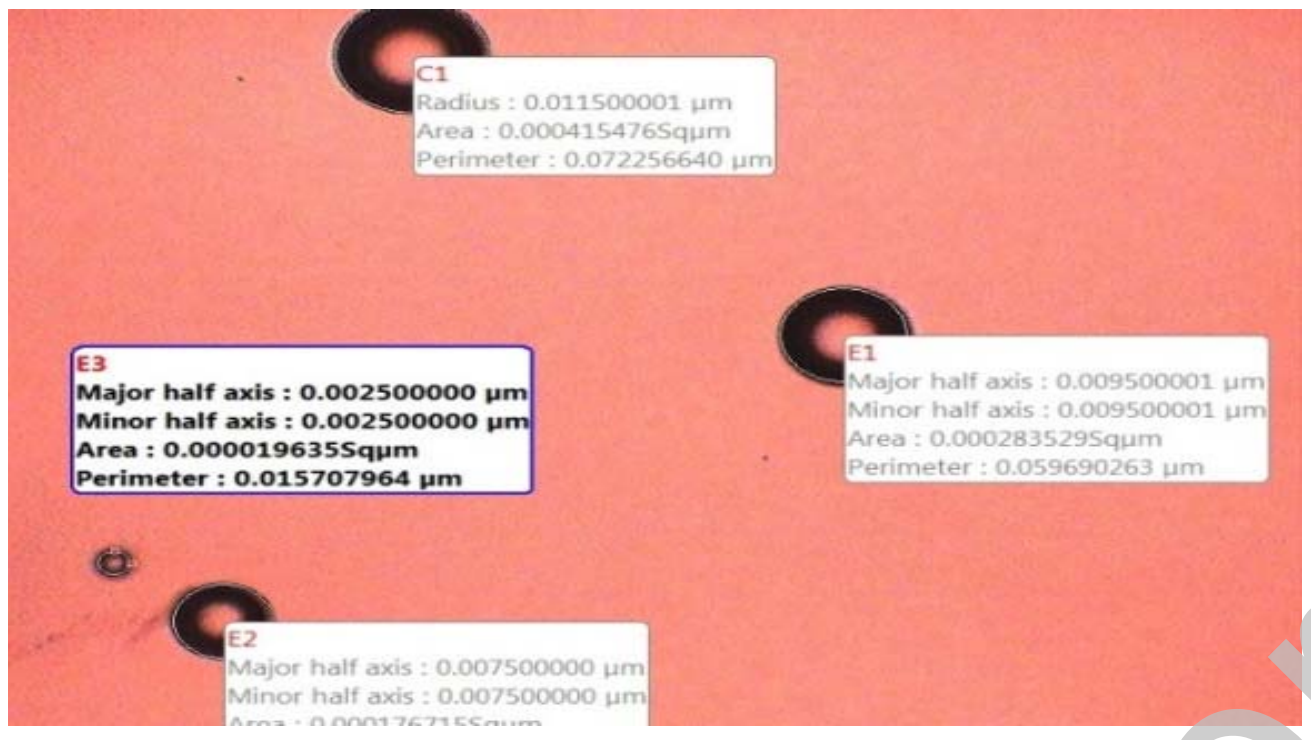

Figure 6: Calibration curve of extract (pH 7.4)

\section{Phospahte buffer (pH 7.4)}

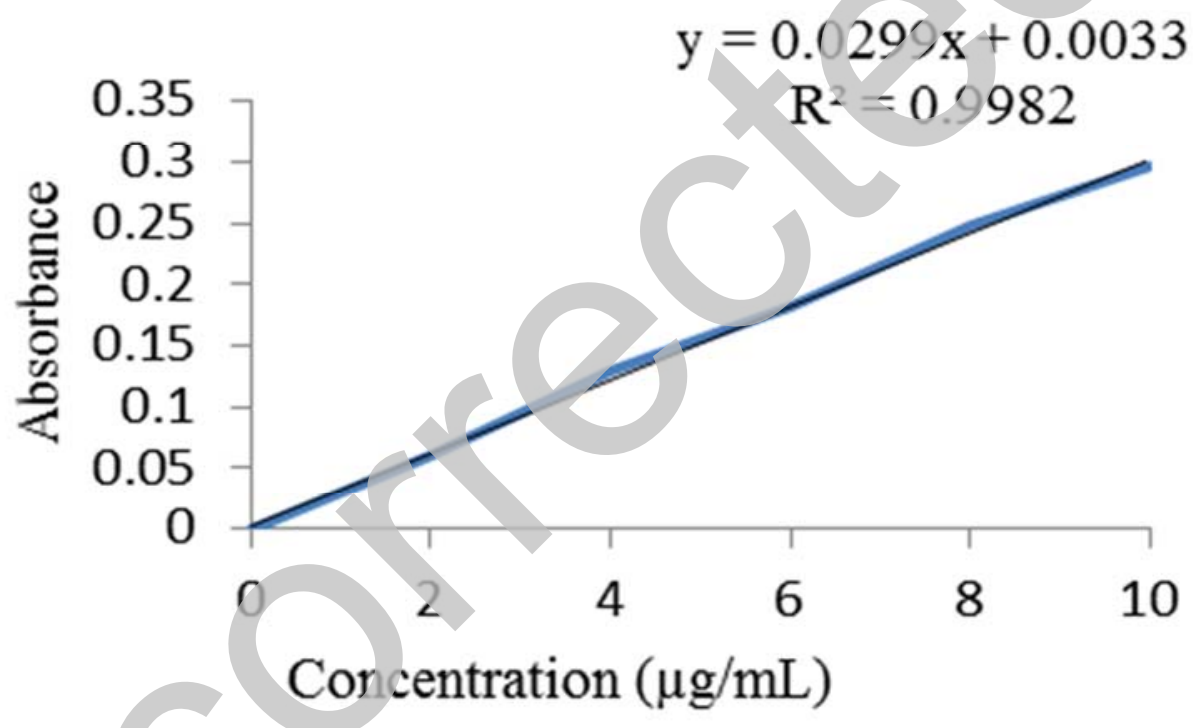

Figure 7: In vitro release profile of transfersomes 
In vitro release profile of Transfersomes

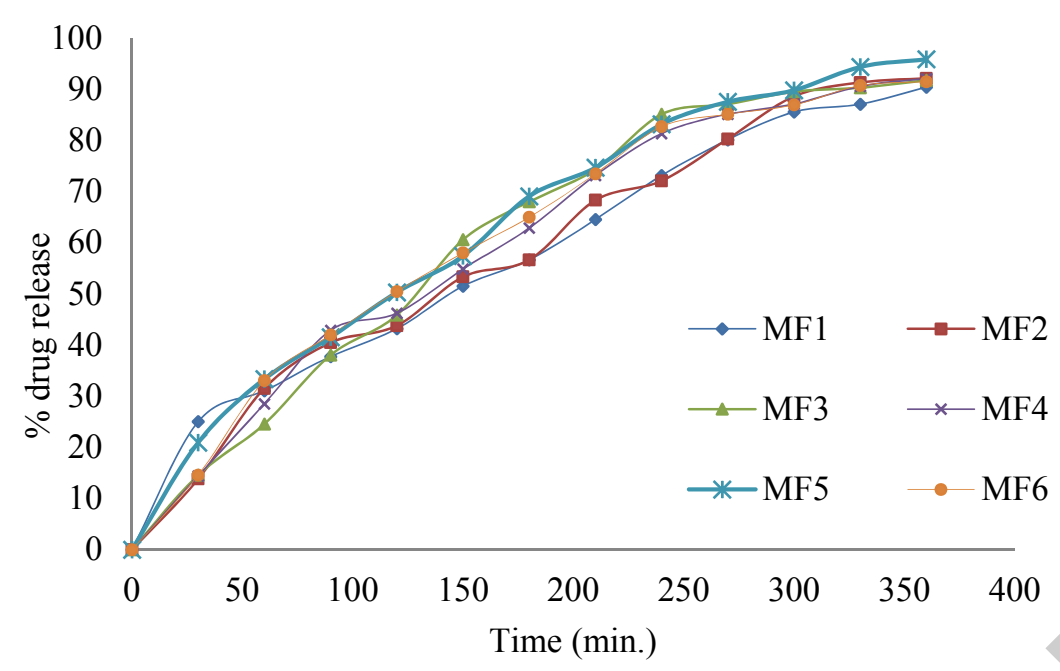

Figure 8: FTIR spectra of transfersomes

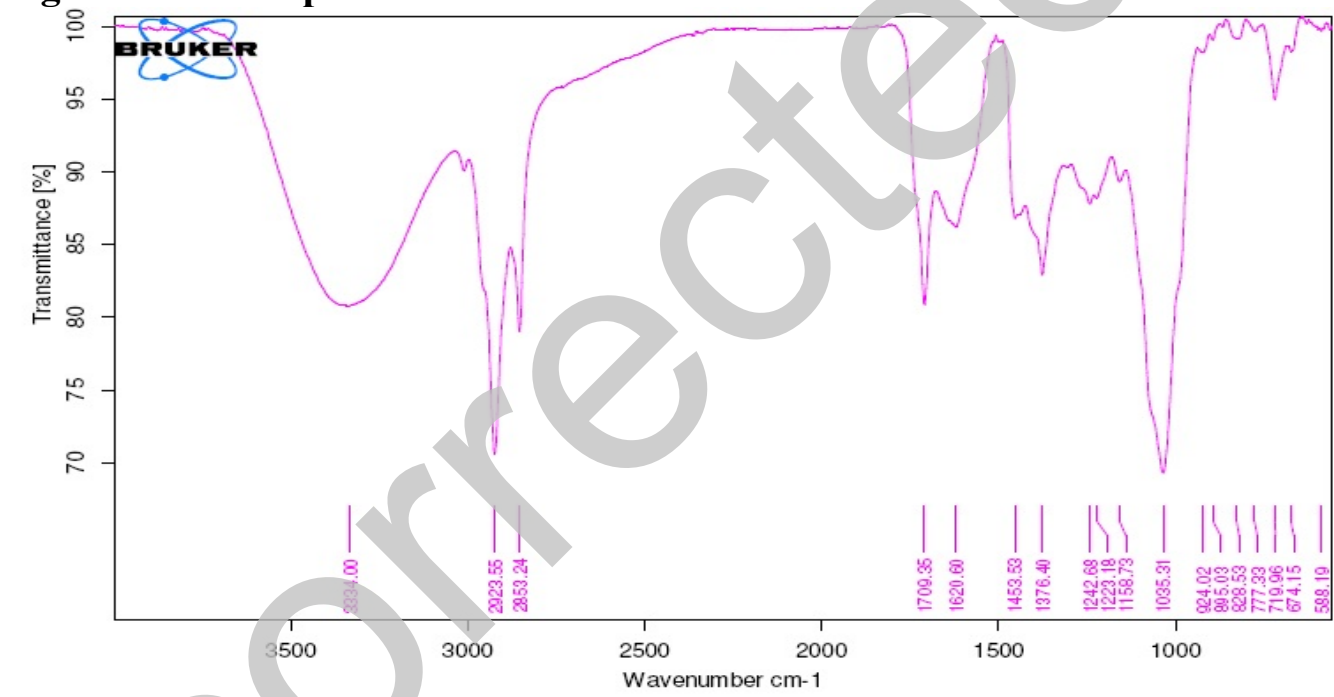

Figure 9: Viscosity of MG1 and MG2 gel 
Viscosity of gel

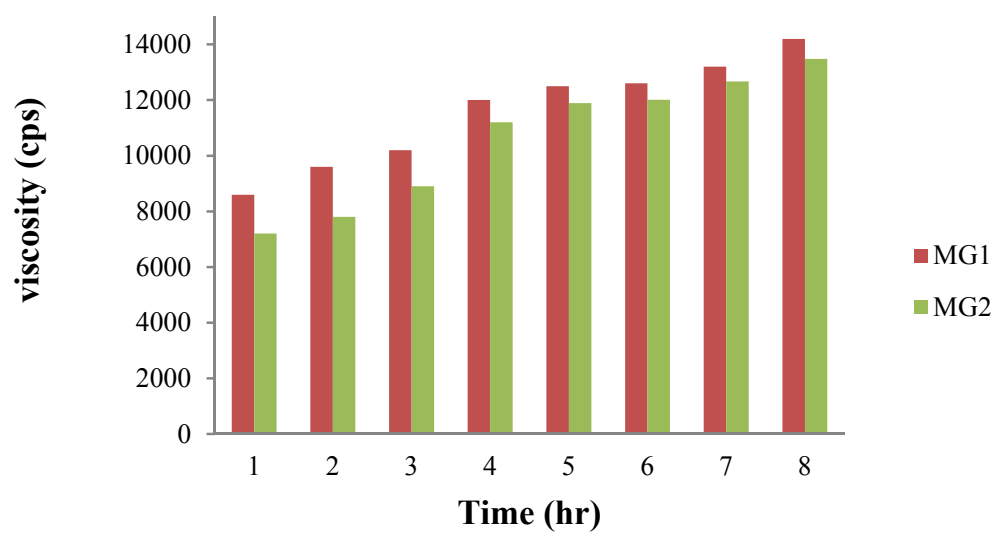

Figure 10: pH of MG1 and MG2 gel

pH of gel

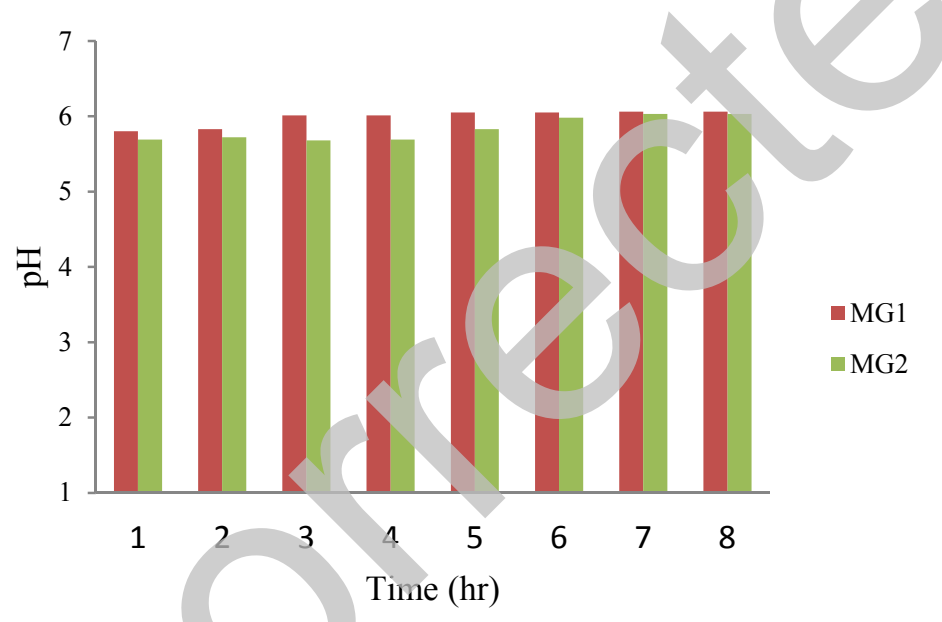

Figure 11: Swelling index of transferosomal gel 


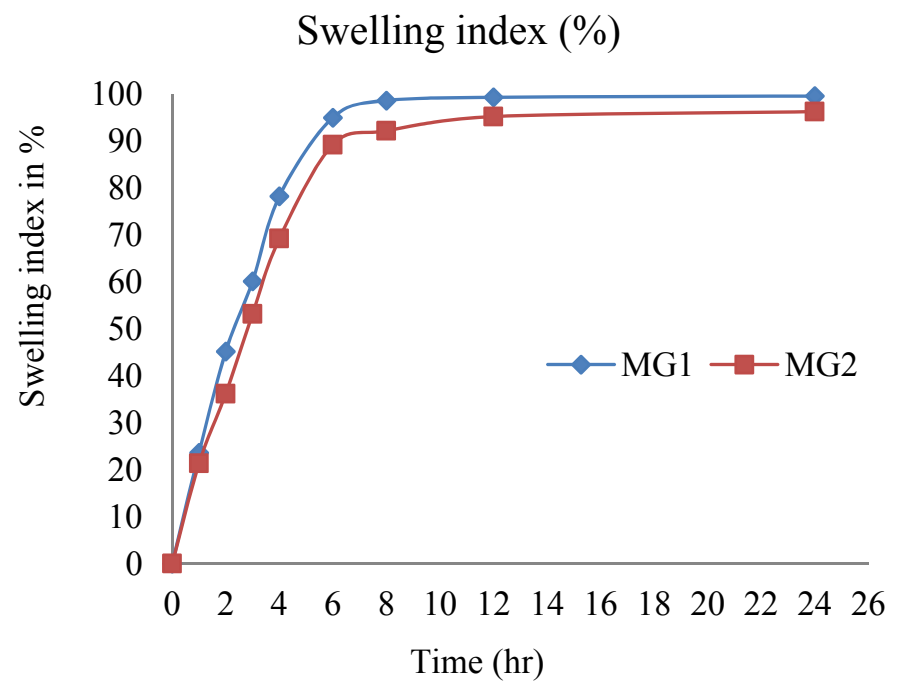

Figure 12: Antioxidant properties and \%EE of MG1 and MG2 gel

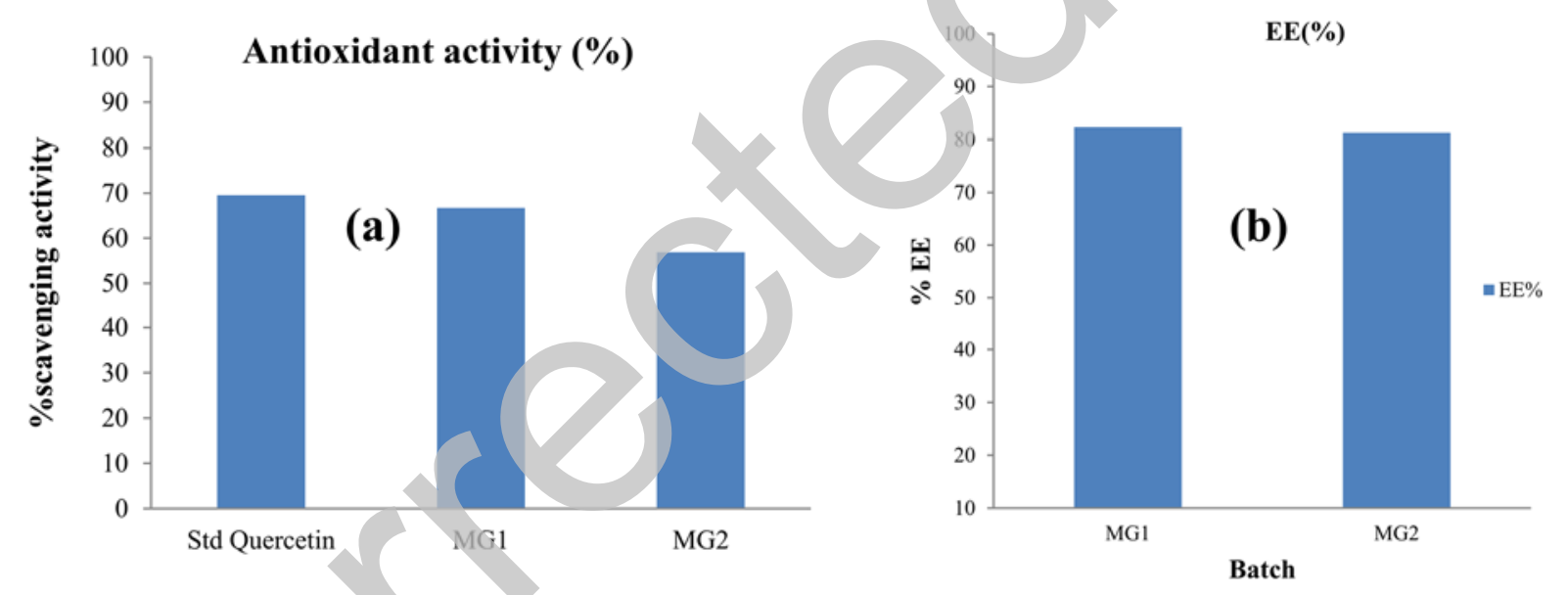

Fiqure 13: a. Std quercetin (Track 1), b. Isolated quercetin (Track 2) and c. Gel

formulation (Track 3)

1. Prabu SL, Umamaheswari A, Rajakumar S, Bhuvaneswari P, Muthupetchi S.

Development and Evaluation of Gel Incorporated with Synthesized Silver Nanoparticle from

Ocimum gratissimum for the Treatment of Acne Vulgaris. American Journal of Advanced Drug Delivery. 2017;5:107-17.

2. Vats A, Sharma P. Formulation and evaluation of topical anti acne formulation of coriander oil. International Journal of Pharmacy and Pharmaceutical Science Research. 2012;2(3):61-6.

3. Surekha Baghel CDK, Gidwani B, Gupta A. Novel drug delivery systems of herbal constituents used in acne. International Journal of Contemporary Research and Review. 2017;8(02). 
4. Latter G, Grice JE, Mohammed Y, Roberts MS, Benson HA. Targeted Topical Delivery of Retinoids in the Management of Acne Vulgaris: Current Formulations and Novel Delivery Systems. Pharmaceutics. 2019;11(10):490.

5. Ghovvati M, Afshari GK, Nasrollahi SA, Firooz A, Samadi A, Karimi M, et al. Efficacy of topical cinnamon gel for the treatment of facial acne vulgaris: A preliminary study. Biomedical Research and Therapy. 2019;6(1):2958-65.

6. Tahir CM. Pathogenesis of acne vulgaris: simplified. Journal of Pakistan Association of Dermatology. 2016;20(2):93-7.

7. Baek J, Lee M-G. Oxidative stress and antioxidant strategies in dermatology. Redo Report. 2016.

8. Vora J, Srivastava A, Modi H. Antibacterial and antioxidant strategies for acne treatment through plant extracts. Informatics in Medicine Unlocked. 2018;13:128-32.

9. Thakur N, Jain P, Jain V. Formulation development and evaluation of transferosomal gel. Journal of Drug Delivery and Therapeutics. 2018;8(5):168-77.

10. Bown D. The Royal Horticultural Society encyclopedia of herbs $\&$ their uses: Dorling Kindersley Limited; 1995.

11. Pujari A, Jadhav N. design and development of anti-diabetic tablet formulation containing spray dried extract of mulberry leaves. Int J Pharm Sci \& Res. 2019; 10(3): 150109 .

12. Lubtikulthum P, Kamanamool N, Udompataikul M. A comparative study on the effectiveness of herbal extracts vs $2.5 \%$ benzoyl peroxide in the treatment of mild to moderate acne vulgaris. Journal of cosmetic dermatology. 2019.

13. Bhasin B, Londhe VY. An overview of transfersomal drug delivery. International journal of pharmaceutical sciences and research 2018;9(6):2175-84.

14. Vinod KR, Kumar MS, Anbazhagan S, Sandhya S, Saikumar P, Rohit RT, et al. Critical issues related to transfersomes-novel vesicular system. ACTA Scientiarum Polonorum Technologia Alimentaria. 2012;11(1):67-82.

15. Rajan R, Jose S, Mukund VB, Vasudevan DT. Transferosomes-A vesicular transdermal delivery system for enhanced drug permeation. Journal of advanced pharmaceutical technology \& research. 2011;2(3):138.

16. Malakar J, Sen SO, Nayak AK, Sen KK. Formulation, optimization and evaluation of transferosomal gel for transdermal insulin delivery. Saudi pharmaceutical journal. 2012;20(4):355-63.

17. Zou Y, Liao S, Shen W, Liu F, Tang C, Chen C-Y, et al. Phenolics and antioxidant activity of mulberry leaves depend on cultivar and harvest month in Southern China. International journal of molecular sciences. 2012;13(12):16544-53.

18. Sanghavi N, Srivastava R, Malode Y. Isolation and identification of the flavonoid "quercetin" from tridax procumbens linn. International Journal of Pharmaceutical Sciences and Research. 2014;5(4):1454-9.

19. Sajeeth C. Quantitative estimation of gallic acid, rutin and quercetin in certain herbal plants by HPTLC method. Der Chemica Sinica. 2010;1(2):80-5.

20. Patil V, Angadi S, Devdhe S. Determination of quercetin by uv spectroscopy as quality control parameter in herbal plant: Cocculus hirsutus. J Chem Pharm Res. 2015;7(1):99-104.

21. Iqbal S, Younas U, Chan KW, Sarfraz RA, Uddin M. Proximate composition and antioxidant potential of leaves from three varieties of Mulberry (Morus sp.): a comparative study. International journal of molecular sciences. 2012;13(6):6651-64.

22. Chauhan P, Tyagi BK. Herbal novel drug delivery systems and transfersomes. Journal of Drug Delivery and Therapeutics. 2018;8(3):162-8. 
23. Rahmi AD, Pangesti DM. Comparison of the Characteristics of Transfersomes and Protransfersomes Containing Azelaic Acid. Journal of Young Pharmacists. 2018;10(2):S11. 24. Duangjit S, Opanasopit P, Rojanarata T, Ngawhirunpat T. Characterization and in vitro skin permeation of meloxicam-loaded liposomes versus transfersomes. Journal of drug delivery. 2011;2011.

25. Laxmi M, Zafaruddin M. Design and characterization of transferosomal gel of repaglinide. Int Res J Pharm. 2015;6(1):37-41.

26. Surini S, Djajadisastra J. Formulation and in vitro Penetration Study of Transfersomes Gel Containing Gotu Kola Leaves Extract (Centella asiatica L. Urban). Journal of Young Pharmacists. 2018;10(1):27.

27. Ali MFM, Salem HF, Abdelmohsen HF, Attia SK. Preparation and clinical evaluation of nano-transferosomes for treatment of erectile dysfunction. Drug design, development and therapy. 2015;9:2431.

28. Laxmi M, Zafaruddin M, Kuchana V. Design and characterization of transferosomal gel of repaglinide. Int Res J Pharm. 2015;6(1):37-41.

29. Preeti MSK. Development of celecoxib transfersomal gel for the treatment of rheumatoid arthritis. Indian J Pharm Biol Res. 2014;2:7-13.

30. Mulani H, Bhise K. QbD Approach in the formulation and evaluation of Miconazole Nitrate loaded ethosomal cream-o-gel. Int Res J Pharm Sci. 2017;8:1-37.

31. Movaliya V, Zaveri M. HPTLC method development and estimation of quercetin in the alcoholic extract of Aerva javanica root. Advance Research in Pharmaceuticals and Biologicals. 2012;2:222-8.

32. Patel R, Singh S, Singh S, Sheth N, Gendle R. Development and characterization of curcumin loaded transfersome for transdermal delivery. Journal of pharmaceutical sciences and research. 2009;1(4):71.

33. Kaza R, Pitchaimani R. Formulation of transdermal drug delivery system: matrix type, and selection of polymer-their evaluation. Current drug discovery technologies. 2006;3(4):279-85.

34. Marwah H, Garg T, Rath G, Goyal AK. Development of transferosomal gel for transdermal delivery of insulin using iodine complex. Drug delivery. 2016;23(5):1636-44.

35. Jain S, Jain P, Umamaheshwari R, Jain N. Transfersomes - a novel vesicular carrier for enhanced transdermal delivery: development, characterization, and performance evaluation. Drug development and industrial pharmacy. 2003;29(9):1013-26.

36. Lichtenberg D, Robson RJ, Dennis EA. Solubilization of phospholipids by detergents structural and kinetic aspects. Biochimica et Biophysica Acta (BBA)-Reviews on Biomembranes. 1983;737(2):285-304.

37. Ascenso A, Raposo S, Batista C, Cardoso P, Mendes T, Praça FG, et al. Development, characterization, and skin delivery studies of related ultradeformable vesicles: transfersomes, ethosomes, and transethosomes. International journal of nanomedicine. 2015;10:5837.

38. Maivern A. Basic Guide to Particle Characterisation. Malvern Instruments, Ltd.: Malvern, UK; 2012.

39. Liu J, Hu G. Advances in studies of phospholipids as carriers in skin topical application. Journal of Nanjing Medical University. 2007;21(6):349-53.

40. Chaudhary H, Kohli K, Kumar V. Nano-transfersomes as a novel carrier for transdermal delivery. International journal of pharmaceutics. 2013;454(1):367-80.

41. Mitkari B, Korde S, Mahadik K, Kokare C. Formulation and evaluation of topical liposomal gel for fluconazole. Indian J Pharm Educ Res. 2010;44(4):324-33.

42. Shaji J, Lal M. Novel double loaded transferosomes: evidence of superior antiinflammatory efficacy-a comparative study. Int J Curr Pharm Res. 2014;6(2):16-25. 
43. Sultana SS, Krishna Sailaja A. Formulation and evaluation of diclofenac sodium transferosomes using different surfactants by thin film hydration method. Der Pharmacia Lettre. 2015;7(11):43-53.

44. Gupta A, Aggarwal G, Singla S, Arora R. Transfersomes: a novel vesicular carrier for enhanced transdermal delivery of sertraline: development, characterization, and performance evaluation. Scientia pharmaceutica. 2012;80(4):1061-80.

\section{Table}

Table 1: Preparation of Mulberry leaves extract transfersomes

Table 2: Transfersomes gel of mulberry leaf extract (MG1) and control extract gel (MG2)

Table 3: Characterization and optimization of prepared transfersomes

Table 4: The flow properties of MG1 and MG2

Table 5: Optimized Parameter of HPTLC for quercetin isolation

Table 6: Stability evaluation of transferosomal gel after 3 month

Table 1: Preparation of Mulberry leaves extract transfersomes

\begin{tabular}{|l|l|l|l|l|l|l|}
\hline \multirow{2}{*}{ Material name } & \multicolumn{2}{l}{ Concentration (\% w/w) } \\
\cline { 2 - 8 } & MF1 & MF2 & MF3 & MF4 & MF5 & MF6 \\
\hline Mulberry leaves extract & 10 & 10 & 10 & 10 & 10 & 10 \\
\hline Tween 80 & 0.3 & 0.3 & 0.3 & 0.4 & 0.4 & 0.4 \\
\hline phopholipon 90G & 2 & 2.5 & 3 & 2 & 2.5 & 3 \\
\hline $\begin{array}{l}\text { Phosphate buffer } \\
\text { (saline pH 7.4) }\end{array}$ & Add 100 & Add 100 & Add 100 & Add 100 & Add 100 & Add 100 \\
\hline
\end{tabular}

Table 2: Transfersomes gel of mulberry leaves extract (MG1) and control extract gel (MG2)

\begin{tabular}{|l|l|l|l|l|l|l|}
\hline Composition & Transfersome & $\begin{array}{l}\text { Extrac } \\
\mathbf{t}\end{array}$ & $\begin{array}{l}\text { Carbapo } \\
\mathbf{9} \\
\mathbf{9 4 0}\end{array}$ & $\begin{array}{l}\text { Triethanolamin } \\
\mathbf{e}\end{array}$ & $\begin{array}{l}\text { Propylen } \\
\text { e glycol }\end{array}$ & $\begin{array}{l}\text { Wate } \\
\mathbf{r}\end{array}$ \\
\cline { 1 - 1 } $\begin{array}{l}\text { Concentratio } \\
\mathbf{( \%} \mathbf{w} / \mathbf{w})\end{array}$ & $\begin{array}{l}\text { Equal to } 10 \% \\
\text { extract }\end{array}$ & - & 1 & 0.1 & 12.5 & $\begin{array}{l}\text { Add } \\
100\end{array}$ \\
\hline $\mathbf{M G 1}$ & - & 10 & 1 & 0.1 & 12.5 & $\begin{array}{l}\text { Add } \\
100\end{array}$ \\
\hline $\mathbf{M G 2}$ & - & & & &
\end{tabular}

Table 3: Characterization and optimization of prepared transfersomes

\begin{tabular}{|l|l|l|l|l|l|}
\hline Batch no. & Particle size & $\begin{array}{l}\text { Zeta } \\
\text { potential }\end{array}$ & PDI & $\%$ EE & $\begin{array}{l}\text { Deformability } \\
\text { Index }\end{array}$ \\
\hline
\end{tabular}




\begin{tabular}{|c|c|c|c|c|c|}
\hline MF1 & $381.9 \mathrm{~nm}$ & $21.19 \mathrm{mV}$ & 0.511 & $68.23 \pm 1.2$ & $3.52 \pm 0.9$ \\
\hline MF2 & $214.5 \mathrm{~nm}$ & $-44.56 \mathrm{mV}$ & 0.421 & $65.23 \pm 1.1$ & $3.63 \pm 0.5$ \\
\hline MF3 & $268.3 \mathrm{~nm}$ & $-21.91 \mathrm{mV}$ & 0.448 & $76.23 \pm 0.9$ & $2.25 \pm 1.3$ \\
\hline MF4 & $401.9 \mathrm{~nm}$ & $-22.39 \mathrm{mV}$ & 0.270 & $77.65 \pm 1.6$ & $3.5 \pm 2.1$ \\
\hline MF5 & 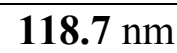 & $-45.11 \mathrm{mV}$ & 0.389 & $86.23 \pm 2.1$ & $1.03 \pm 0.8$ \\
\hline MF6 & $416.6 \mathrm{~nm}$ & $-27.73 \mathrm{mV}$ & 0.628 & $80.23 \pm 1.8$ & $2.05 \pm 1.5$ \\
\hline
\end{tabular}

$\mathrm{n}=3,( \pm): \mathrm{sd}$

Table 4: The flow properties of MG1 and MG2

\begin{tabular}{|c|c|c|c|c|}
\hline \multirow{2}{*}{ Properties } & \multicolumn{2}{|l|}{ MG1 } & \multicolumn{2}{|l|}{ MG2 } \\
\hline & 0 days & 10 days & 0 days & 10 days \\
\hline Homogeneity rate $(1 / 10 \mathrm{~mm})$ & $60.54 \pm 1.6$ & $99.58 \pm 2.9$ & $59.23 \pm 1.2$ & $\overline{99.03 \pm 3.6}$ \\
\hline Tensile strength $(\mathrm{Kg} / \mathrm{cm})$ & $30.25 \pm 0.9$ & $35.62 \pm 1.7$ & $30.01 \pm 1.9$ & $33.87 \pm 2.8$ \\
\hline Elongation rate $(\%)$ & $200.21 \pm 1.4$ & $282.3 \pm 2.5$ & $199.56 \pm 1.6$ & $2 7 \longdiv { 6 . 2 \pm 3 . 1 }$ \\
\hline Spreadability $(\mathrm{cm})$ & $9.80 \pm 0.9$ & $9.98 \pm 0.9$ & $8.01 \pm 0.9$ & $8.26 \pm 0.9$ \\
\hline
\end{tabular}

$\mathrm{n}=3,( \pm): \mathrm{sd}$

Table 5: Optimized Parameter of HPT $L C$ for quercetin isolation

\begin{tabular}{|c|c|c|c|}
\hline Parameters & Description & Parameters & Description \\
\hline $\begin{array}{l}\text { Stationary } \\
\text { Phase }\end{array}$ & $\begin{array}{l}\text { Merck Silica gel } 60 \text { F254 HPTLC } \\
\text { pre-coated plates }\end{array}$ & Plate size & $4.0 \mathrm{~cm} \times 10.0 \mathrm{~cm}$ \\
\hline $\begin{array}{l}\text { Mode of } \\
\text { separation }\end{array}$ & Normal phase & $\begin{array}{l}\text { Development } \\
\text { chamber }\end{array}$ & $\begin{array}{l}\text { Camag twin trough } \\
\text { chamber }\end{array}$ \\
\hline Mobile phase & $\begin{array}{l}\text { Ethyl acetate: Toluene: Formic } \\
\text { acid }(4: 3.5: 0.5 \mathrm{v} / \mathrm{v} / \mathrm{v})\end{array}$ & Bandwidth & $7.0 \mathrm{~mm}$ \\
\hline $\begin{array}{l}\text { Chamber } \\
\text { saturation }\end{array}$ & $30 \mathrm{~min}$ & $\begin{array}{l}\text { Space between } \\
\text { the bands }\end{array}$ & $7.0 \mathrm{~mm}$ \\
\hline $\begin{array}{l}\text { Sample } \\
\text { ap plicator }\end{array}$ & Camag Linomat V & Syringe & Hamilton, $100.0 \mu \mathrm{L}$ \\
\hline $\begin{array}{l}\text { Distance from } \\
\text { the edges of the } \\
\text { plat }\end{array}$ & $13.0 \mathrm{~mm}$ & $\begin{array}{l}\text { Rate of a } \\
\text { sample } \\
\text { application }\end{array}$ & $150 \mathrm{~nL} / \mathrm{sec}$ \\
\hline $\begin{array}{l}\text { Lamp and } \\
\text { wavelength }\end{array}$ & Deuterium, 246nm & $\begin{array}{l}\text { Development } \\
\text { distance }\end{array}$ & $85.0 \mathrm{~mm}$ \\
\hline $\begin{array}{l}\text { Densitometric } \\
\text { scanner }\end{array}$ & \multicolumn{3}{|c|}{$\begin{array}{l}\text { Camag Scanner IV equipped with win-CATS Planar Chromatography } \\
\text { manager software version 1.4.7 }\end{array}$} \\
\hline
\end{tabular}


Table 6: Stability evaluation of transferosomal gel after 3 months

\begin{tabular}{|c|c|c|c|c|}
\hline \multirow{2}{*}{\multicolumn{3}{|c|}{ Properties }} & \multicolumn{2}{|l|}{ Gel formulation } \\
\hline & & & \multirow{2}{*}{$\begin{array}{l}\text { MG1 } \\
\text { Slightly yellowish }\end{array}$} & \multirow{2}{*}{$\begin{array}{l}\text { MG2 } \\
\text { Greenish }\end{array}$} \\
\hline \multirow{5}{*}{$\left(4^{\circ} \mathrm{C} \pm 2^{\circ} \mathrm{C}\right)$} & & Color & & \\
\hline & & pH & $5.62 \pm 0.23$ & $5.89 \pm 0.95$ \\
\hline & & Viscosity(CPS) & $14005 \pm 230$ & $13202 \pm 456$ \\
\hline & & EE $(\%)$ & $84.96 \pm 2.35$ & $78.35 \pm 3.69$ \\
\hline & & Drug content $(\%)$ & $98.01 \pm 2.61$ & $89.40 \pm 3.10$ \\
\hline \multirow{5}{*}{$\left(40^{\circ} \mathrm{C} \pm 2^{\circ} \mathrm{C}\right)$} & & Color & Slightly yellowish & Greenish \\
\hline & & pH & $5.95 \pm 1.02$ & $6.23 \pm 1.63$ \\
\hline & & Viscosity (cps) & $13750 \pm 412$ & $12889 \pm 362$ \\
\hline & & $\operatorname{EE}(\%)$ & $83.69 \pm 4.02$ & $73.23 \pm 5.06$ \\
\hline & & Drug content (\%) & $97.96 \pm 00.97$ & $84.25 \pm 2.96$ \\
\hline
\end{tabular}

$\mathrm{n}=3,( \pm): \mathrm{sd}$

\section{Legend}

\section{Figure}

Figure 1: TLC plate developed under UV light at $254 \mathrm{~nm}$

Figure 2: UV spectra of Standard quercetin (a) Isolated quercetin (b)

Figure 3: Calibration curve of Standard quercetin(a) and Isolated quercetin (b)

Figure 4: FTIR spectra of Standard quercetin (a) and Isolated quercetin(b)

Figure 5: Unsonicated transfersomes vesicles by Motic microscopy

Figure 6: Calibration curve of extract ( $\mathrm{pH} 7.4)$

Figure 7: In Vitro release profile of transfersomes

Figure 8: FTIR spectra of transfersomes

Figure 9: Viscosity of MG1 and MG2 gel

Figure 10: $\mathrm{pH}$ of MG1 and MG2 gel 
Figure 11: Swelling index of transferosomal gel

Figure 12: Antioxidant properties and \%EE of MG1 and MG2 gel

Figure 13: a. Standard quercetin (Track 1), b. Isolated quercetin (Track 2) and c. Gel formulation (Track 3)

Figure 14: Overlay at 246nm of Standard quercetin, Isolated quercetin, and Formulation (MG1) in HPTLC

Figure 15: Dissolution profile of MG2 and MG2 gel.

Figure 1: TLC plate developed under UV light at $254 \mathrm{~nm}$

Figure 2: UV spectra of Standard quercetin (a) Isolated quercetin (b) 

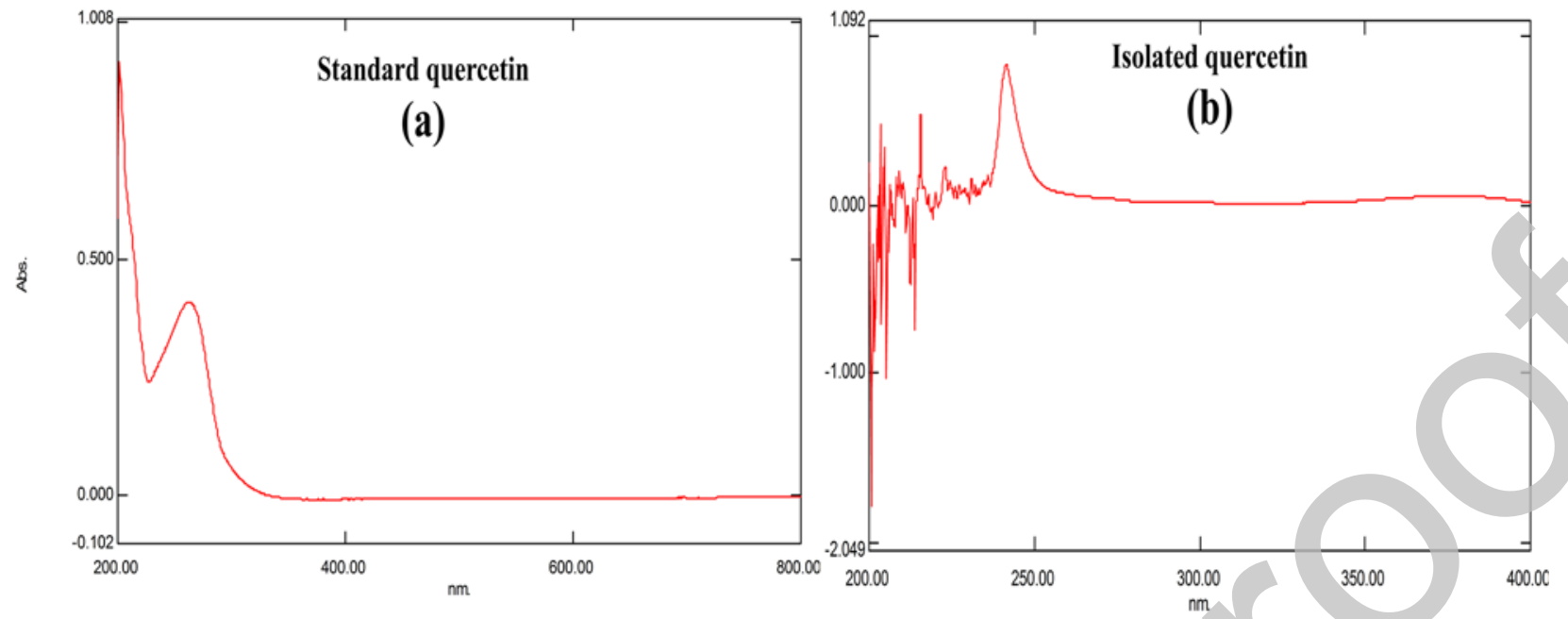

Figure 3: Calibration curve of Standard quercetin(a) and Isolated quercetin (b)
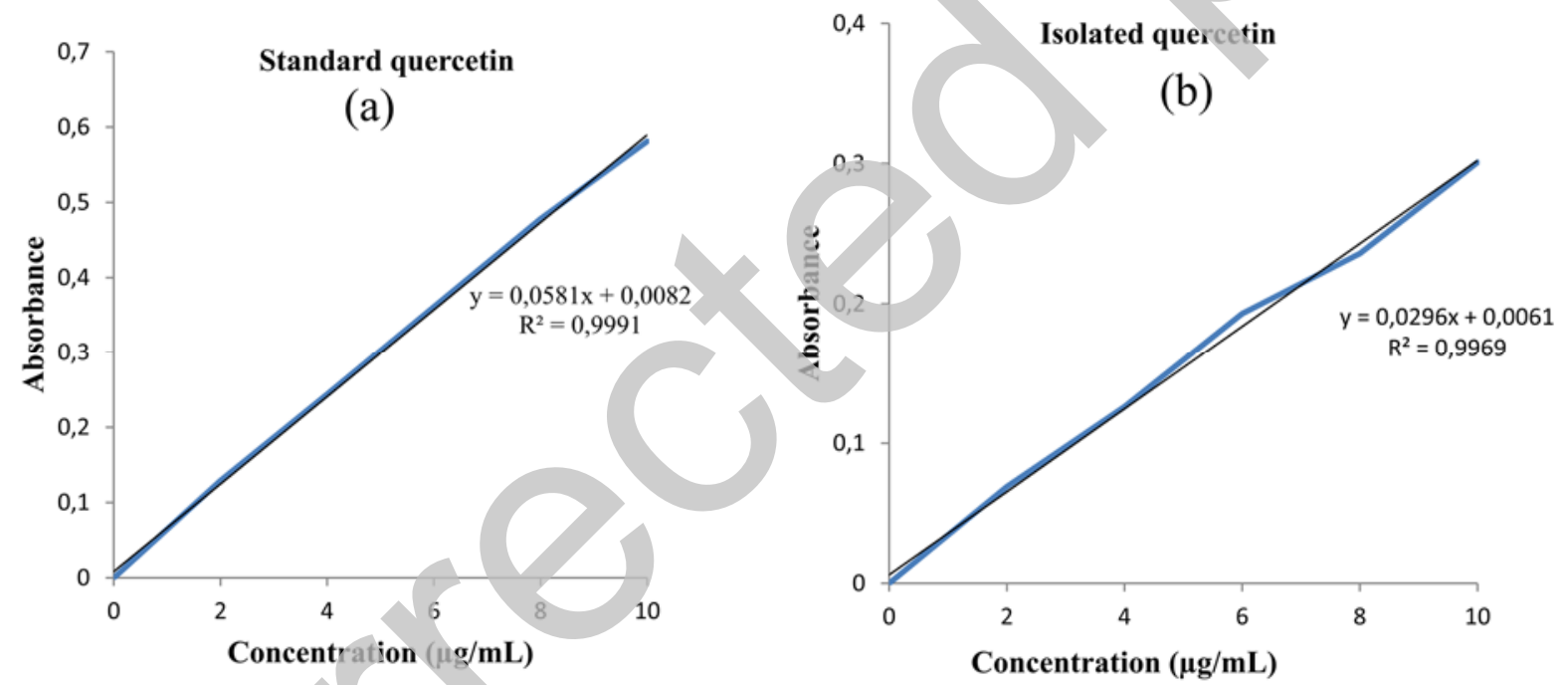

Figure 4: FTIR spectra of Standard quercetin (a) and Isolated quercetin(b) 

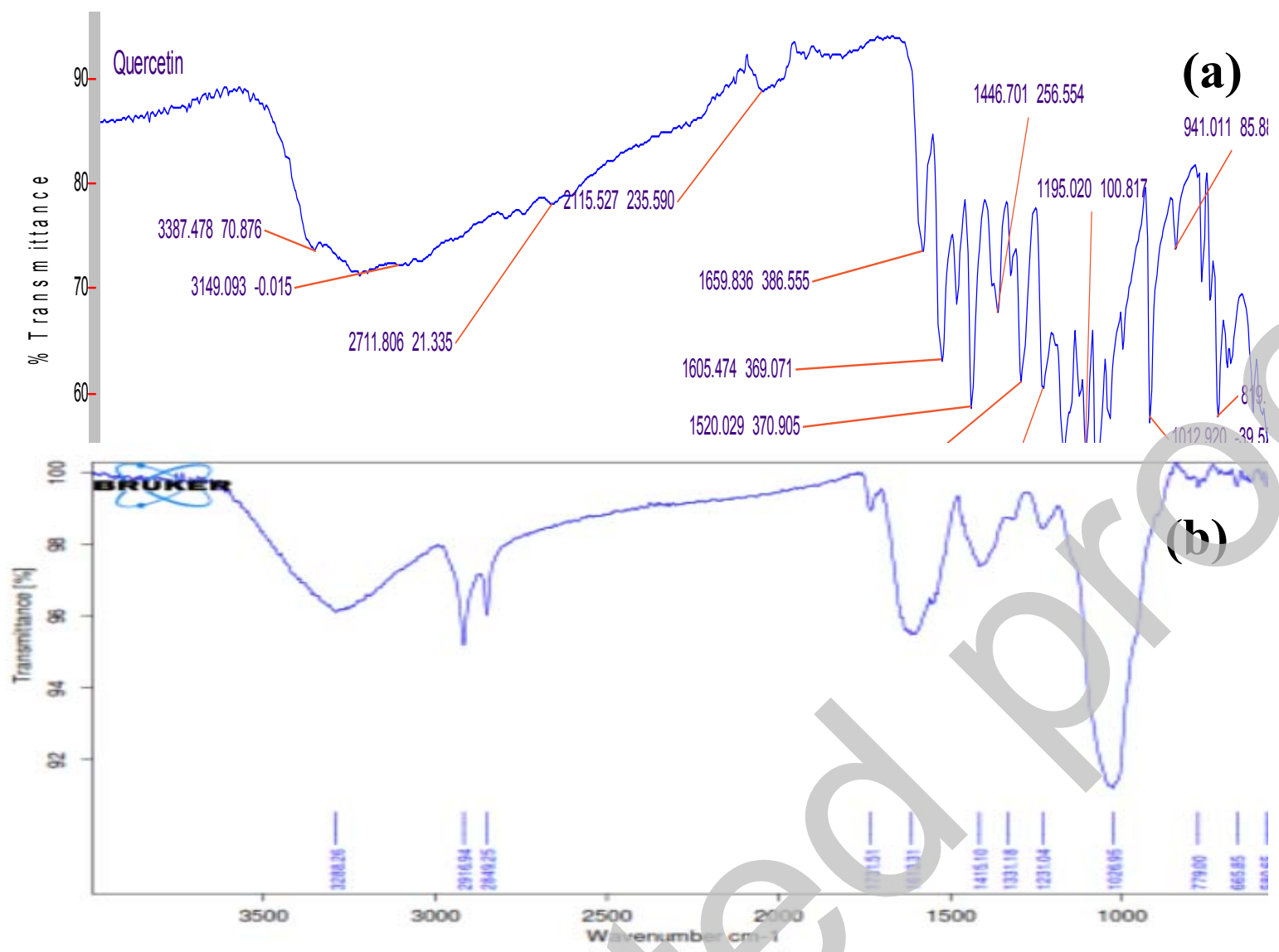

Figure 5: Unsonicated transfersomes vesicles by Motic microscopy

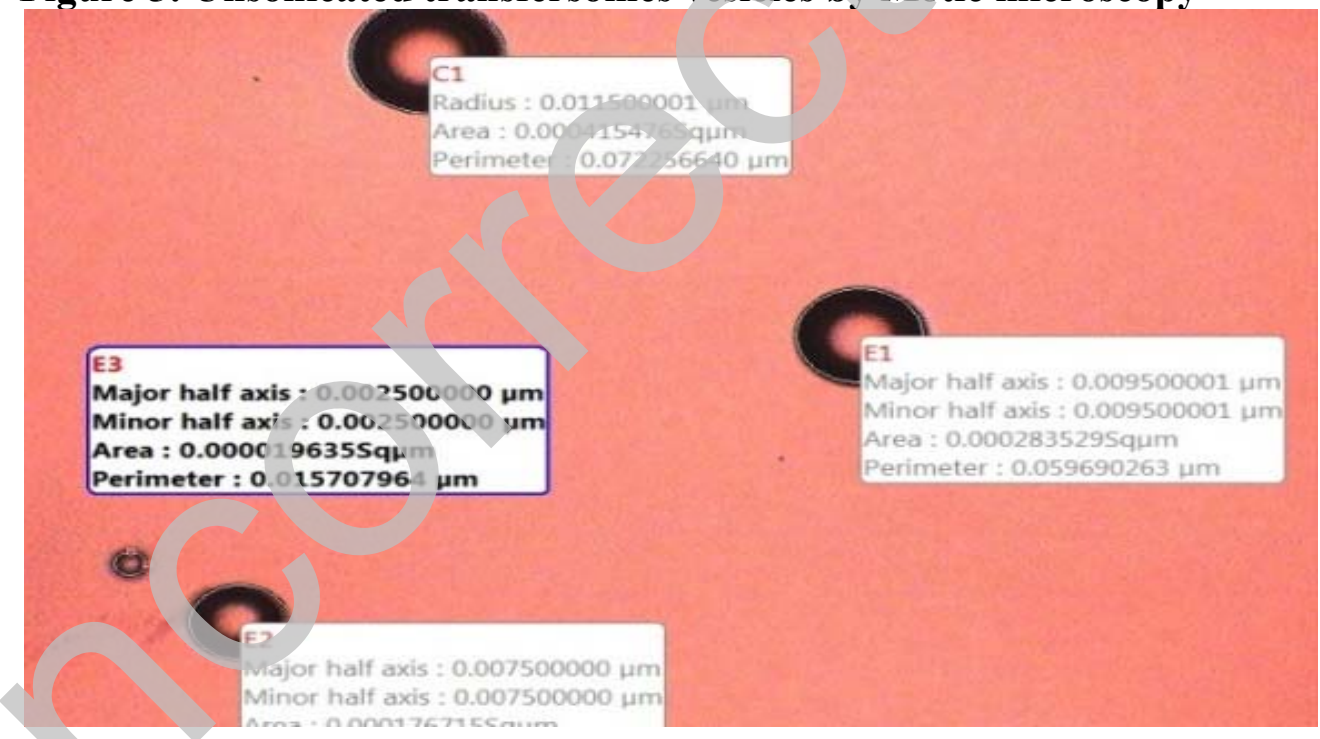

igure 6: Calibration curve of extract (pH 7.4) 


\section{Phospahte buffer (pH 7.4)}

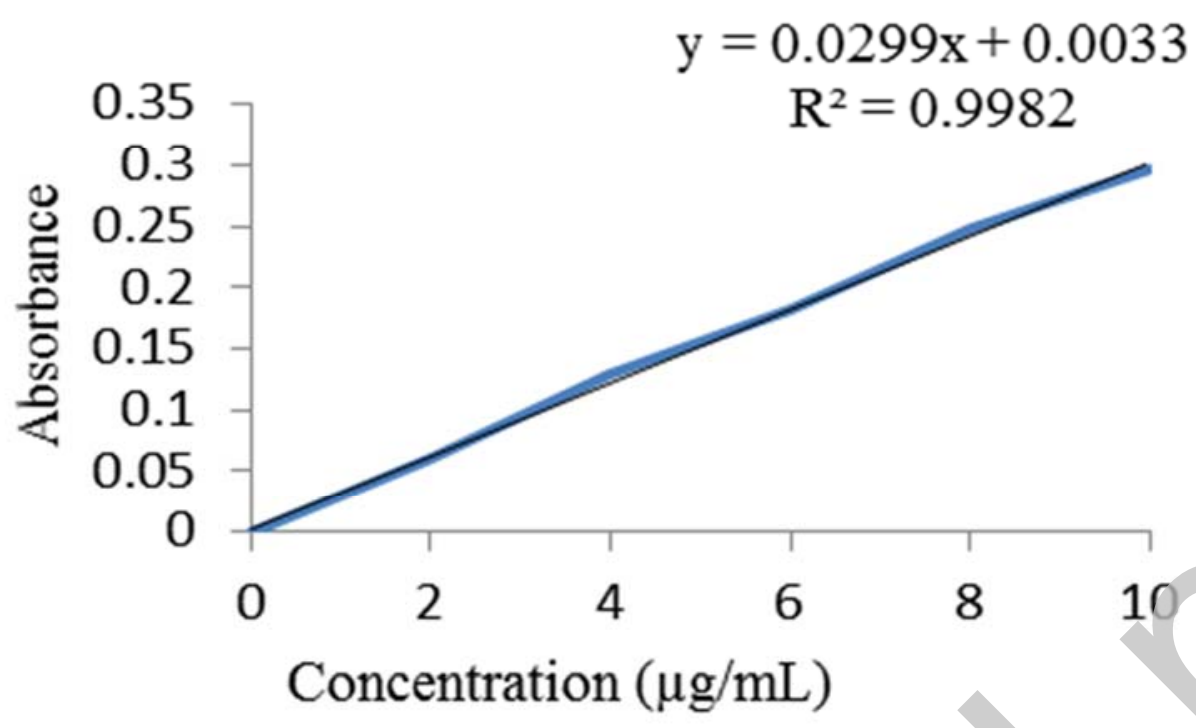

Figure 7: In Vitro release profile of transfersomes

In vitro release profile of Transfersomes

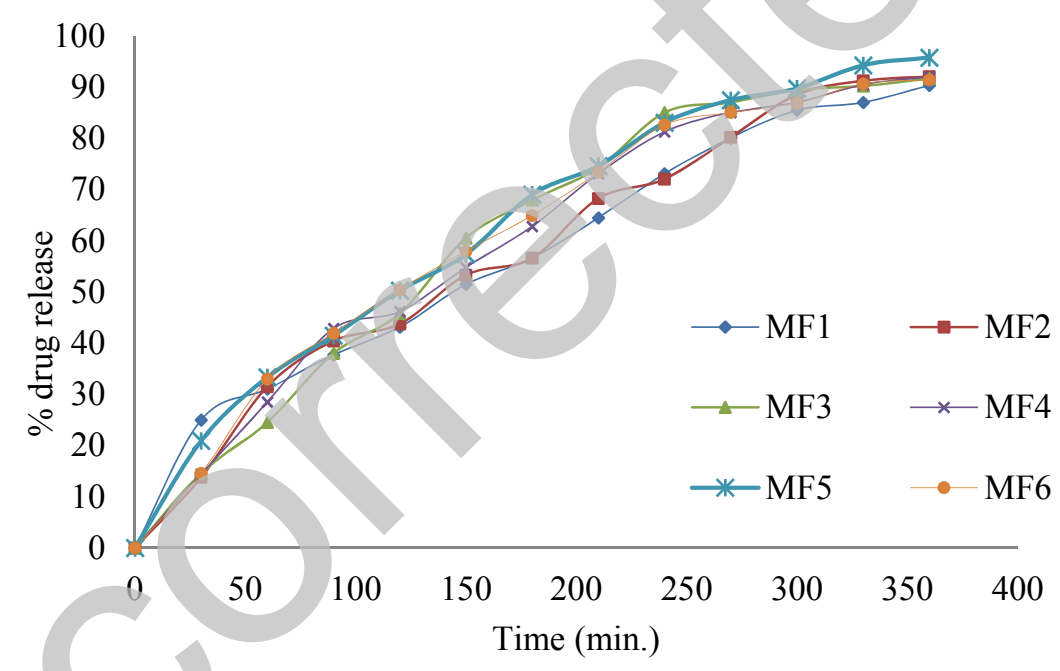

Figure 8: FTIR spectra of transfersomes 


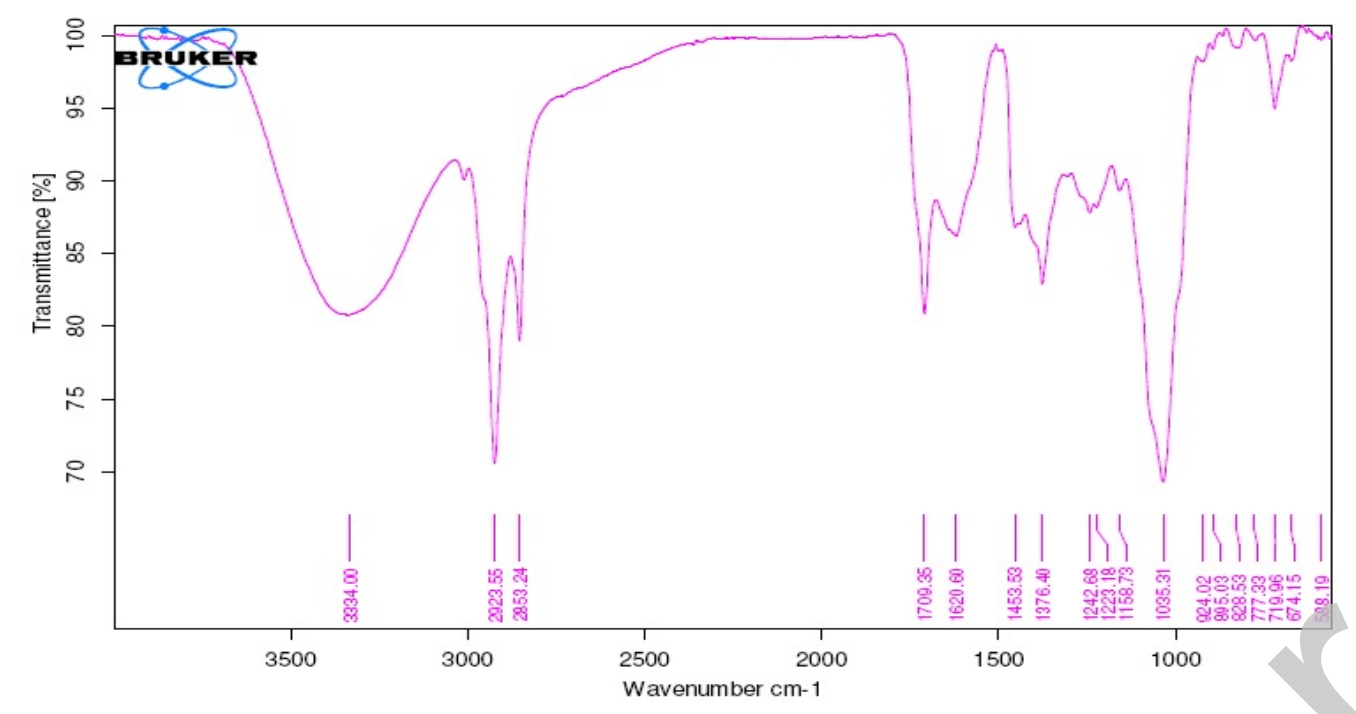

Figure 9: Viscosity of MG1 and MG2 gel

Viscosity of gel

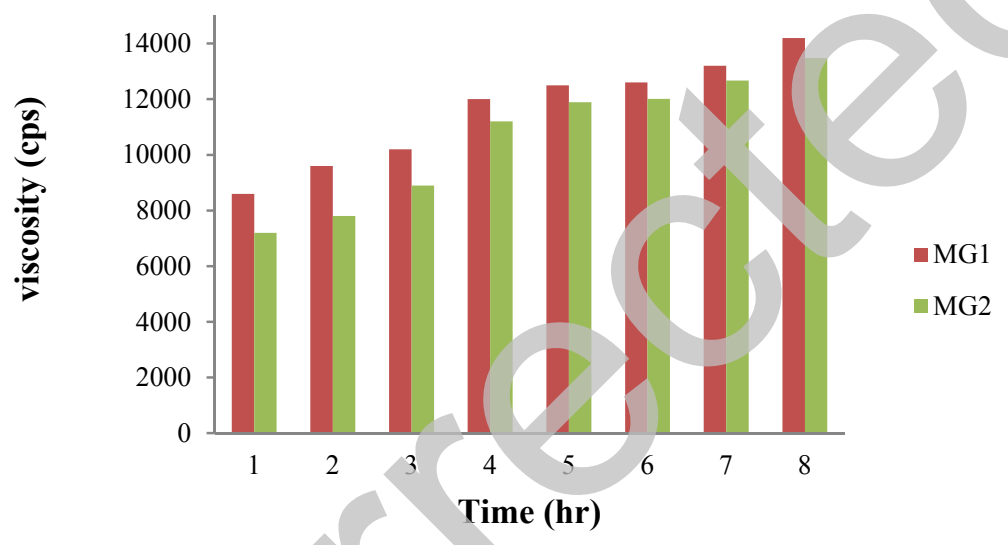

Figure 10: pH of MG1 and MG2 gel 
pH of gel

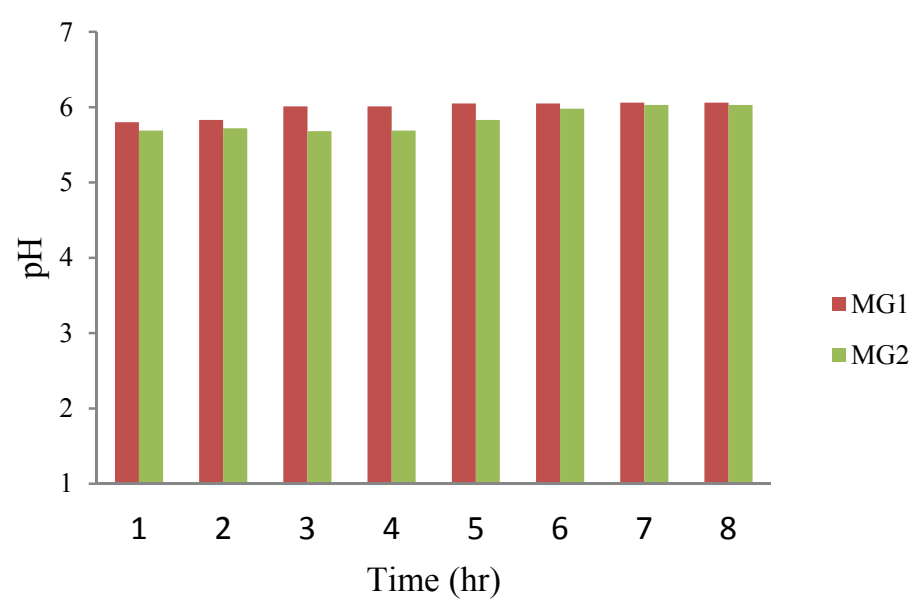

Figure 11: Swelling index of transferosomal gel

Swelling index $(\%)$

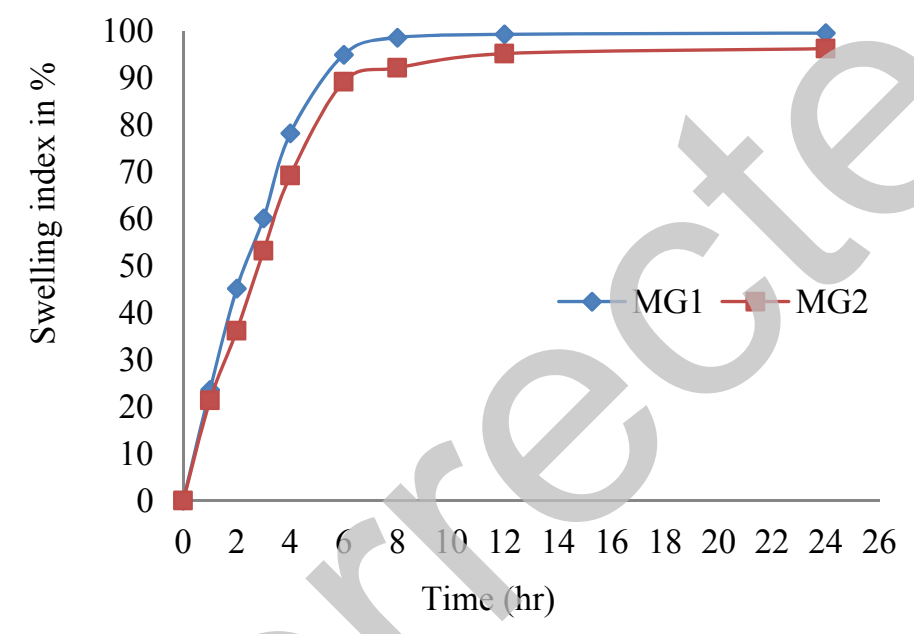

Figure 12: Antioxidant properties and \%EE of MG1 and MG2 gel 

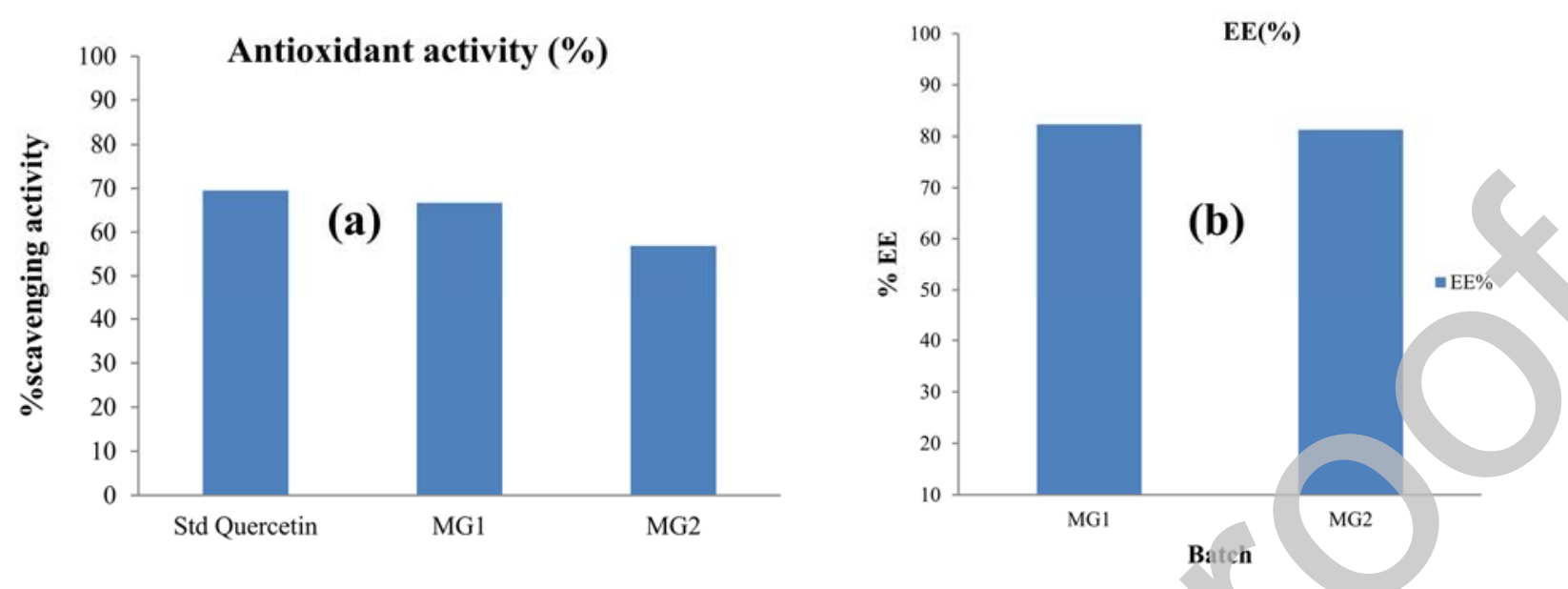

Fiqure 13: a. Std quercetin (Track 1), b. Isolated quercetin (Track 2) and c. Gel formulation (Track 3) 

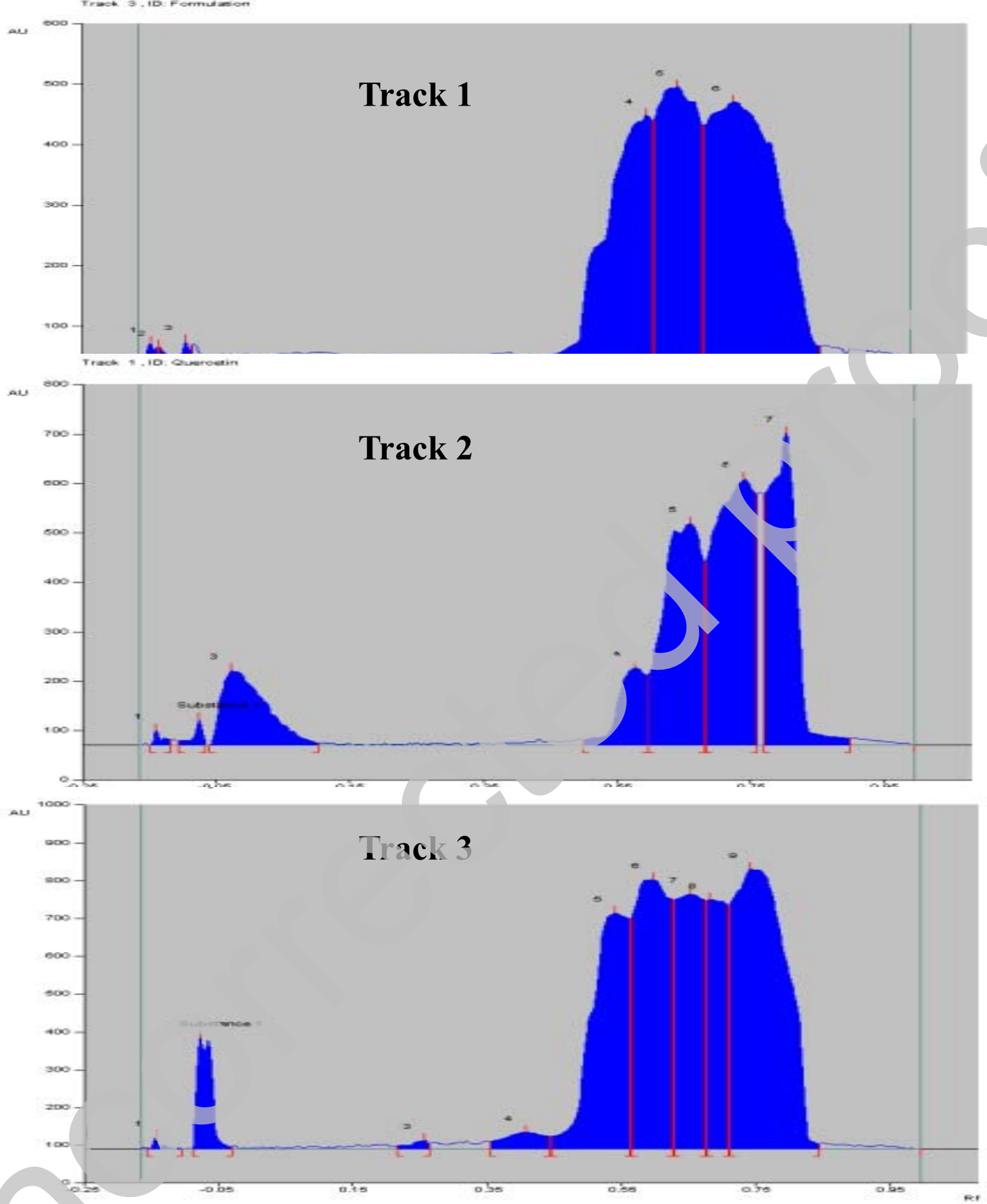

Figure 14: Overlay at 246nm of Standard quercetin, Isolated quercetin, and Formulation (MG1) in HPTLC 


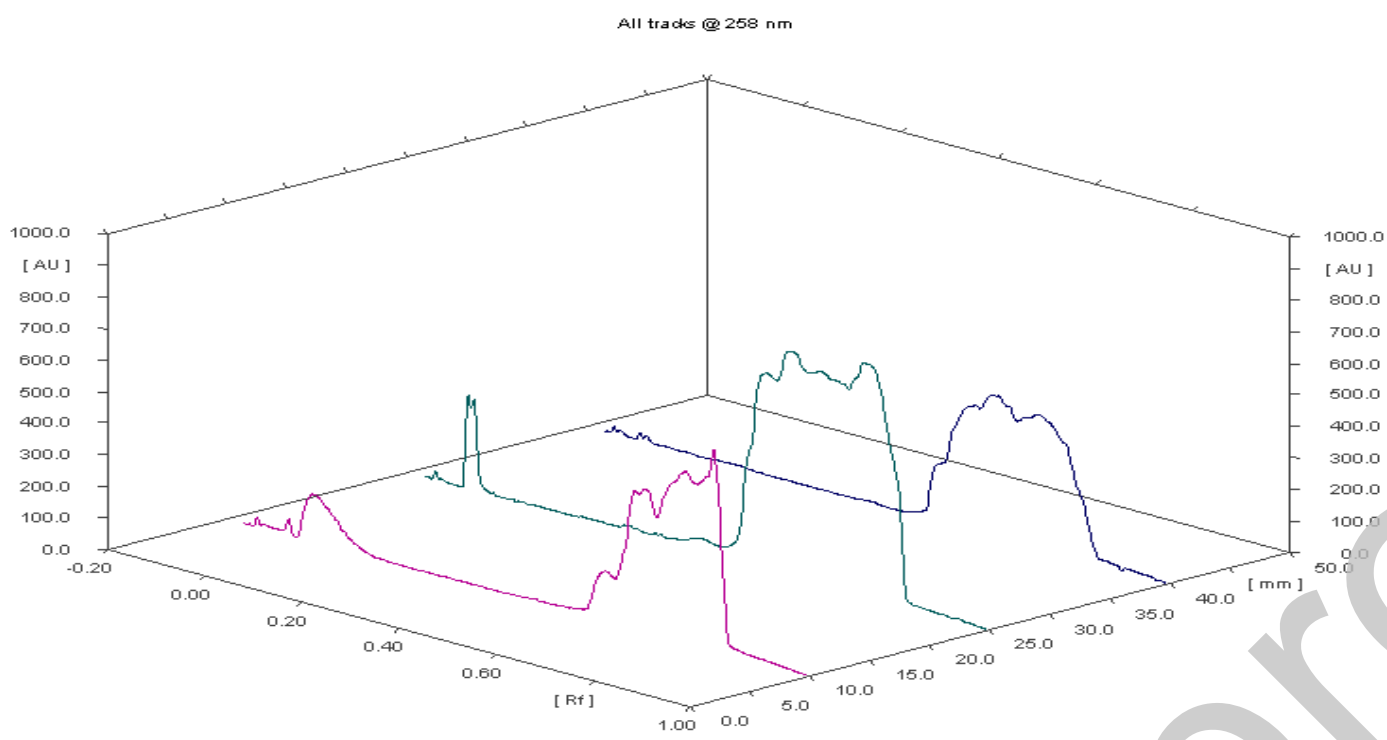

Figure 15: Dissolution profile of MG2 and MG2 gel

Ex vivo percent drug release

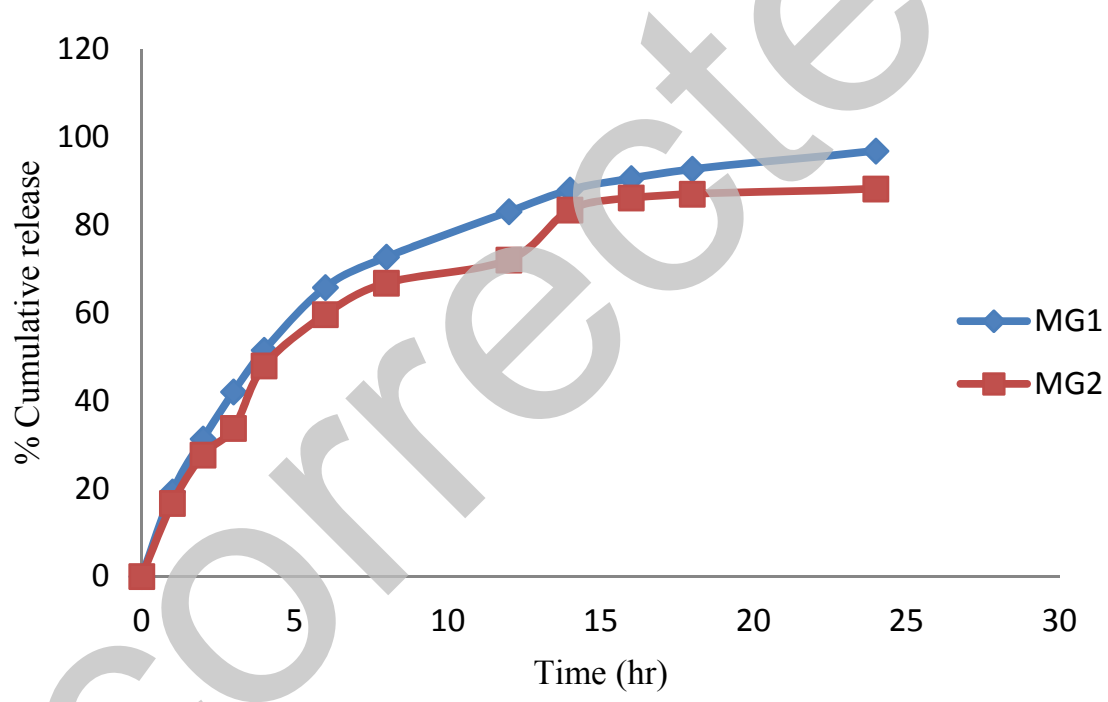

Figure 14: Overlay at 246nm of Standard quercetin, Isolated quercetin, and Formulation (MG1) in HPTLC 


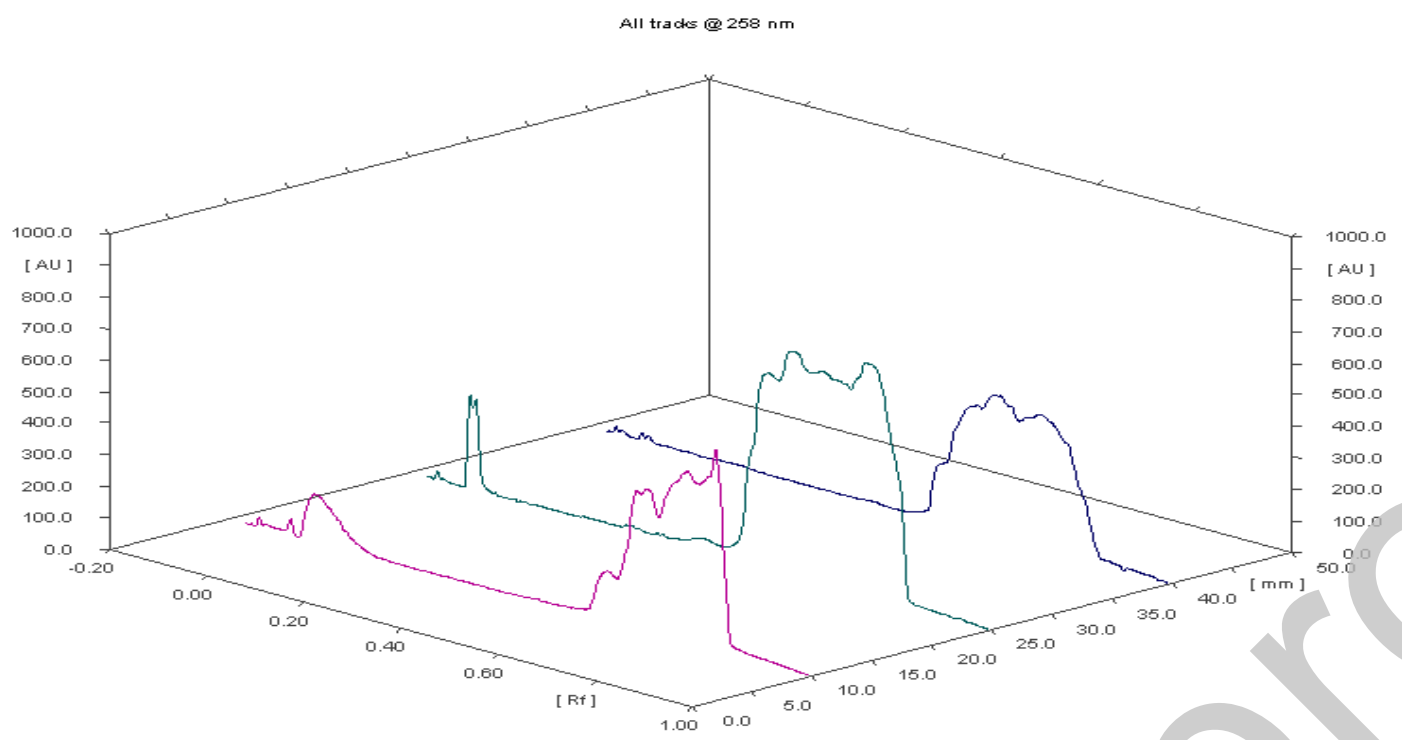

Figure 15: Dissolution profile of MG2 and MG2 gel

Ex vivo percent drug release

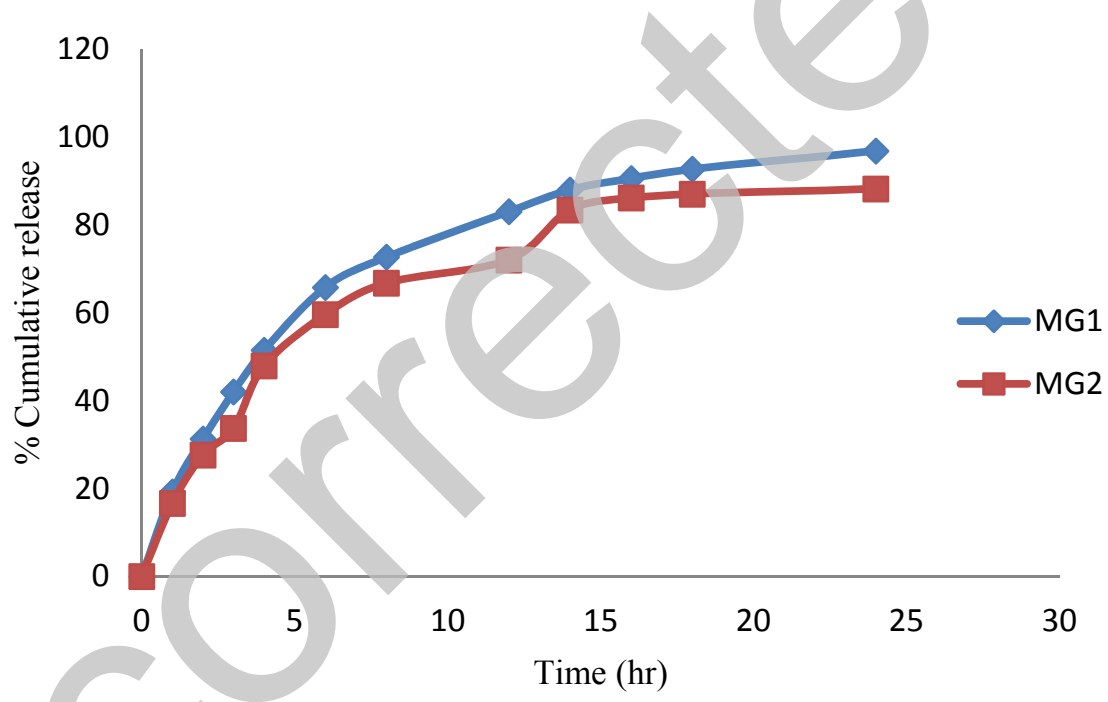

